\title{
THE PALLET PARADIGM A NEW BEGINNING FOR PALLET ARCHITECTURE
}

\author{
BY AARON MILLER
}

A 120 -point thesis submitted to the Victoria University of Wellington in partial fulfilment of the requirements for the degree of Master of Architecture (Professional)

Victoria University of Wellington School of Architecture 


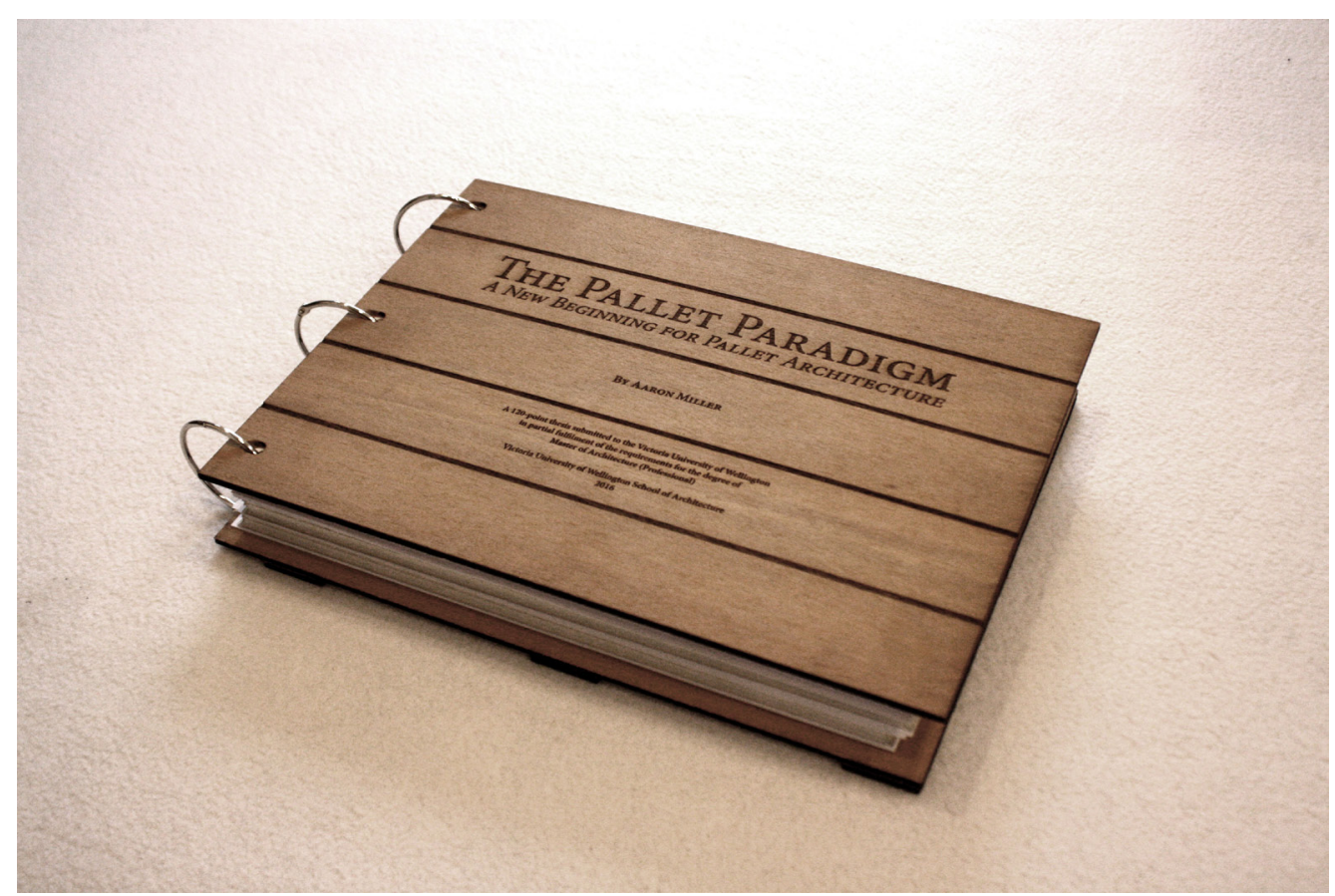




\section{ABSTRACT}

Timber pallets are too often discarded as waste after their shipping lives. If not rescued for upcycling pallets end up in landfills or burnt for firewood which can release harmful chemicals. There is an opportunity in this resource going beyond current design use to foster a more authentic pallet architecture - one where pallets are utilised to their module's full potential as a primary and structural building element.

This thesis explores to what extent pallets can be utilised in construction and determines their feasibility as structural entities. The themes of modularity and transportability act as key design drivers due to being inherent to the pallets nature. A construction system which effectively uses this nature is the aim, and designed systems are tested through application to the design of mobile architecture

The final outcome of this exploration is a full scale pallet pavilion utilising a modular authentic - system which enables an easily portable and structural solution. However the application of similar systems to a larger scale is limited as pallets with consistent module and high strength are rare difficult to source.

A new pallet design is proposed with inherent application as a building component. This design aims to be a highly precise modular and structural system as its primary function, allowing for universal use as wall, roof and floor. The central purpose of exploration is to create high quality, affordable, efficient and adaptable prefabricated dwellings from an otherwise discarded item - this is the potential for the research in future. If the 'building pallet' design was integrated into circulation the impact and application on construction from upcycling them into prefabricated building elements could be worldwide. 


\section{PREFACE}

Recycling pallets for D.I.Y. furniture design projects and utilising them for disaster relief or temporary housing situations are currently very popular trends in society and the architectural world. Despite upcycling pallets being a buzz topic, my interest in a thesis centred on the humble shipping pallet has nothing to do with its new popularity and rather comes from my upbringing and educational experiences up until this point.

My upbringing in New Zealand has surrounded me with the 'number eight wire' mentality and the country's clean, green culture. I have always had an interest in making and building things - from being inventive with toys like K'NEX to constructing tree houses and endless driftwood huts with whatever rough, old or washed up materials I could find. My education has always provided me with conscious thought towards principles of sustainability - in general and in an architectural sense - which has influenced my personal ideas. As a result I share these common kiwi mantras and they have a strong impact on my way of thinking.

Leading up to my thesis year at Victoria University of Wellington I was searching for a topic that could have some real meaning, and that also would allow for a very hands-on approach. Prefabrication and disaster relief architecture were two areas of research I was considering but a venture out with a friend in search of free wood for a project provided a new opportunity. Upon merely inspecting a pile of ten or so pallets stacked in an industrial area of Wellington, an excited employee approached us to see if we wanted to take off his hands any of the hundred odd pallets he was desperately trying to get rid of. We thought we had hit the jackpot, but as I later discovered this was a common theme around wellington. The opportunity to repurpose and recycle this 'junk' material suddenly stood out as being a positive and potentially very meaningful contribution I could make through my research. It became clear that timber pallets were a seemingly abundant, underutilised and free resource, and such provided the catalyst to combine my interests and desires into a single project. 


\section{ACKNOWLEDGEMENTS}

To my supervisor Daniele thank you for always seeing the best in my work, always supporting me in my activities inside and outside of university and providing invaluable opportunity to exhibit as part of my research.

Also, to my parents Roger and Heather thank you for always being there through my studies when I needed a hand up or a second opinion, and always supporting my decisions.

Finally, to my girlfriend Melissa thank you for your patience and support through this endeavour - being with you has kept me sane and happy, and you have always been there to make my study breaks more enjoyable. 


\section{TABLE OF CONTENTS}

Title Page

Abstract

iii

Preface

Acknowledgements

IINTRODUCTION

1. Problem Statement: . . . . . . . . . . . . . . . . . . . . 1

2. RESEARCH QUESTIONS . . . . . . . . . . . . . . . . 2

3. Aims ANd OBJECTIVES . . . . . . . . . . . . . .

4. DeSign Methodology . . . . . . . . . . . . . . . 4

5. SCOPE OF DESIGN RESEARCH . . . . . . . . . . . . . . . 5

II PALLET OVERVIEW

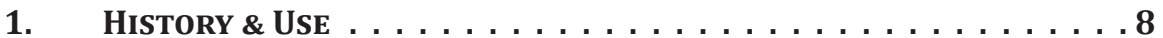

2. TYPES ........................ .

$2.1 \quad$ Pallet Type Models. . . . . . . . . . . . . . . . . 11

3. TREATMENT . . . . . . . . . . . . . . . . . 12

4. Sourcing PALlETS . . . . . . . . . . . . . . . . . . . . . . 13

III LITERATURE REVIEW

1. SUSTAINABILITY. . . . . . . . . . . . . . . 16

1.1 Jneycling

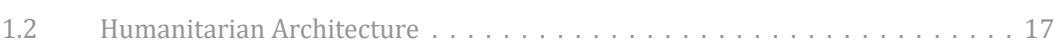

1.3 Low-Tech Temporary Architecture. . . . . . . . . . . . 18

2. PREFABRICATION . . . . . . . . . . . . . . . . . . . . . . 19

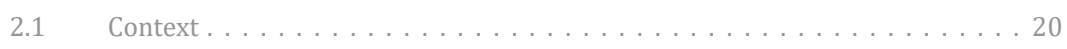

$2.2 \quad$ Mobile Prefab. . . . . . . . . . . . . . . . . 21

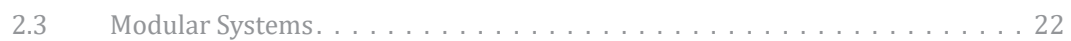

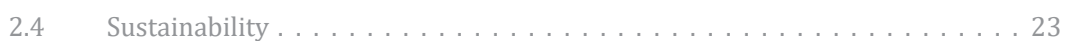

IV CASE STUdies

1. Paletten Haus - Claus Schnetzer \& Gregor Pils. . . . . . . . . 26

2. Pallet House - I-Beam Design. . . . . . . . . . . . . . 28

3. Hexa Structures - BC Studies \& Michael Lefeber . . . . . . . . 30

4. BINA KABINA - MDH ARCHITECTS \& QUENTIN LE GUEN-GEFFROY . . 32

5. Polish Pavilion, Expo Millano 2015 - 2Pm Architekci . . . . . . 34

V INITIAL EVALUATION

1. FIRST IMPRESSIONS. . . . . . . . . . . . . . . . . . . .

2. Previous Design Work . . . . . . . . . . . . . . . . . 39

VI Preliminary Design

VII CONTEXTUALISED DESIGN 47

1. Existing Pallet Type APPlications . . . . . . . . . . . . . . 48

2. Connection DetaILS \& Formal QuALITIES . . . . . . . . . . . 49

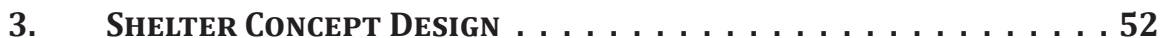

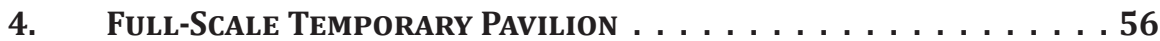

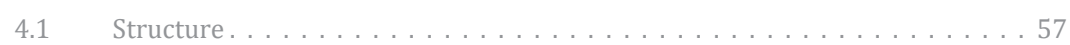

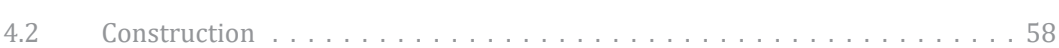

$4.3 \quad$ Transport \& Assembly . . . . . . . . . . . . . . . 60

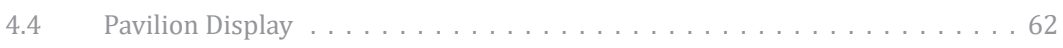

$4.5 \quad$ Model of Built Pavilion . . . . . . . . . . . . . . . . . . . . . . . . . 67

VIII 'Building Pallet' Re-Design 69

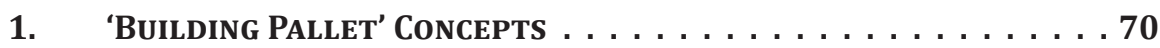

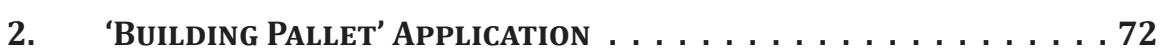

2.1 'Building Pallet' Models with Subsequent Prefab Building Elements . . . . . 75

IX Conclusions And CRITICAL REFLECTION 77

1. Existing PALlet Conclusions $\ldots \ldots \ldots \ldots$

2. 'Building Pallet' Conclusions . . . . . . . . . . . . . . . . 79

Bibliography $\quad 80$

List of Figures $\quad 82$ 


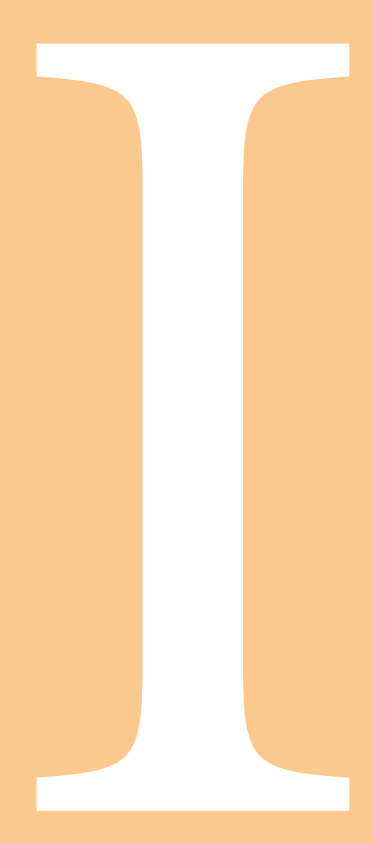




\section{Problem Statement:}

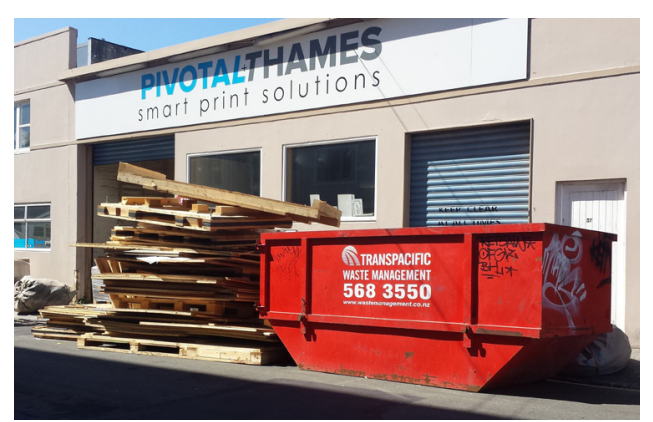

Fig. I-01. Pallets discarded as waste - an all too common occurrence in Wellington
Construction from timber shipping pallets (to be referred to just as pallets) is not a new idea. However in the New Zealand context an opportunity presents itself by the seemingly abundant supply of pallets too often seen discarded on city streets (see Fig. I-01). If pallets are not rescued for upcycling - recycling into higher quality or value than original product - they often end up in land-fills or as firewood as they are generally unwanted by industry after their initial life shipping and storing goods.

Pallets are commonly being upcycled for D.I.Y. furniture projects, incorporated into architectural design ideas and are rapidly influencing the growing area of temporary dwelling solutions for either the post-disaster or economic homeless around the world. The pallet's potential is vast: they are a natural building material due to their dimension module, the fact that they are built for transport offers inventive possibilities and they are abundant and universal enabling worldwide uptake of any innovation. However their full potential has not yet been reached as a building block solution that acts as primary structure and design driver.

With the goal of repurposing this 'junk' material into innovative architectural systems and solutions this thesis will explore to what extent pallets can be utilised in the construction of shelter. Their feasibility as structural entities and workability as modular, transportable panels will be fully explored. 


\section{Research Questions}

How widely can existing timb er pallets be utilised as a construction material?

Can a system of construction be developed which takes advantage of the existing nature of timber pallets effectively to create portable, sustainable and attractive temporary architecture?

How can the shipping pallet be redesigned to foster a built-in post shipping life as a modular, high-tech, affordable and adaptable universal building component? 


\section{Aims and Objectives}

This thesis has been divided into two main design phases each with slightly different aims and objectives: first to design with existing pallets, and second to propose a new 'building pallet'.

The existing pallet design phase aims to change people's perception of pallets from being a junk throwaway material to a valuable construction resource. It also aims to develop systems to re-use discarded pallets in construction that will improve their uptake in the design of temporary architecture of larger scale. This pallet architecture can be used to help house the less fortunate in society due to financial means or disaster situations, and can also be used to give new life to cities' public spaces through the display of temporary pavilions - not burdened by financial means.

The 'buillding pallet' design phase aims to remove all future pallet waste by redesigning the pallet to have a second life as a building component pre-built into its module. This new pallet aims to be a universal modular building component with which multiple can be assembled quickly and easily on site. The central purpose is to create high quality, affordable, efficient and adaptable architectural solutions, and improve people's perception of prefabrication as a building technique. The 'building pallet' also strives to improve housing affordability and ownership due to the reduced cost associated with prefabricated and modular homes.

The thesis as a whole also aims to explore and showcase the pallet aesthetic, creating attractive architectural statements that are undeniably pallet construction whilst empowering others to do the same with their own designs. 


\section{Design Methodology}

From the beginning of the thesis process it became clear that the most suitable methodological approach to this research through design project would be rationalism.

The rational method of Rene Descartes outlined in his Discourse on the Method was re-interpreted and used to inform architecture and design notably in the modern movement, as stated in Reyner Banham's Theory and Design in the First Machine Age (1980) and Erik Brynjolfsson \& Andrew McAfee's The Second Machine Age: Work, Progress, and Prosperity in a Time of Brilliant Technologies (2014). Seeing architecture as a rational process of design enables detailed understanding of the whole problem by deconstructing it into elements, solving each element individually and repeating this process for all parts.

The structure of this thesis was based directly upon this rational method. Demonstrated in the structural diagram a series of small tasks looking at specific aspects of the problem build knowledge and collectively aided understanding of the whole problem.

Each project stage was also broken down into manageable portions enabling meaningful analysis within the pallet overview, literature review, case study and initial evaluation stages, and in-depth, specific and informed exploration through the subsequent design stages. Not all analysis and experimentation resulted in positive outcomes, but this is not a negative as there is always a lot to be learned from looking at the issues and shortcomings (Montaner, 1999).

The first sections lay the foundation for the following design work:

- Pallet Overview (Context) - History, use, types, treatments and sources.

- Literature Review (Theory) - Consisted of research into sustainability in terms of upcycling, humanitarian architecture and temporary dwellings, and into prefabrication including portable architecture and modular construction

- Case Studies (Exemplars) - Case studies were then analysed to understand exemplary ways in which pallets have already been utilised architecturally and other relevant examples

- Initial Evaluation (Impressions) - Initial thoughts on solving the problems at the inception of this project, based upon previous knowledge and experiments 
Following the foundation sections are preliminary design experiments which develop through contextualised designs towards the final full-scale pavilion test. This design work builds upon analysis of context, theory, exemplars and impressions:

- Preliminary Design (Modular) - modular + scale tests

- Contextual Design (Structure) - modular + structure + connections

- Contextual Design (System) - modular + structure + system + assembly

$$
\rightarrow \text { Pavilion Concepts }
$$

- Full-Scalle Pavilion (Feasibility) - modular + structure + system + details

$$
\rightarrow \text { Feasibility Design Test }
$$

The project then changed direction from utilising low-tech - inaccurate - upcycled pallets to designing high-tech - precise - prefabricated 'building pallets' which aim to act as universal modular building components post-shipping.

- 'Building Pallet' Concepts (Universal Component) modular + structure + connections + adaptability + universality

- Final 'Building Pallet' Design (Adaptable Composition) modular + adaptability + universal component + details

$$
\rightarrow \text { Adaptable Architectural Solution }
$$

Each design experiment built upon the previous using the new understanding to explore further each time, whilst continually drawing from design precedents. The results were logical interim conclusions at each stage which led to greater understanding of the problem as a whole.

The most important design method for this thesis has been physical model making. Physical models require and enable greater understanding of the design - structure and buildability in particular are aspects perfectly testable by this method (Lin, 1999). Small scale models enable rapid prototyping of ideas, while 1:1 scale real world experiments provide contextual understanding of the whole issue. Digital 3D modelling and hand sketching have also been important design methods for conceptual thinking. However in this design process concepts were then tested in physical models to keep the project grounded in reality and ensuring all research would be replicable.

\section{SCOPE OF Design RESEARCH}

Primary concerns of this thesis lie with pragmatic issues like buildability, efficiency, portability and cost.

While a key concern is how the pallets perform structurally, actual structural performance of the developed systems and built prototypes was outside the scope of this project, apart from understanding gained through the physical modelling and generic structures knowledge. Similarly while the aspects of energy efficiency and construction speed are significant, in-depth calculations of actual performance of the designed systems were also outside of this project's scope and may warrant future research.

Qualities like atmosphere, the notion of experience and architectural narrative were also outside the scope of research considered relevant for a one year project. Inclusion of these aspects may provide a more holistic understanding of the potential of the designed building systems in future, through further research outside of this project. 


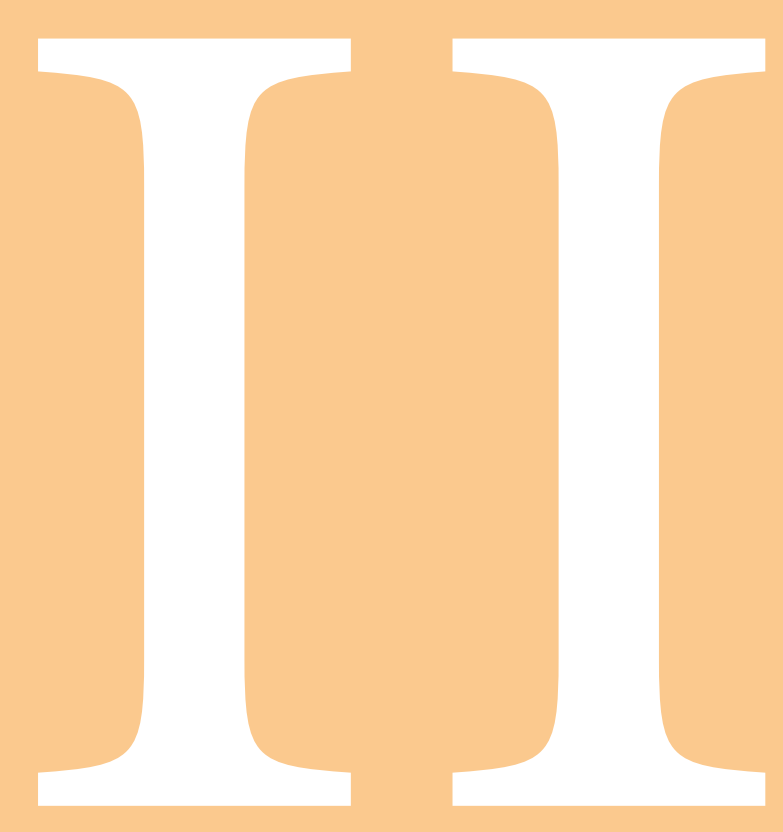




\section{Pallet Overview}

The pallet overview offers a summary of existing pallets' context and sets out the knowledge required to safely and efficiently source appropriate pallets.

The context of existing pallets is explored through history, uses, types, treatment and sourcing. Information has been gathered from the limited relevant literature and from personal observation. 


\section{History \& UsE}

Pallets are an "indispensable tool" throughout the supply chain for the storage, stacking, handling, and transportation of goods and merchandise in all sectors of industry (Drouet, 2015, p.9).

Pallets first came into being in America in the 1930s. During WWII the US government greatly expanded pallet use for the transportation and storage of equipment in vast quantities. By the late 1940s pallets had become essential for industry to stay competitive and successful. In Europe it wasn't until the 1970s that industry grasped the full potential of the advantages utilising pallets. "Reconditioning" of pallets - being upcycled and utilised by the public - began emerging in 1975-1980 to economise on raw materials following the first oil crisis, and also partly in response to users not wanting the burden of the constraints of returnable pallets (Drouet, 2015, p.9). Since then shipping pallets made from new materials have been developed in plastic, cardboard, metal and other composites, however the use of standardised timber pallets is still the most commonly used in industry, and most frequently found discarded. Typically timber pallets in New Zealand are radiata pine but spruce, fir and cedar are also found being utilised. 


\section{TYPES}

Simplifying pallets down to their simplest components: they are designed to standard modules, are designed for being lifted by forklift and are built for supporting various goods and produce (stationary or in transport). These components define the different pallet types

\section{Dimension Module}

The dimension module is very important, and while pallets of different forklift access types or from different manufactures may be used in the same industry or country, it is best practice and most efficient for these pallets to have consistent dimensions and access. Typical dimensions for international shipping pallets follow, and are in the form length $\mathrm{x}$ width (in millimetres):

- 1200 x 1000 - New Zealand standard pallet, common in Europe and Asia

- 1219 x 1016 (48” x 40") - North America standard pallet

- $\mathbf{1 2 0 0}$ x 800 - European standard pallet (Euro-pallet)

- $1100 \times 1100$ - Asia standard pallet, common in Australia

- 1067 x 1067 (42" x 42") - North America, Europe and Asia common pallet

- 1165 x 1165 - Australia standard pallet

Typically the thickness of pallet modules is in the vicinity of $140 \mathbf{m m}$ however some block pallets get up to $160 \mathrm{~mm}$ due to their need for cross pieces, but this is not an issue as the most important dimension factor is that they fit together and align in plan.

\section{STRUCTURAL MAKE-UP}

The structural make-up of a pallet determines whether the forklift access is two-way or four-way. Stringer pallets have three stringer beams, between which is the access from the two opposite ends, making them two-way. Block pallets have a rectangular grid of nine blocks arranged three by three, between which is the access from all four sides, making them four-way. Notched stringer pallets' make-up is identical to stringer pallets, but they are given extra access through the two notches in the stringers to become also four-way. Fig. II-01 compares the three pallet structure types. (Drouet, 2015, p.9)

\begin{tabular}{|c|c|c|c|}
\hline & ACCESS & VARIATION & MAKE-UP \\
\hline Stringer Pallet & Two-Way & $\begin{array}{l}\text { Can be: } \\
\cdot \quad \text { Reversible } \\
\text { Can have: } \\
\text { - } \quad \text { Fully or Partially } \\
\quad \text { Covered Top Deck }\end{array}$ & $\begin{array}{ll}\text { - } & \text { Top Deck } \\
\text { - } & \text { Stringers } \\
\text { - } & \text { Bottom Deck or Base } \\
& \text { Boards }\end{array}$ \\
\hline $\begin{array}{c}\text { Notched } \\
\text { Stringer Pallet }\end{array}$ & Four-Way & $\begin{array}{l}\text { Can have: } \\
\text { - Fully or Partially } \\
\text { Covered Top Deck }\end{array}$ & $\begin{array}{ll}\text { - } & \text { Top Deck } \\
\text { - Notched Stringers } \\
\text { - Base Boards }\end{array}$ \\
\hline Block Pallet & Four-Way & $\begin{array}{l}\text { Can have: } \\
\text { - } \text { Fully or Partially } \\
\text { Covered Top Deck } \\
\text { - } \text { Base Boards or } \\
\\
\text { Perimeter Cover }\end{array}$ & $\begin{array}{ll}\text { - } & \text { Top Deck } \\
\text { - } & \text { Cross Pieces } \\
\text { - } & \text { Blocks } \\
\text { - Base Boards }\end{array}$ \\
\hline
\end{tabular}

Fig. II-01. Pallet type overview including access, variation and make-up

These three pallet types each have the top deck in common, which is always covered in boards but can have large or small gaps between depending on the pallet's requirements. There is variation with the rest of the pallet however, as the different structure types have limitations on board coverage of the bottom deck - only stringer pallets have the option of being reversible, notched stringer pallets can only have base boards and block pallets either base boards or perimeter covering. Fig. II-02 compares the make-up of the three structure types and looks at the similarties and differences between each. Fig. II-03 allows for a closer look at possible variations between pallet types. It is important to note that only block pallets have cross pieces, which are required to attach the top decking to the blocks. (Drouet, 2015, p.9)

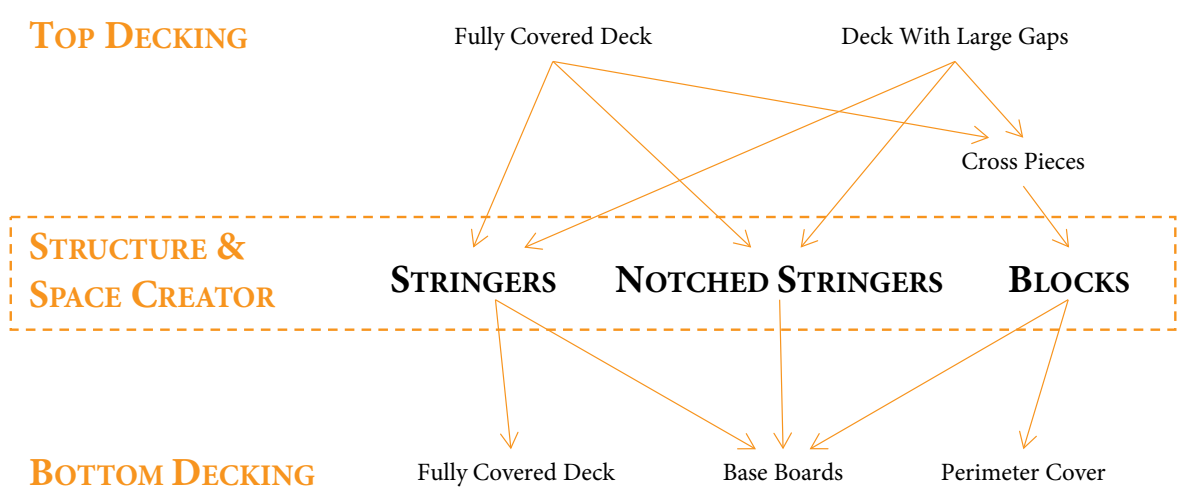

Fig. II-02. Analysis of the make-up of the three different pallet structure types 


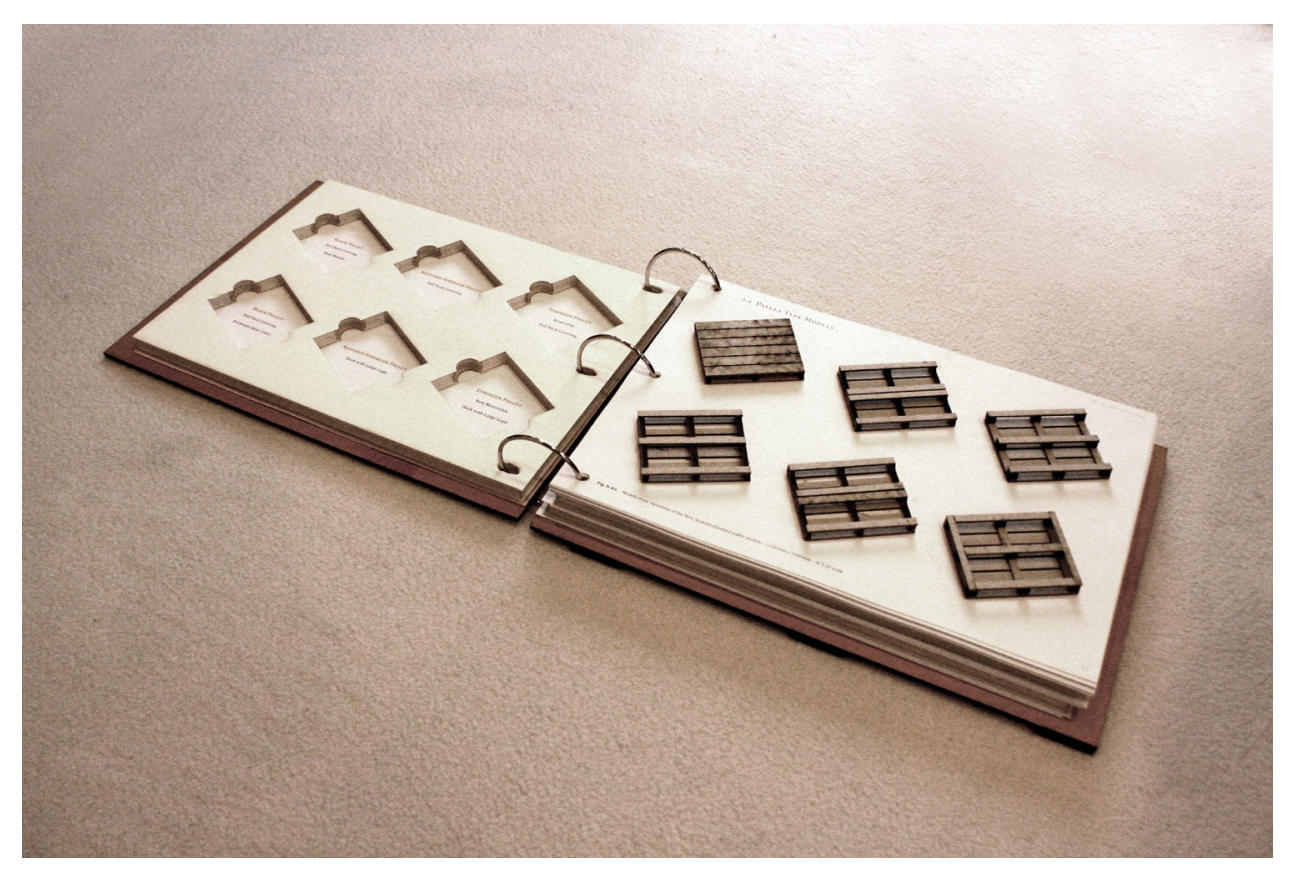




\subsection{Pallet Type Models}
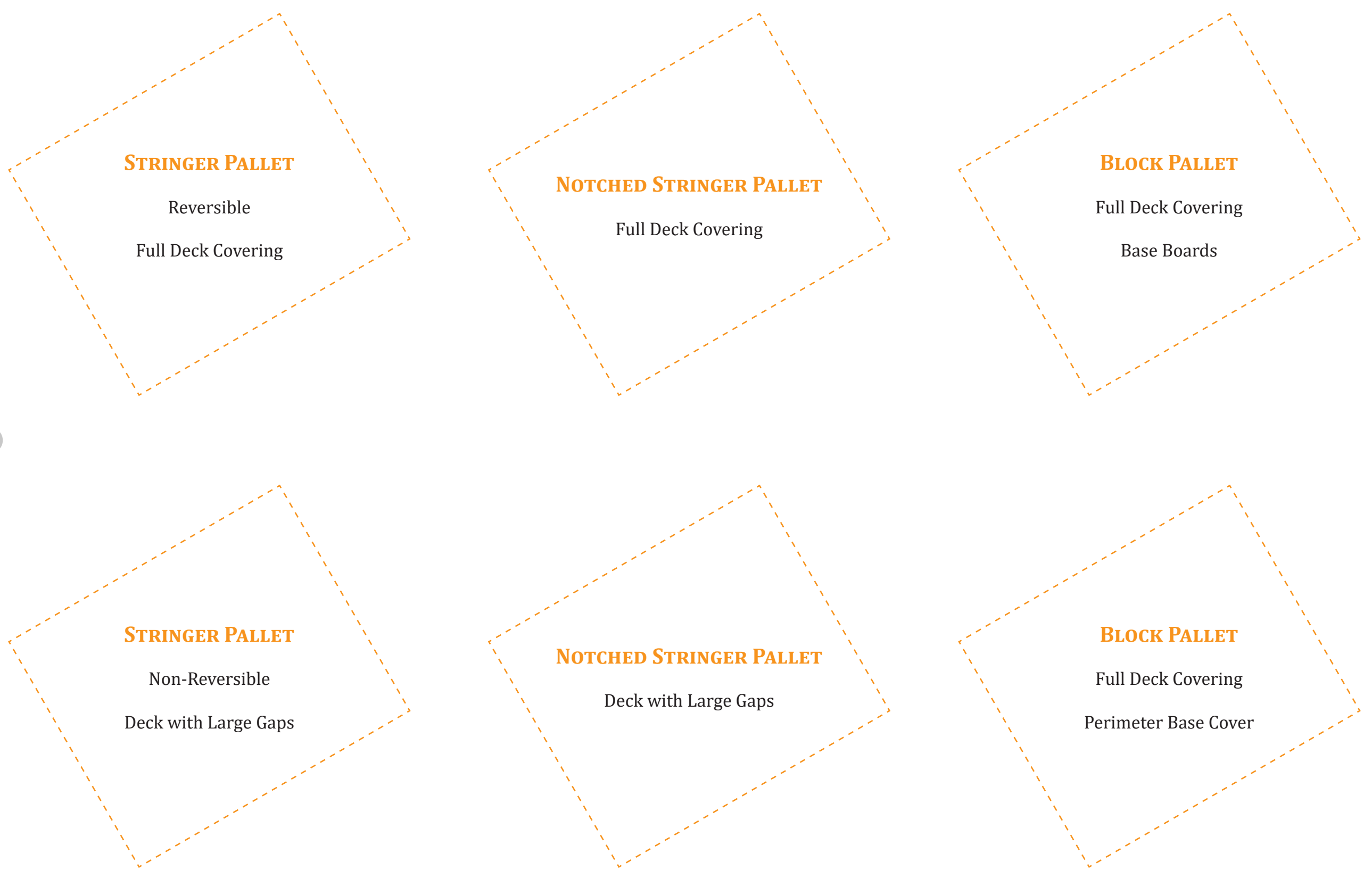

Fig. II-03. Models of six variations of the New Zealand standard pallet module $-1200 \mathrm{~mm} \times 1000 \mathrm{~mm}-$ at 1:20 scale 


\section{Treatment}

Pallets may undergo a range of treatments before or during their shipping lives - some safe and others harmful - so it is important to be informed and only use appropriately treated pallets for any construction project.

The International Standards for Phytosanitary Measures No. 15 (ISPM 15) was developed by the International Plant Protection Convention (IPPC) and controls the various treatments that timber for shipping pallets and crates undergo before international use. To protect local ecosystems from the spread of invasive insect species and plant disease across borders IPPC standards require all raw timber to be treated by way of heat treatment, chemical fumigation or debarking (International Plant Protection Convention, n.d).

- Heat Treated - 'HT' - pallets have had their core temperature heated to a minimum of $56^{\circ} \mathrm{C}$ for at least 30 minutes to sterilise the wood. Being chemicalfree HT pallets are safe.

- Kiln-Dried - 'KD' - pallets undergo a refined process of HT but with the aim of also reducing moisture content to reduce warping. KD pallets are safe.

- Methyl Bromide Fumigation - 'MB' - acts as a powerful pesticide warding off insects but the chemicals are harmful and contact with skin and food should be avoided. This treatment is being phased out worldwide due to links to human health problems and ozone depletion so MB fumigated pallets should be avoided. Sawdust from working with MB pallets is particularly unsafe as sawing will help release the chemicals.

- Debarking - 'DB' - is the removal of bark where surface insects and disease may lurk. This treatment may be used stand-alone or in conjunction with others, and is only unsafe to use when paired with MB (DBMB).

- Untreated pallets - unstamped/unmarked - are typically constructed for limited domestic use and in theory are safe to use.

(Bunde, 2014, p.15; Drouet, 2015, p.11; Gleason, 2013, p.13)

An IPPC standard pallet containing a typical stamp with the IPPC logo and the country, supplier and treatment codes is shown in Fig. II-04. 


\section{Sourcing Pallets}
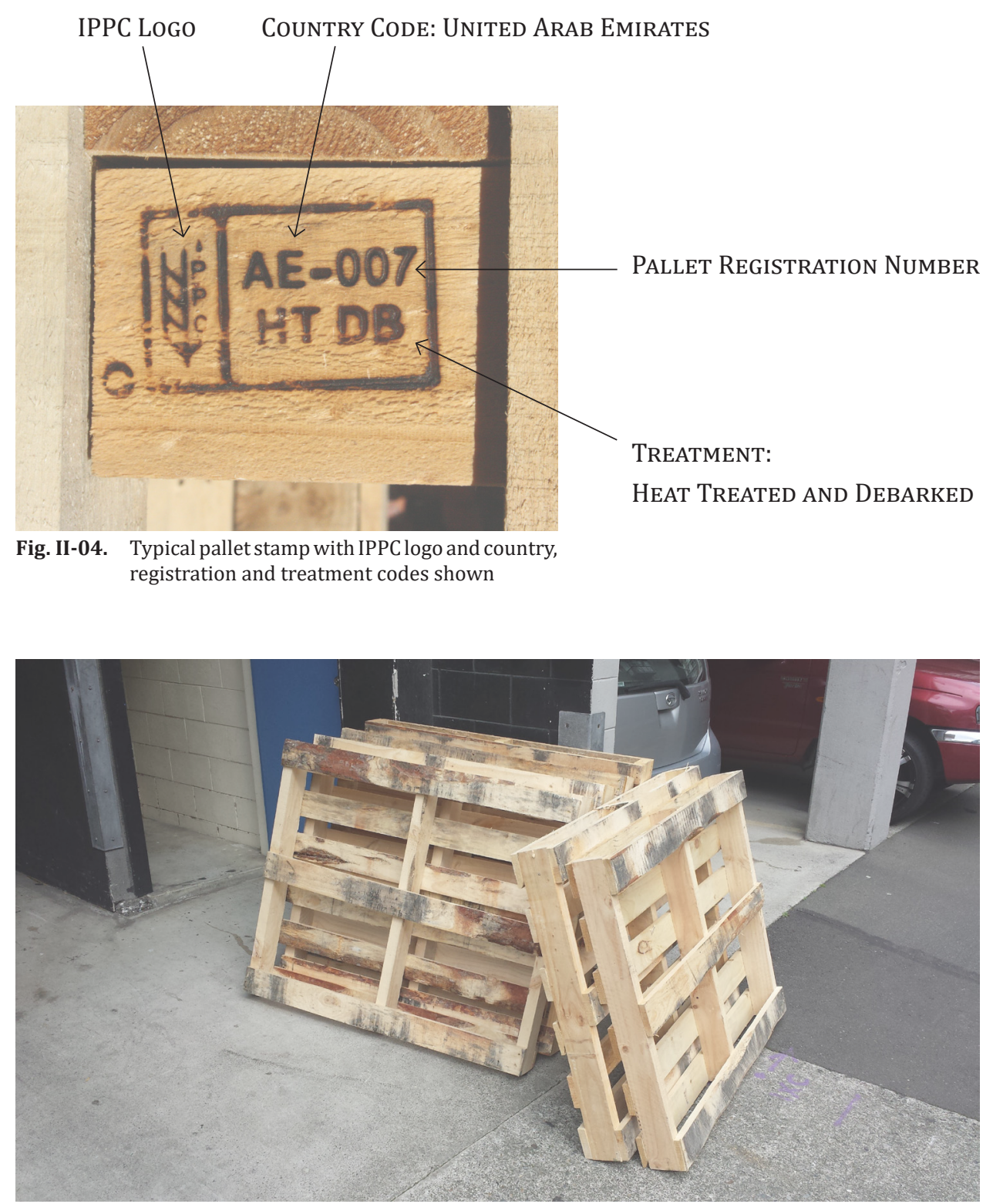

Fig. II-05. These single-use pallets were continuously discarded as new deliveries kept the source stocked. Ideal pallet source for building due to consistency in type, dimensions and high quality - later utilised in 1:1 scale pavilion test.
When sourcing pallets there are features to be conscious of and attributes to avoid. While certain pallet structure types or dimension modules may be desired care must also go towards identifying signs of damage and hazards. Pallet with the following signs should be avoided:

- Evidence of wildlife - bugs, termites and borer

- Signs of mould - being unusually heavy and holding liquid can also be due to mould

- Evidence of liquid spillage - hazardous chemicals may have leaked during shipping

- Unappealing odour - possible sign of chemical residue

- Colour stained pallets - tend to be 'returnable pallets' and part of huge pools belonging to distribution companies and manufacturers - not free to take.

(Bunde, 2014, p.16; Drouet, 2015, p.10; Gleason, 2013, pp. 12-13)

Karah Bunde (2014), author of DIY Wood Pallet Projects: 35 Rustic Modern Upcycling Ideas to Personalize Your Space, suggests that irregularities like broken slats, holes, cracks and rusty nails should be embraced and expressed in design. When sourcing pallets for this project Bunde's principles have been upheld except where imperfections have decreased the structural integrity of the pallet. In these cases pallets were instead deconstructed for their components.

Local industrial areas where goods are readily delivered on pallets are the best sources, and you will soon learn the particular shops which discard the pallets most ideal to the desired task (see Fig. II-05).

Block pallets are designed for long term re-use while stringer and notched stringer pallets are designed for limited use - often being disposed after only few shipments (Drouet, 2015, p.9). Stringer type pallets are therefore more commonly discarded and available compared to more robust block pallets. However pallets' shipping lifespan isn't directly relative to their strengths in a building-block context as stringers allow for spanning and blocks offer strength; all pallet structure types are therefore desirable for being sourced, tested and utilised. 


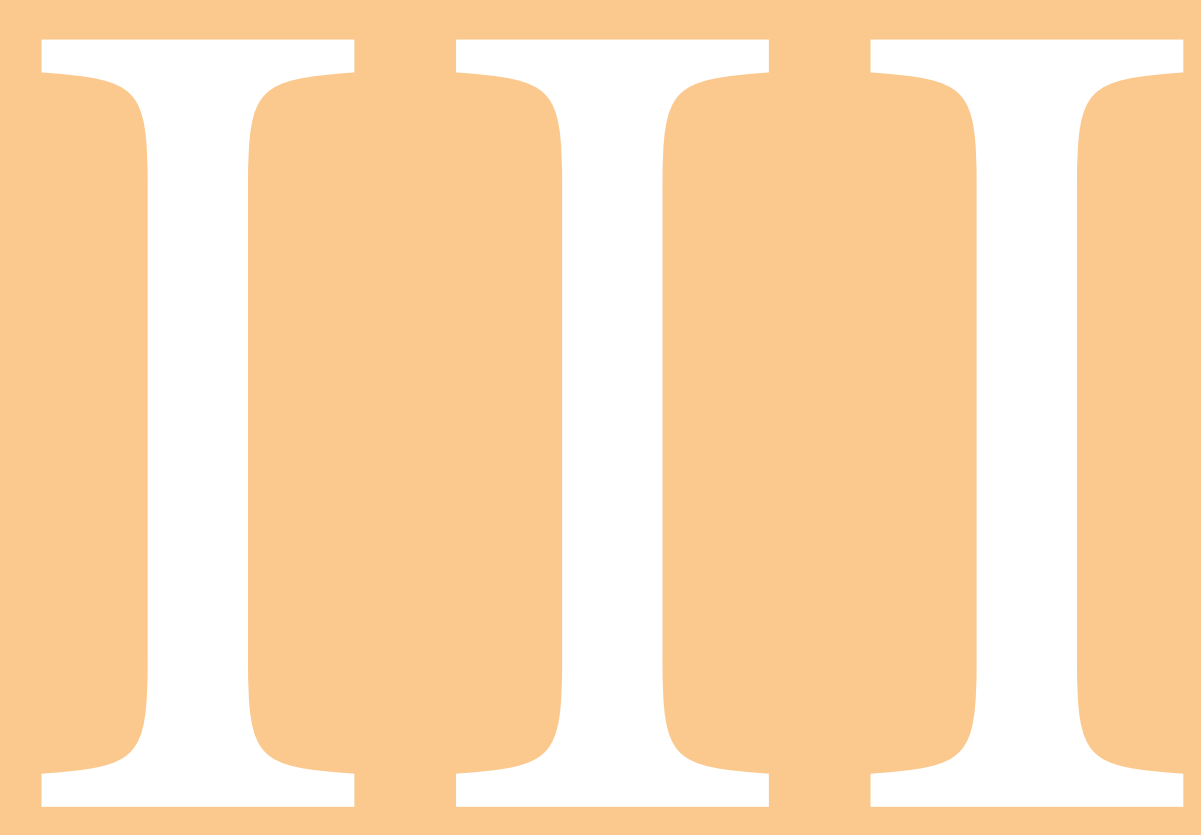




\section{LITERATURE REVIEW}

The literature review covers key theory in the topics of sustainability and prefabrication. The particular sources used were the most relevant for a thesis working with the humble pallet, and act to locate the thesis within existing literature while bringing all key design principles to the fore.

The sustainability chapter includes upcycling, humanitarian architecture and low-tech temporary architecture, and aims to inform the existing pallet design phase.

The prefabrication chapter includes design principles, context, mobile prefab, modular systems and sustainability and aims to inform the 'building pallet' design phase. 


\section{SUStainability}

\subsection{UPCYCLING}

Folke Koebberling and Martin Kaltwasser (2006) - experts in designing with waste materials - in City as a Resource: One Man's Trash is Another Man's Treasure describe their key projects and principles for recycling discarded material into "treasure". The projects are built from cost-free resources in the form of others' waste - including pallets - found on the streets of Berlin.

In Berlin the idea of community recycling is common and gives new life to the streets (Koebberling \& Kaltwasser, 2006). Neighbours would display unwanted belongings in public space around their buildings and others take what they wanted for themselves - like a free garage sale - and eventually all discarded items would find a new home (Koebberling \& Kaltwasser, 2006). Koebberling and Kaltwasser themselves would source material in this fashion for construction of 'temporary buildings' for public display, a term enabling constructions normally prohibited by German building law (2006, p.15). Their designs exhibited the potential for upcycling in an urban context due to the public's positive perception of temporary architectural works in improving public space.

Robert Kronenburg (2003) - Professor of architecture at University of Liverpool and mobile architecture expert - holds similar views, pointing out even low-tech or free recycled materials can be used for experimentation in temporary building. 
Fig. III-01. Besnard's design for the Modulopal is a perfect example of pallet's democratic nature as it was designed to be an emergency shelter for the homeless, and is notable for its modular cub construction from $1200 \mathrm{~mm} \times 800 \mathrm{~mm}$ standar Euro-pallets stacked two-high. Besnard's cabin test ended up atop a cliff as a fishing shelter due to its hardiness.

Fig. III-02. Bachmayr's 'pallet truss' - being assembled by unskilled is constructed primarily from stringer pallets to utilise the integrity of stringers for the truss's top and bottom chords. Pallet decking is used as gussets to connect stringer chord menbers ecting is used as gussets to connect stinger cho (amportant to have sufficient nails at each joint to ensure consistent strength along the entire truss. (Bachmayr, 2004, p.28)

\subsection{Humanitarian ArChiteCture}

Pallets are a valuable resource in the realm of humanitarian architecture. Kate Stohr and Cameron Sinclair (2006), co-founders of Architecture for Humanity until 2013, are leaders in architectural humanitarian crisis design and see pallets as being the perfect post-disaster building material due to already transporting aid to crisis zones. Philippe Besnard, designer-architect responsible for the Modulopal cabin (see Fig. III01), similarly describes pallets as being "democratic" as they are affordable or even free, and often found discarded making them very easy to source (as cited in Drouet, 2015, p. 172).

Alfred Von Bachmayr - award-winning architect for low-cost, energy-efficient and sustainable buildings - designed the low-tech 'pallet truss' to remedy inadequate roof structures while doing philanthropic research in Ciudad Juárez, Mexico. Hightech building materials were scarce and expensive so Bachmayr utilised discarded pallets, dismantling them into individual components and reassembling to form a truss capable of significantly increased span and insulation levels (Bachmayr, 2004). The designed system employed a jig with outlines of the required members drawn on, allowing unskilled builders to quickly create a consistent roof truss (see Fig. III-02). Bachmayr (2004) saw the 'pallet truss' as being a viable alternative roof structure in developing areas of the world.

The principle of disassembling pallets to utilise their individual components as additional structure is an important strategy and is tested through design within this project.

Jennifer Siegal - founder of Office of Mobile Design - is renowned for her expertise in portable architecture and its interrelation with sustainability. Siegal compares the nomadic cultures - "who needed to provide shelters that were durable, lightweight, flexible and ultimately transportable by low-tech means" - to the new wave of interest in portable dwellings (2002, p.16).

This thesis will apply these specific nomadic tendencies to temporary architecture in a way applicable for those living in post-disaster instability or urban homelessness whom have need for easily portable dwellings. In these situations dwellings must be easily manageable and able to be assembled without skilled workers. 


\subsection{Low-Tech Temporary Architecture}

Wang Shaoqiang - Professor at Guangzhou Academy of Fine Arts - sees the social role of temporary architecture as giving meaning to people's environment with its "singular characteristics of lightness, transience and practicality" (2014, p.6). While only at a certain site for limited time, Shaoqiang (2014) believes the impact on people's emotions can be lasting. The "dramatic erection and dismantling procedures" can also create excitement of their own - exemplified by Tadao Ando's Karaza Theatre (see Fig. III-03) which was assembled from scaffolding in fifteen days in 1987 (Kronenburg, 2003, p.19). The use of scaffolding for temporary works seems to be most common, as this modular system is easy to erect and demount.

An important factor designing portable buildings is weight, and minimising the complexity of the design helps keep weight down. This goes far beyond simply the use of lightweight materials, to also how they are expressed in their construction; disguising and hiding elements adds material and weight, so structure and construction should be exposed and honest (Kronenburg, 2003).

Australian architect Tone Wheeler states that the future will be more about "the spanner, than the hammer" shifting towards bolts, screws, reuse and adaptability, and away from glue, nails and waste (as cited in Bell \& Southcombe, 2012, p. 140). When temporary architecture's time runs out their key feature is that buildings are disassembled and redeployed rather than destroyed (Shaoqiang, 2014). Environment impact is minimised as there are no long term effects of temporary architecture on their surroundings (Kronenburg, 2003).

See original images in Kronenburg, 2003, pp. 58-59

Fig. III-03. Exemplified in Tadao Ando's Karaza Theatre, the simple assembly procedure of scaffolding allowed this portable theatre to be built in fifteen days in 1987 (Siegal, 2002, p.23). Images show three stages of assembly. 


\section{Prefabrication}

Prefabrication, otherwise known as prefab or offsite construction, means any part of a building constructed away from site.

Prefabrication is by definition transportable - as it is built for initial transport to site - but is not necessarily built for easy mobility like temporary and high-tech portable architecture which are easily relocatable. Prefabrication has the potential for greater sustainability due to less material waste, higher energy efficiency and in the case of portable prefab - no lasting impact on site due to relocation. Prefabrication can also be modular and adaptable - able to be added to or altered over time due to interchangeable and flexible modules making up the whole.

When architecture is based on prefabricated elements the "building work thus becomes an assembly process" rather than construction (Staib, Dörrhöfer \& Rosenthal, 2008, p.47).

"The traditional building paradigm is to gather all parts of a building at the site and then assemble them piece by piece" (Kieran \& Timberlake, 2003, p.40). Prefabrication in the current construction industry is partially componentised where pre-nailed roof trusses and prefab window modules are well utilised, and pre-nailed wall framing is becoming more common (Fig. III-04). Architects Kieran and Timberlake (2003) imagine a world where all building assembly is with larger modules incorporating windows, insulation, cladding, services and fittings - built in controlled factory conditions.

There are five scales of prefabrication: individual components, panels, modular segments, hybrid and complete buildings (Bell, 2010, p.4). See Fig. III-05 for overview.

For this project component and panel prefab will be explored in a modular fashion.

- Component - pre-made elements like windows, doors, trusses

- Panel - whole wall solutions ready for assemly

- Module-3-dimensional segment which makes up the whole

- Hybrid - combination of smaller scales of prefab 


\subsection{CONTEXT}

According to Gerald Staib, Andreas Dörrhöfer \& Markus Rosenthal - Lecturers at the Technical University of Dresden - the main reason 'assembly line' architectural production is widely considered undesirable is due to the misconception this matches the aesthetic of industrial prefabrication - "associated with mass production and monotony" (2006, p.226).

Mark Southcombe - senior lecturer at Victoria University of Wellington's School of Architecture - describes the word 'prefab' as, until recently, having bad connotations in the New Zealand context and often being associated with "drab, cheap, temporary, poorly designed school classrooms" (2002, p.10). This perception is changing however, with prefab homes becoming more synonymous with high quality finishes, efficiency, productivity, customisation and suiting individual client and site needs (Southcombe, 2002).

Pamela Bell, author of 2009 thesis Kiwi Prefab: Prefabricated Housing in New Zealand: an Historical and Contemporary Overview with Recommendations for the Future, is a key author as her thesis places prefabrication within the New Zealand context and out outlines ways for the prefab business to increase - streamlining the construction industry. See Fig. III-06 for Bell's findings on the technical, social, economic and sustainable merits of prefabrication. The conclusions of Bell's research was that people's conceptions needed to change to reflecting prefab as a high quality, on-time, budget-conscious and sustainable construction process to improve uptake of prefab in New Zealand $(2009 ; 2010 ; 2012)$.

Bell paved the way for several initiatives regarding New Zealand design, construction and manufacturing industries, which in turn resulted in the establishment of the new pan-industry body PrefabNZ. PrefabNZ aims to address housing shortages by increasing productivity in the building sector but not by "mass-standardisation"; instead "mass-customisation" utilising the high-tech will result in high quality individualised building solutions (Bell, 2010, p.10). 
Fig. III-06. Bell's 2010 research outlines the distinct advantages of prefabrication:

- Technical merits - quality controls, factory manufacture, testing, joint minimisation, tighter tolerances and the ability to eliminate defects.

- Social merits - indoor protection, material and tool security, worker health and safety, machinery and training investment, employment stability and design variation.

- Economic merits - time savings (30-60\% saved on traditional methods), cost savings, reduced dependence on weather, coordinated trade inhouse, bulk ordering, reduced transport to site and reduced floor area.

- Sustainable merits - reduced material waste (up to $75 \%$ saved) increased energy efficiency (due to tighter building envelope) and less disruption at site (noise, pollution, effluence, ground-works, traffic etc.). (Bell, 2010, p.4)

See original image at http://www.lot-ek.com/MDU-Mobile-Dwelling-Unit/

Fig. III-07. LOT/EK's Mobile Unit Dwelling is built from the re-use of a standard shipping container. Sections of the walls have been cut out and attached to modules which slide outward from the container creating new spaces within

\subsection{Mobile Prefab}

Portable architecture's principles are dependent on the scale of prefabrication. When component, panel, module and hybrid prefab are considered portable they are "design[ed] for disassembly" (Bell \& Southcombe, 2012, p.140). However complete portable architecture is instead designed for mobility of the whole.

Mobile architecture today "rolls, flows, inflates, breathes, expands, and contracts" (Siegal, 2002, p.16). New technology enables new possibilities; pneumatic, tensile and kinetic structures - some with the ability to self-deploy and self-erect - are leading the field to a new, high-tech, mobile (Kronenburg, 2002).

These high-tech mobile architecture principles are also applicable to low-tech temporary architecture. They will inform the contextualised design phase in terms of mobility and opening strategy, despite making use of low-tech materials.

Kronenburg (2002) sees ability to be mobile as paramount for many real clients as it offers performance advantages compared with the standard, static, building solution. In the Wellington context public space is often utilised by temporary buildings whose mobility allows redeployment when no longer needed or after certain period of time.

The Mobile Dwelling Unit, by LOT/EK, explores the adaptive reuse of ISO shipping containers as building-block solutions for a worldwide, standardised, domestic unit (see Fig. III-07).

The shipping container, like the pallet, is a "tough, modular, movable tool that is incorporated into a worldwide standard for ease of transportation," making it a perfect base building form due to its ability to readily use cranes, lorries and ships for relocation (Kronenburg, 2003, p.8). It is becoming common to incorporate shipping containers into the construction industry due to their size and ability to become instant dwellings. If pallets were finished to a higher - more precise - standard they could be used in a very similar fashion to shipping containers, though in the form of a modular panel rather than complete unit. 


\subsection{Modular Systems}

Bell (2010) describes modular prefab as being three-dimensional building segments which combine to make the whole. However for this project 'modular design' has a different meaning.

Staib, Dörrhöfer and Rosenthal describe modular construction systems as being "closed systems in which the elements are prefabricated by the manufacturers independent of a particular building," before being organised into complete entities by combining into a range of flexible compositions $(2008, \mathrm{p} .43)$.

Designing with this definition of 'modular' is most applicable to the design process. Pallets - both existing and the proposed 'building pallets' - will have a standard dimension module as the starting point for design.

Peggy Deamer (2012) - Assistant Dean and Professor of Architecture at Yale University - believes that prefabrication in the 21st Century shouldn't be about industrialised mass production, but rather about being culturally authentic, site specific and customised solutions. Bell (2012) has similar views seeing the future of prefabrication as the architect designing customisable modular systems. This enables the client to act as space-designer, able to pick and choose their individualised design within the modular system. Designing prefabricated systems with modular principles offers potential for new invention, individuality and customisation in solutions, and is an attempt to "reconcile singular artistic creation with mass production" (Bergdoll \& Christensen, 2008). See Fig. III-08 and Fig. III-09 for system examples.

Of particular importance in designing modular systems are joint jointing details and dimensional tolerances.

Jointing details of prefabricated elements must be designed with great care, must be protected against moisture by constructional solutions or in combinations with sealants, and should be minimised in number by maximising module size with respect to their production and transport conditions (Staib et al., 2008)

"Tolerances describe possible differences between the nominal and the actual dimension of a building element" (Staib et al., 2008, p.47). Tolerance for dimensional deviations in elements must be taken into account to ensure the building pieces all fit together to achieve the desired overall dimensions, and allowing space for extras like sealants to fit between panels (Staib et al., 2008). 


\subsection{SUSTAINABILITY}

A

See original images in Staib et al., 2008, p.25

Fig. III-08. At the 1927 Stuttgart exhibition - The Apartment - Walter Gropius demonstrated his new solutions for industrialised building, including house no. 17 which was constructed from industrially prefabricated elements to a basic plan module dimension of 1.06 metres (see plans B \& C). The house's prefabricated steel frame was first assembled followed adding external and internal cladding, as well as cork panel insulation between. The structure (A) detailing and layout all following the same dimension module making each element type a mass producible entity not destined for use in identical dwellings, but rather transferable to raft of adaptable and interchangeable solutions.

(Staib et al., 2008, p.25)
Brenda Vale (2012) - Professorial Research Fellow specialising in sustainable building design and prefabrication - in the essay Prefabs and Sustainability outlines the ways in which prefabrication can contribute to making modern housing more sustainable. Vale (2012) sees housing sustainability principles as going against the universal approach to prefabricated design as these principles are about reducing resource use, particularly from non-renewable resources, and designing to local climate conditions.

In the New Zealand context of a 50 year life cycle of a house, energy used for operation is a far larger component than that of embodied energy in materials used for construction and maintenance (Vale, 2012). Energy efficiency therefore allows for prefabricated sustainability through being highly insulated passive solar buildings with minimal energy requirements (Vale, 2012).

The 'building pallet' must be a highly insulated panel that allows considerable customisation in order to best suit any building site and have optimal energy efficiency.

Fig. III-09. In 1943-44 the General Panel System - developed by Konrad Wachsmann in collaboration with Walter Gropius - was developed and sold as 'General Panel Units' with the intention of being the most complete prefabricated system possible; capable of producing any configuration of single or double storey dwelling required, and able to be simply assembled on site by untrained workers without any prior knowledge or skills.

(Staib et al., 2008, pp. 27-28) 
IV 
The case study section analyses existing project solutions relevant to the thesis problems:

- Palletten Haus - Claus Schnetzer \& Gregor Pils - upcycling, humanitarian, temporary and prefabrication

- Hexa Structures - BC Studies \& Michael Lefeber - upcycling, temporary and modular

- Pallet House - I-Beam Design - upcycling, humanitarian, temporary and modular

- BINA Kabina - MDH Arkitekter, Quentin Le Guen-Geffroy \& Florian Kosche - upcycling, temporary and modular

- Polish Pavilion, Expo Milano 2015 - 2pm Architekci - tpeycling and modular

Each project begins with a brief overview referencing the related thesis research themes - upcycling, humanitarian, temporary, prefabrication, mobile and modular system - before being analysed in terms of the following relevant criteria:

- $\quad$ Structure - Primary, secondary, cladding and effectiveness

- Construction - Altering/adding to pallets, level of prefabrication and modular

- Assembly - Assembly/disassembly, mobility, opening mechanism and ease

- Services - Waterproofing, insulation, services and structure

- Aesthetic - Honest material use, attractiveness and special qualities

Designs are critiqued and possible application of ideas is considered. 


\section{Paletten Haus - Claus Schnetzer \& Gregor Pils}

\section{KEY THEMES: \\ Upcycling, Humanitarian,} Temporari, Modular \& Prefabrication
Overview

The Paletten Haus by Claus Schnetzer and Gregor Pils is a high-quality low-income house replicable in developing countries where building materials are scarce. As students Schnetzer and Pils won the 2008 GAUDI European Student Competition with their Paletten Haus which has since been redeployed around Europe due to being hugely popularity.

800 standard Euro-pallets - block pallets - are required for the typical construction which measures $60 \mathrm{~m} 2$ and costs an average of €8 per pallet including services and labour.

Pallets have been utilised in a modular fashion as roofing, flooring, exterior walls and interior partitions with added timber structure hidden between the depth of the double-pallet building surfaces. The double-pallet surfaces also contain insulation, conduits, plumbing and waterproofing.

Pallets are used whole in this temporary building with all services being prefabricated systems which incorporate within the pallets on-site. The construction process is therefore a process of assembling parts

Sources: (Meinhold, 2010; http://www.palettenhaus.com/) 


\section{Structure}

- Pallets are secondary structure acting as cladding, roofing, flooring and interior partitions

- Primary structure - timber beams - hidden within pallet surfaces

\section{Construction}

- Panel-type prefab where pallets and services are prefabricated

- Few pallets require pre-cutting to shape - off-site

- Modular system with building dimensions determined by whole pallet module - building is three pallets high externally (two internally), five pallets wide and set pallet number length - this length is flexible (see Fig. IV-02)

\section{Assembly}

- All elements arrive on site prefabricated and are assembled

- Mobile due to its ease of assembly, disassembly and portability

\section{Services}

- Pallet surfaces are all two pallets thick with all services - structure, insulation, conduits, plumbing and waterproofing - hidden within

\section{Aesthetic}

- Three whole pallets used for walls making wall to roof and floor junctions tidy due to overlapping and covering the floor and roof from side view

- Very attractive architecture due the bold modern form and glazed walls at the two ends

- Building glows at night due to transparent skin (see Fig. IV-03)
- Addition of structure within pallets - while tidy as structure is hidden creates less authentic 'pallet architecture'

- Assembly process effective as all elements are prefabricated

- Attractive finish is significant as this is achieved through good design irrespective of utilising 'junk' material, however pallet aesthetic is partially lost due to design simplicity and cladding monotony (see Fig. IV-01)

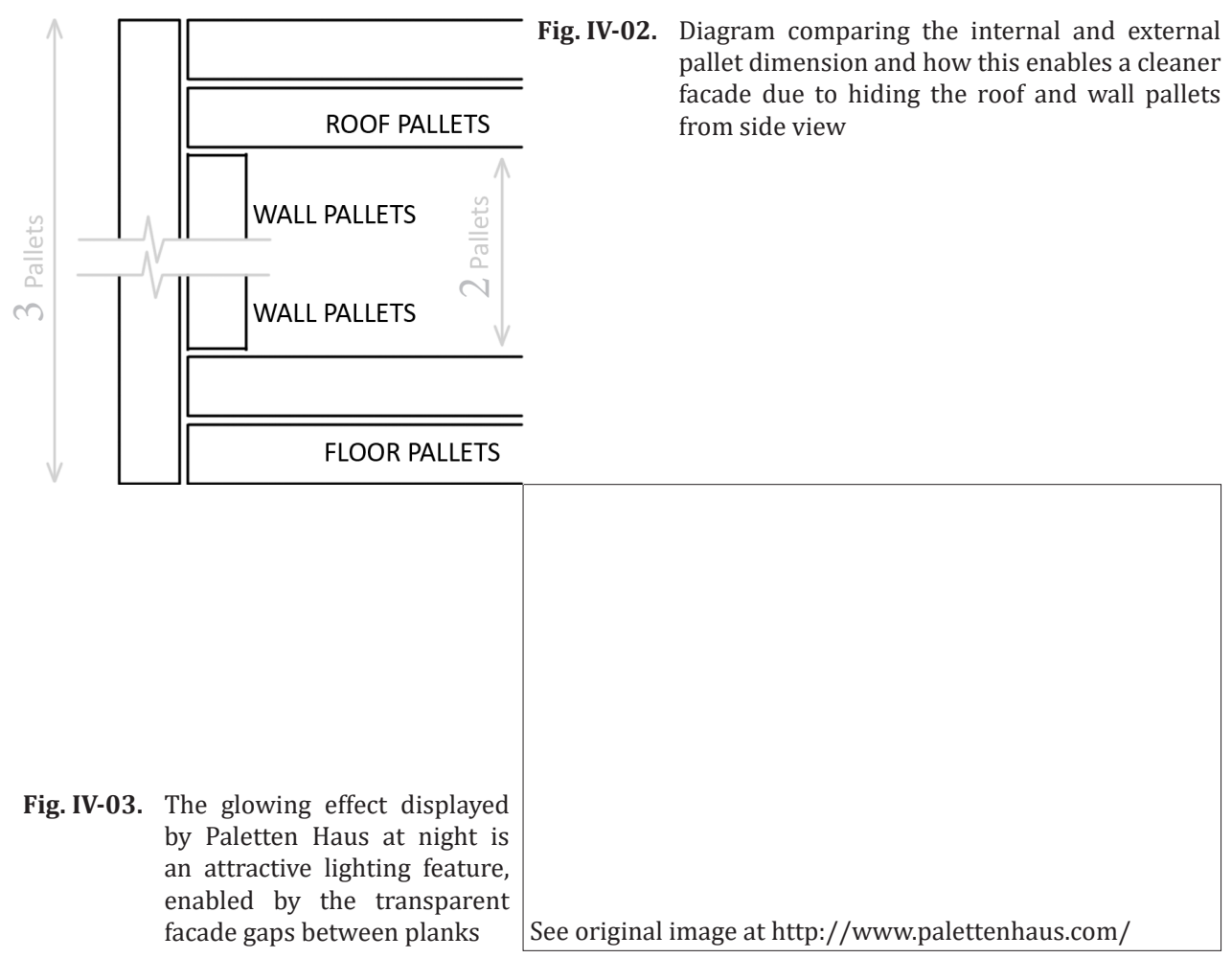




\section{Pallet House - I-Beam Design}

\section{Key themes: Upcycling, Humanitarian,} TEMPORARY \& MOdULAR
Overview

The Pallet House by I-Beam Design is a relief shelter aiming to house displaced families and refugees around the world utilising ubiquitous pallets (see Fig. IV-05).

The design is a modular system adaptable to the needs of each family and is erected by 4-5 people in a week using simple hand tools. 100 pallets are used in a secondary manner, nailed to larger timber members required for primary structure.

Pallets utilised for floor, wall and roof cladding, furniture and module to determine layout and window positions.

Each dwelling built to specific climate conditions in terms of level of waterproofing and insulation. Transforms from temporary condition shelter to permanent home over time - improved upon by the inhabitants

Source: (The Pallet House, 2010) 


\section{Structure}

- Pallets are secondary structure acting as cladding, base roofing and flooring

- Primary structure added timber beams, studs and rafters which run the full length of the walls and roofs

\section{Construction}

- Not prefabricated as all construction work happens on-site

- Some pallets require cutting to align with the sloped roofs

- Modular system as pallet width defines stud spacing

- Size and layout of dwelling flexible to needs of each family

Assembly (see Fig. IV-04)

- Primary structure elements are first placed before pallets are added between

- Easily and quickly assembled by four people in a week using only simple hand tools

\section{Services}

- Waterproofing added after assembly in the form of corrugated iron or plastic for roofing and plastic sheets cut to width between pallet stringers and inserted

- Insulation added depending on deployed climate

- Gaps left at wall tops in hot climates for circulation

\section{Aesthetic}

- Majority of pallets utilised whole - not all

- Has pallet aesthetic
- Addition of quality timber members as primary structure should be avoided as this adds cost and sourcing issues

- Long assembly time as no prefabricated elements - entire shelter constructed on-site

- Flexibility provided by the modular system very applicable to entire thesis

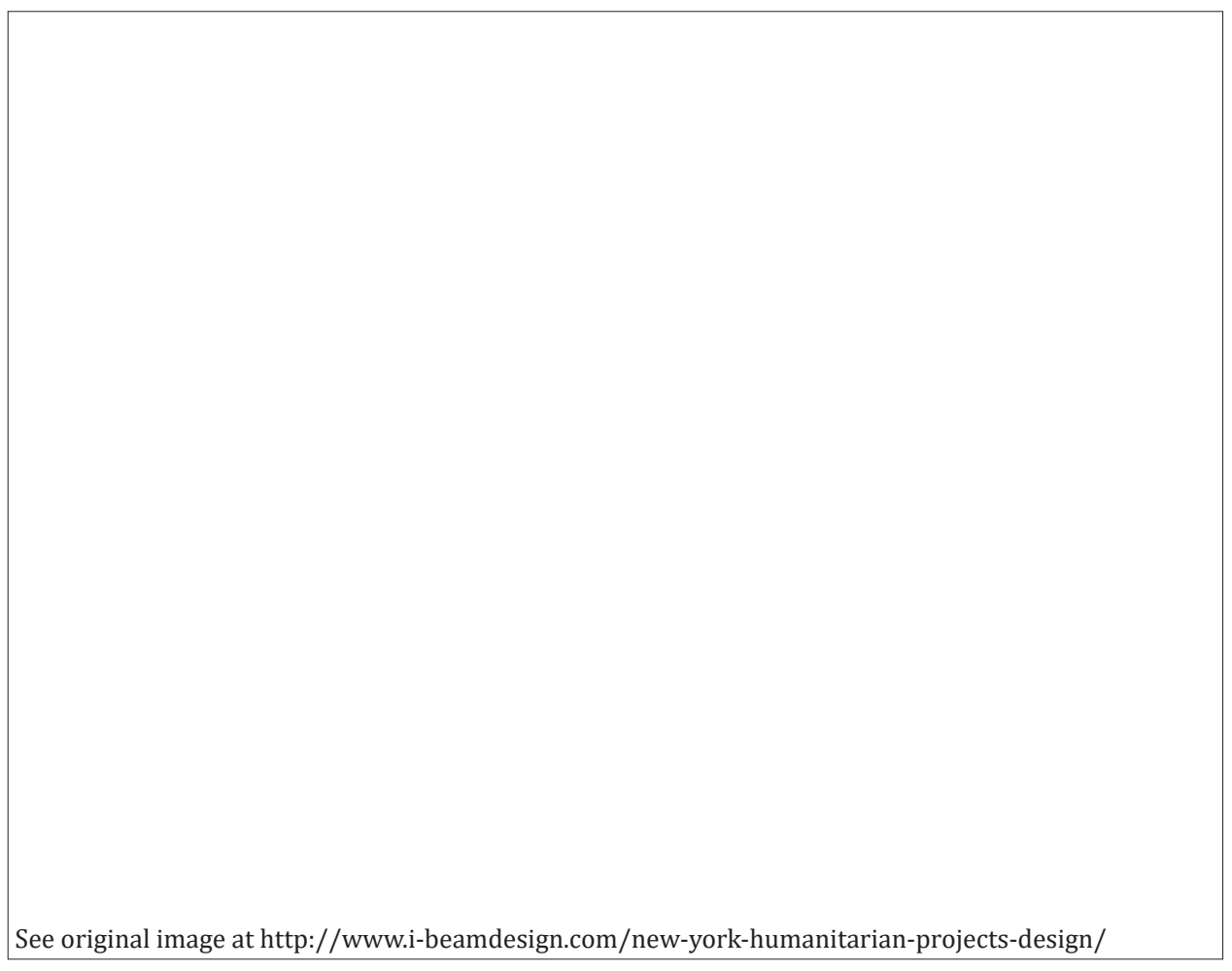

Fig. IV-05. Pallet House prototype built for Prince Charles' Royal Gardens, 2010. Notice the studs between the pallet walls and the spacing of elements as determined by the pallet dimension module 


\section{Hexa Structures - BC Studies \& Michael Lefeber}

\section{KEY THEMES:}

UPCYCLING, TEMPORARY

\& ModulaR

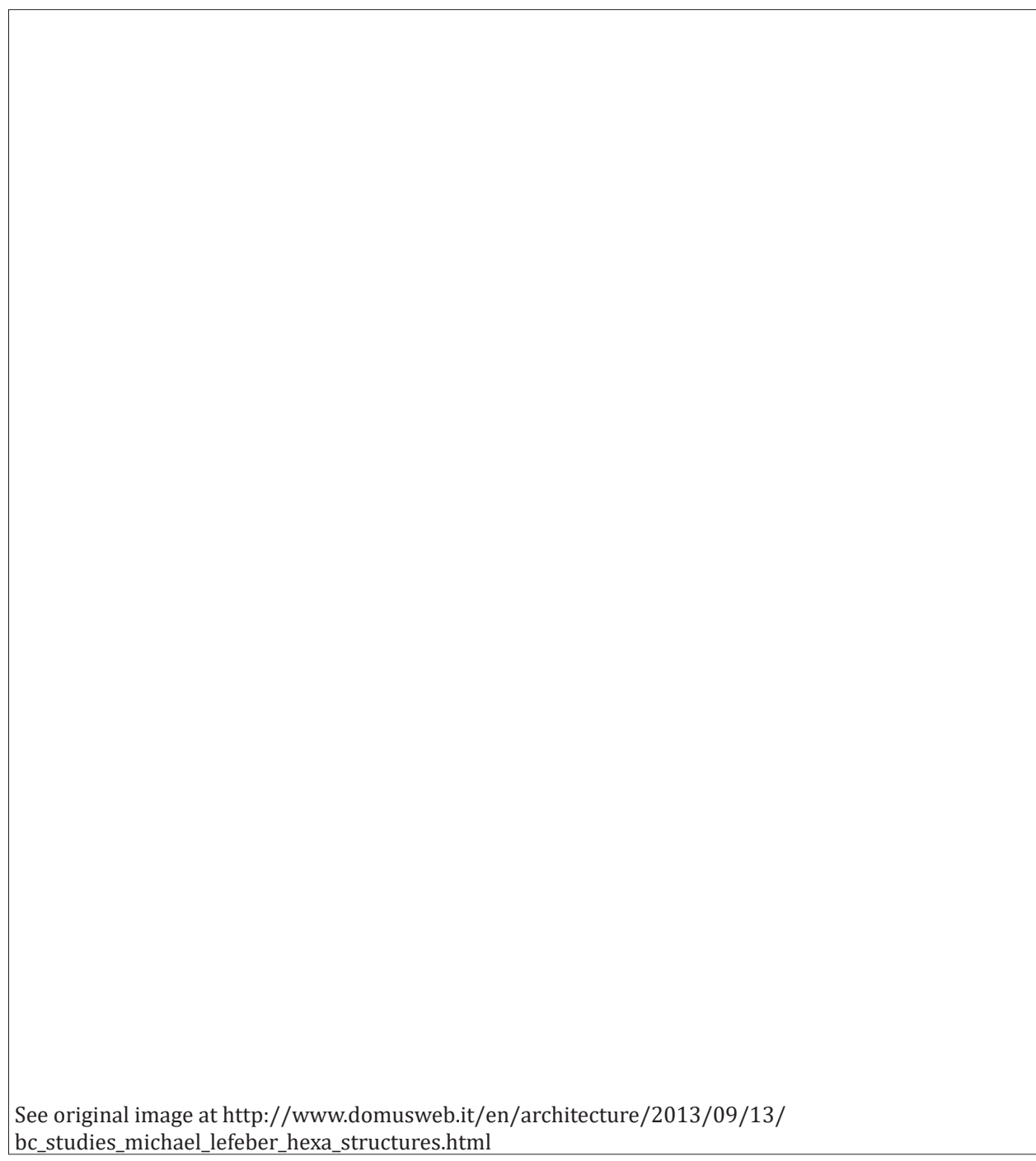

Fig. IV-06. Cover image from Domus's online magazine. Featuring in Domus proves the significance of BC Studies and Michael Lefeber's Hexa Structures for the architectural profession due to prestige
Overview

Hexa Structure - developed by BC Studies and Michael Lefeber in Marseille, 2013 - is an adaptable modular construction system applicable for a number of building functions: exhibition space, urban accommodation, bar and a tool for re-appropriating public space. The system is also flexible in form due to the modular nature of materials making it perfect for experimental temporary public projects.

The use of pallets combined with steel scaffolding as structure provides a low-cost and low-waste method of construction. The scaffolding utilises its standard components to set up the structural grid with which pallets are fixed using low-tech fastening techniques - simplifying the material palette. The scaffolding provides the structure while the pallets inform the scale due to their module (see Fig. IV-07B).

Plastic skins and timber panels or blinds are added to the finished structure as cladding to offer waterproofing and privacy (see Fig. IV-07A).

Fig. IV-06 shows Hexa Structures featuring on Domus online magazine, a sign of the project's significance to the architectural profession.

Source: (BC Studies \& Lefeber: Hexa, 2013)

A

See original images at http://www.domusweb.it/en/architecture/2013/09/13/

bc_studies_michael_lefeber_hexa_structures.html

Fig. IV-07. External view of shelters with various coverings - glass, plastic, timber slats and panels - acting to shelter and weatherproof (A). Internal view showing triangulated structural elements and their incorporation with pallet modules (B) 


\section{Structure}

- Pallets are secondary structure acting to clad the roofs, walls and floors

- Steel scaffolding elements are primary structure, supporting and integrating with the pallets

- Rigid due to triangulated structure

\section{Construction}

- The scaffolding is a prefabricated system assembled on site, while the pallets require additional work in order to integrate with the primary structure

- Modular and flexible system directly informing the scale due to the hexagonal form of whole pallets

- Slightly irregular pallets allowed to being secondary and marginally smaller than the structural grid

\section{Assembly}

- Triangulated hexagonal scaffolding grid assembled first and clad with pallets before adding waterproofing

- Scaffolding already a modular and flexible system resulting in simple clickassembly

\section{Services}

- Structure runs within pallet

- Waterproofing in the form of corrugated plastic and plastic sheets added to external surface of pallets after construction, allowing light through

- Triangular particle board covers added to ends of shelter to give privacy but do not waterproof

\section{Aesthetic}

- Pallet nature expressed due to clear differentiation in pallet through change in angle

- Rather than being a pallet system this is actually a scaffolding construction system with its scale and aesthetic being informed by pallets

- Hexagonal triangulated grid effective as structure and allows organic form

\section{Critique \& Application}

- Perfect example of a modular system directly informed by a pallet's module

- Form and scale of design being based upon pallet module clearly expresses pallet's nature and aesthetic

- Vast flexibility in possible space shapes enables the system and designed forms to be highly versatille in application

- Relying on other materials as primary structure limits the authenticity of being considered 'pallet architecture' 


\section{BINA Kainina - MDH Architects \& Quentin Le Guen-GefFroy}

\section{Key THEMES: $\quad$ UpCyCling, Temporary}

Modular \& Mobile
Overview

BINA Kabina - designed by MDH Architects \& Quentin Le Guen-Geffroy - was a pavilion for the International Architecture Week in Belgrade, Serbia 2012.

The temporary pavilion acts as a tool to revitalise public space by giving new function; the pavilion is a presentation area, cafe and general seating for impromptu use (see Fig. IV-09).

Euro-pallets are stacked in pairs to create floor, seating, wall and roof in a modular fashion where each layer of paired pallets overlaps the above and below layer by half pallet widths. This use turns pallet pairs into brick building blocks which together give the pavilion strength. Additional timber elements bond pallet bricks together to support the roof structure.

The internal pallet surface blends from floor to steps, seating, terraces, walls and ceiling creating autonomous landscape (see Fig. IV-08).

Source: (http://mdh.no/project/bina-kabina/)

See original image at (http://mdh.no/project/bina-kabina/

Fig. IV-08. View through pavilion showing pallet-brick seating and terraces, and the flow of pallet form 


\section{Critique \& Application}

\section{Structure}

- Pallets predominantly act as primary structure

- Low-tech timber elements bond the pallet-bricks together to support the roof

\section{Construction}

- Simple flexible modular system by stacking pallet-bricks out of sync by half pallets

\section{Assembly}

- Due to low-tech nature of design there are only few materials so easily dismantled for mobility after temporary period

- Small scale allows ease for simple assembling and disassembling by few people with common tools

\section{Services}

- Appropriate terrace seating height and depth created by pallet-brick module

- Due to temporary outdoor nature no other services are required

\section{Aesthetic}

- Pallet re-use is authentic as they act as structure and inform space and use
- The key aspect of this pavilion is the low-tech nature of pallets acting as primary structure - this is the desired trait for pallet use in this thesis

- The pallet module has informed structural rationale - lining up pallets to bond with additional structure and overlapping pallets to improve strength

- The pallet module also acts as design driver due to use creating appropriately arranged seating

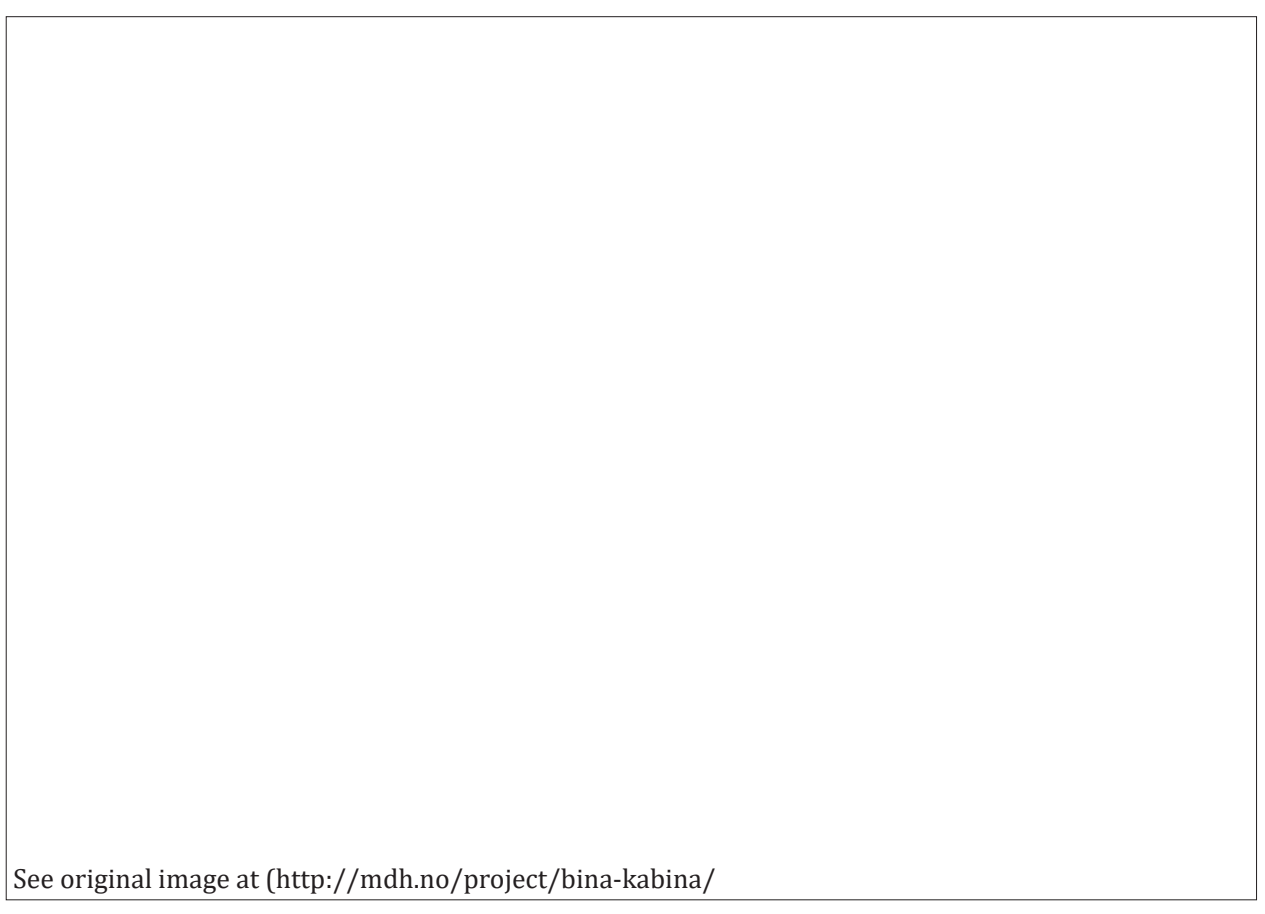

Fig. IV-09. Presentations took place throughout the International Architecture Week utilising the terraces 


\section{Polish Pavilion, Expo Milano 2015 - 2PM Architekci}

KEY THEMES:

\& MODULAR
OverView

The Polish Pavilion by 2pm Architekci for Expo Milano 2015 aims to reference the Polish agricultural industry and landscape through its concept.

The façade is of particular significance and is seemingly clad with stacked timber crates - representing packaging and transport of local Polish fruit and vegetables. However this layer is purely aesthetic as there is no link to recycling (see Fig. IV-10). The pavilion façade's structure is timber and steel columns with slats attached rather than the apparent stacked boxes.

Sources: (own observations; http://2pm.com.pl/pl/pawilon-polski)

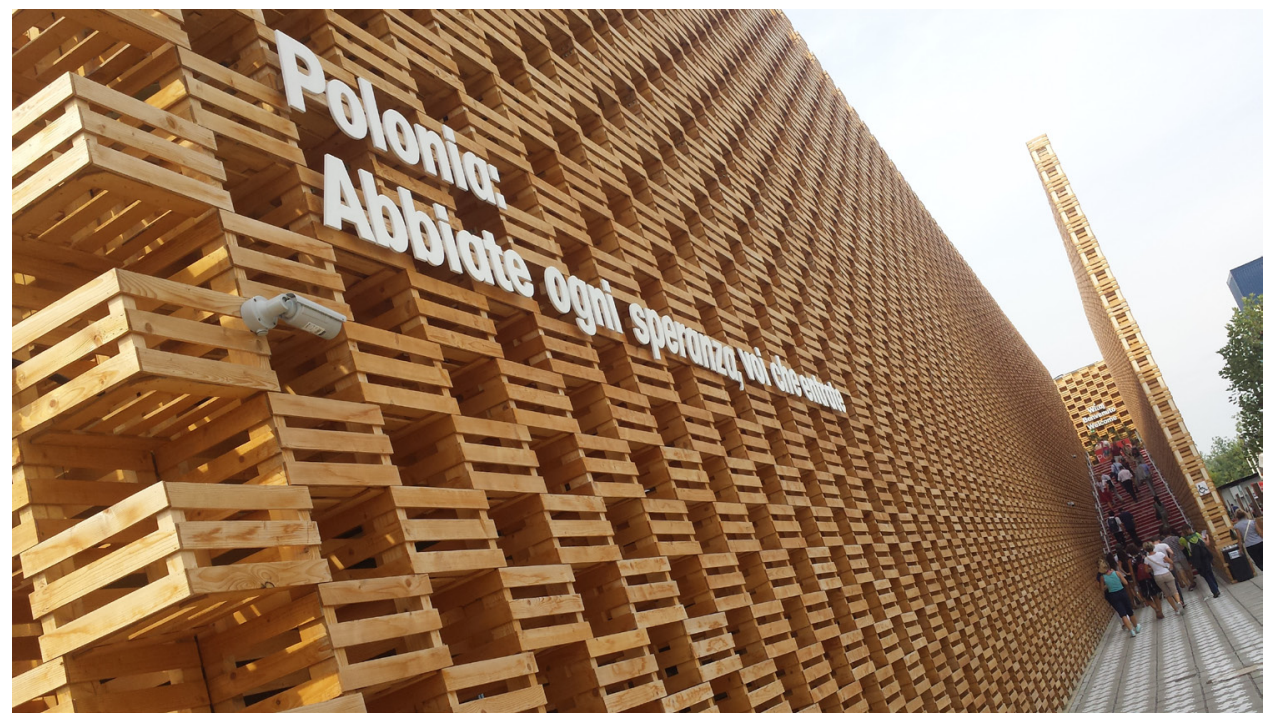

Fig. IV-10. External view of facade and entrace to 2pm Architekci's Polish Pavilion which aims to be stacked wooden fruit and vegetable crates 


\section{Structure}

- Primary façade structure is full height timber and steel elements extended by steel joints (see Fig. IV-12)

- The slats are merely an afterthought it terms of structure as their function doesn't go beyond light effects

\section{Construction}

- Timber slats are attached to the outside, inside and between the wall's depth to mimic food crates

- Modular as the stud spacing and subsequent timber slats allows the crate module to be expressed

Aesthetic

- Dishonest use of material to mimic fruit and vegetable crates

- Crates as skin causes modulated light effects to interior spaces (see Fig. IV-11)

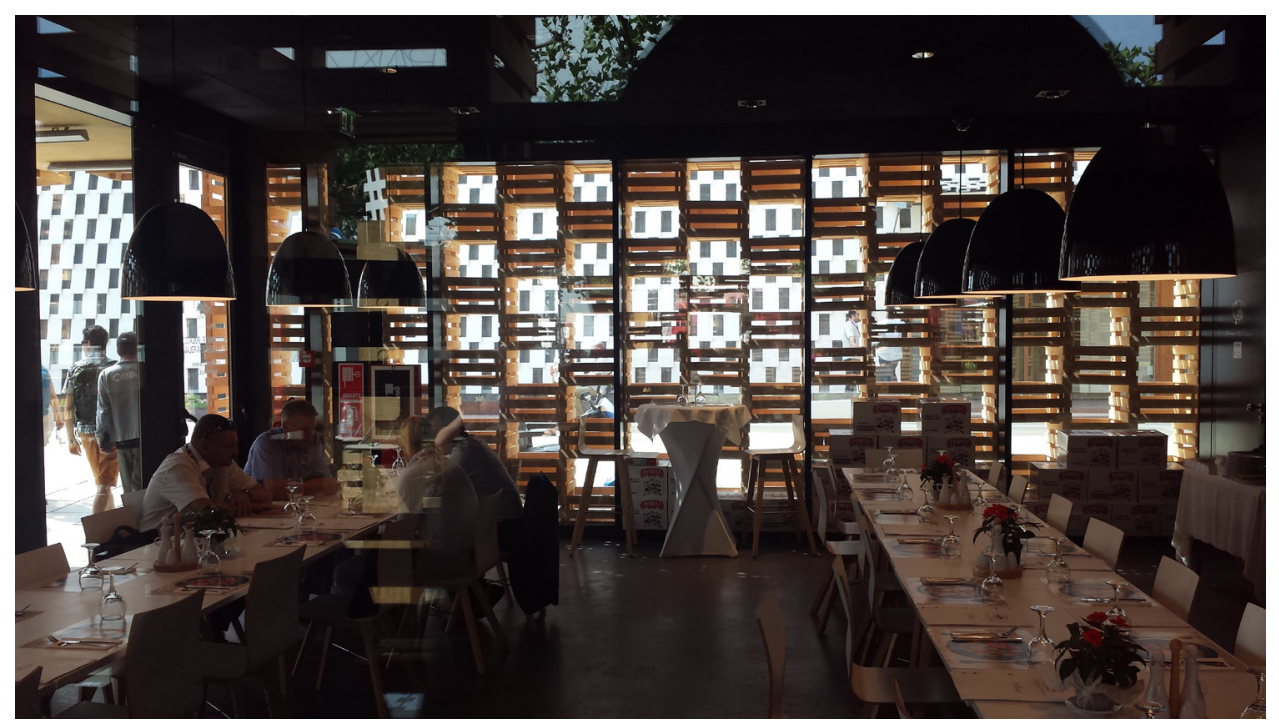

Fig. IV-11. Internal view of facade through restaurant are with created light effects
The inclusion of this project - while not timber pallets - is due to the distinct inauthenticity of materials

- The design aims to look like it is built from stacked wooden crates - a link to the Polish landscape - due to their use to package and transport local fruit and vegetables. However the material use is not authentic as the wooden box motif is actually simply fixed onto studs spanning the full height of the pavilion. A more authentic design would have been to develop a system utilising existing wooden crates as opposed to mimicry - adding the layer of upcycling to the concept.

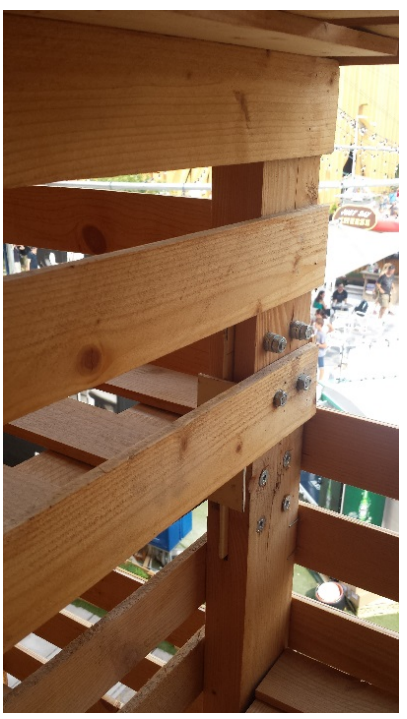

Fig. IV-12. Structural connection fixing two stud end-to-end with attached slats clearly directly fixed 
V 
The initial evaluation covers the initial thought process on solving the problems at the inception of this project, based upon first impressions and previous years design work.

\section{First Impressions}

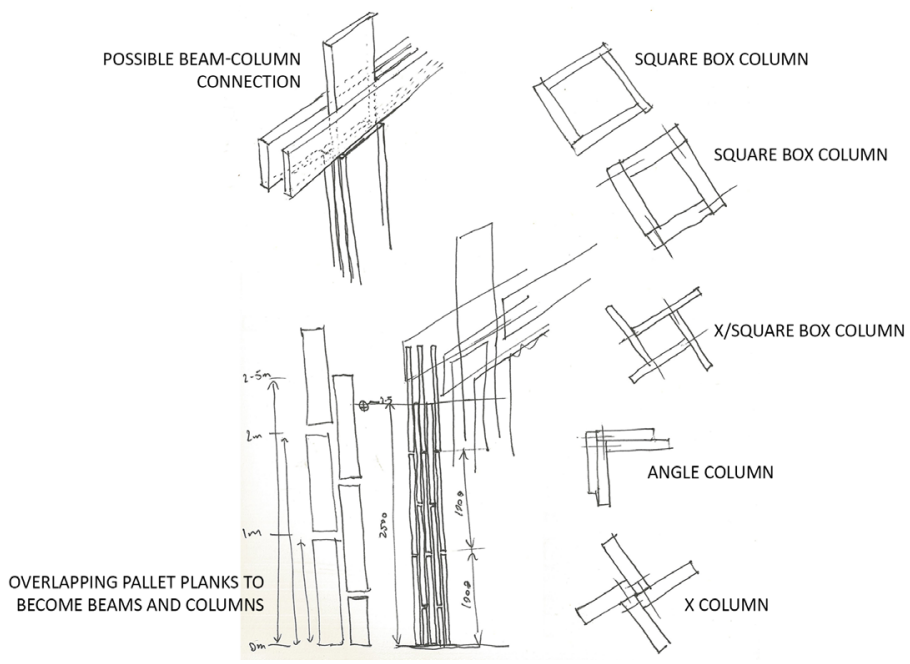

Fig. V-01. Early sketches of building up pallet components into structural building elements

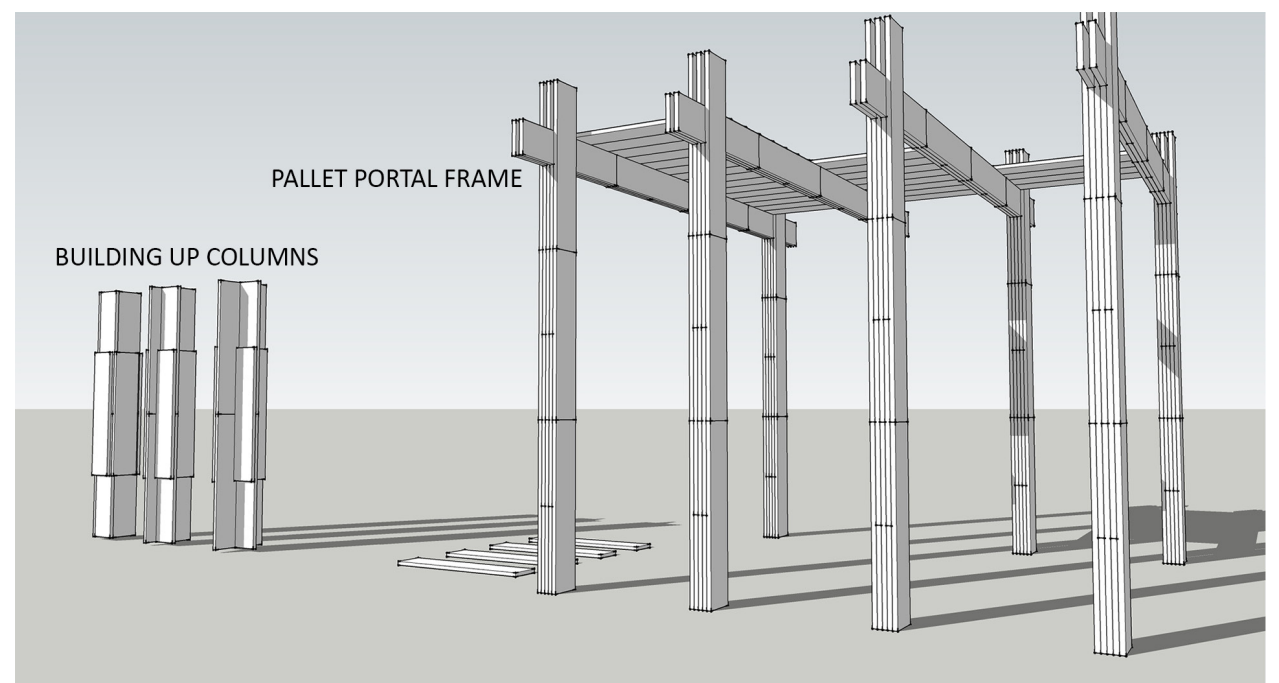

Fig. V-02. Pallet plank-laminated columns and beams forming a modular portal frame
Prior to any literature or precedent research being undertaking the initial design stage occurred and is based on first impressions of solving the project problems.

The first exploration looked at improving pallet wood strength by dismantling for individual components and combining these into primary structural elements - wall and roof structure.

The starting sketch experiment tested different arrangements in plan for combing pallet decking components into columns (see Fig. V-01). Simply arranging elements creates the problem of how to stack these short columns. The solution was to stagger the heights of planks with greater strength resulting from the overlaps.

This structural form - essentially a laminated beam but with nails instead of glue - was able to be applied as column and beam creating portal frames that seemed structurally sound (see Fig. V-02).

The next stage was to determine the strength of typical discarded pallet timber to test the feasibility of the initial idea. The result was significant loss of integrity due to cracking and the observation that pallets are not consistent in type, strength or dimension.

This makes their componentised application limited in that identical pallets would need to be sourced in order to build up consistent building elements 
The weak pallet wood went into designing at much smaller scale to determine their workability. The resultant design was a cutting schedule for the timber able to construct a small shelf. Thinking in terms of small components assembling into a whole made designing easy. But imagining each cut-off as wall or floor elements makes the shelf an instant building form.

Dismantling into parts without purpose is not a good strategy in designing with pallets and their module must be utilised and become a building block as existing.

\section{Findings:}

- Very time consuming pulling pallets apart

- Many members get damaged during the dismantling

- High effort and cost required to build-up components into stronger building elements

\section{Application:}

- Small scale (furniture) pallet construction suits utilising pallets whole or for their components

- Larger scale (building) pallet construction suits utilising pallets whole due to their module acting as a building block and can be design driver
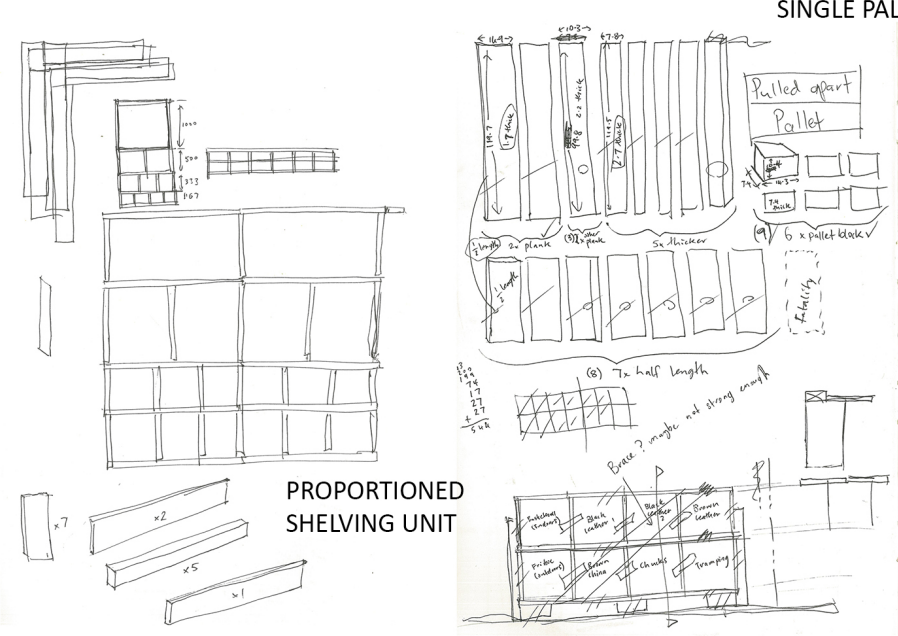
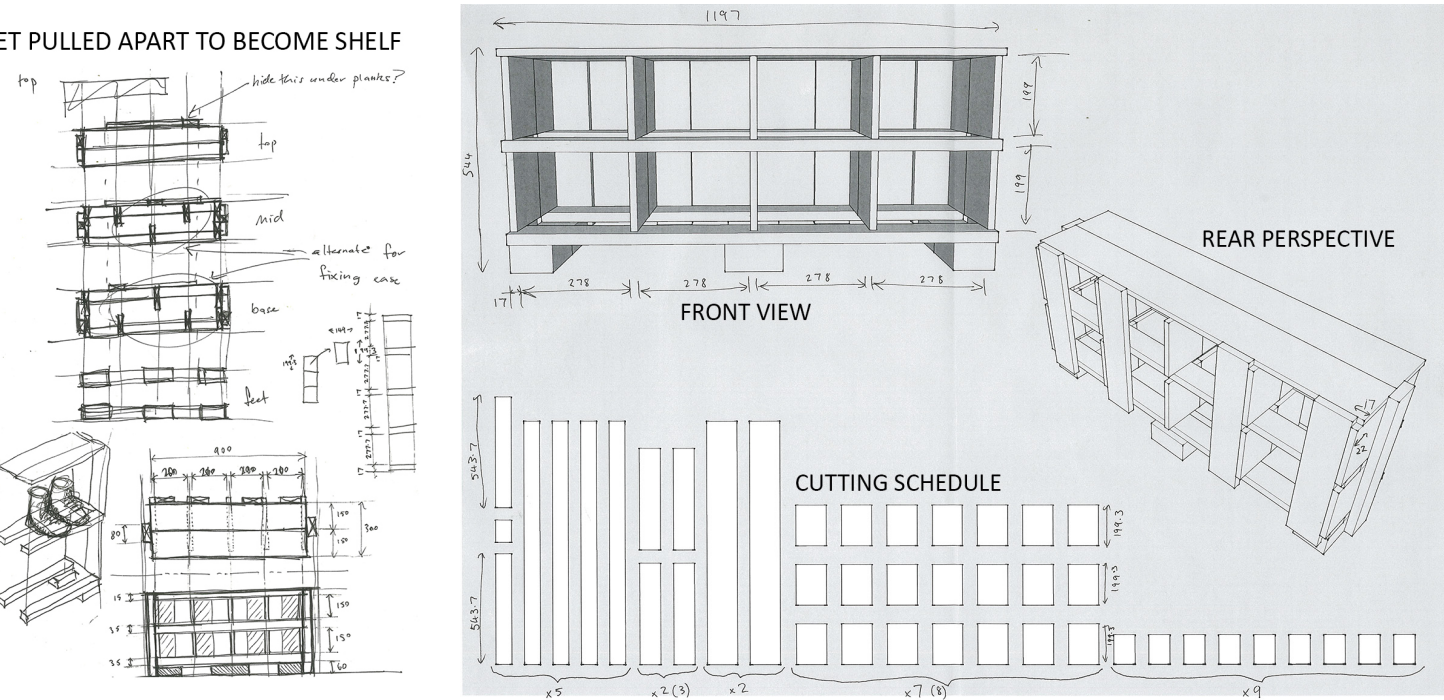

Fig. V-03. Sketch experiment utilising a single pallet to create furniture to assess workability 


\section{Previous Design Work}

Temporary Flat-Packed Unfolding Pavilion Design

This previous project grew particular interest in temporary pavilion design, flat-pack assembly, hinges and cantilevering structure, subsequently informing future design drivers and interests

The key aims for this project were to create a temporary pavilion built for easy assembly that was easily portable by use of shipping container.

The images in Fig. V-04, Fig. V-05 and Fig. V-06 explore relevant aspects of this project.

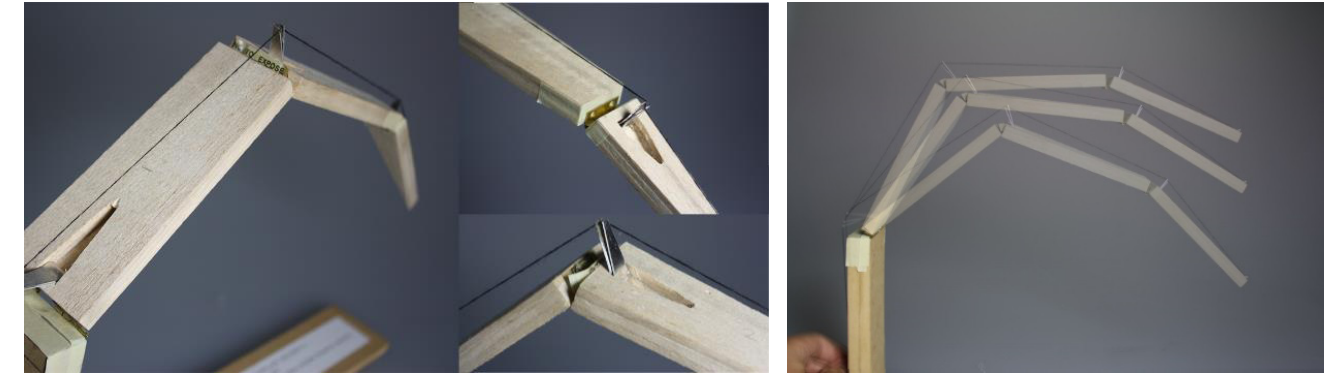

Fig. V-05. The cantilevering structure is flexible in form due to adjustable tension cable structure
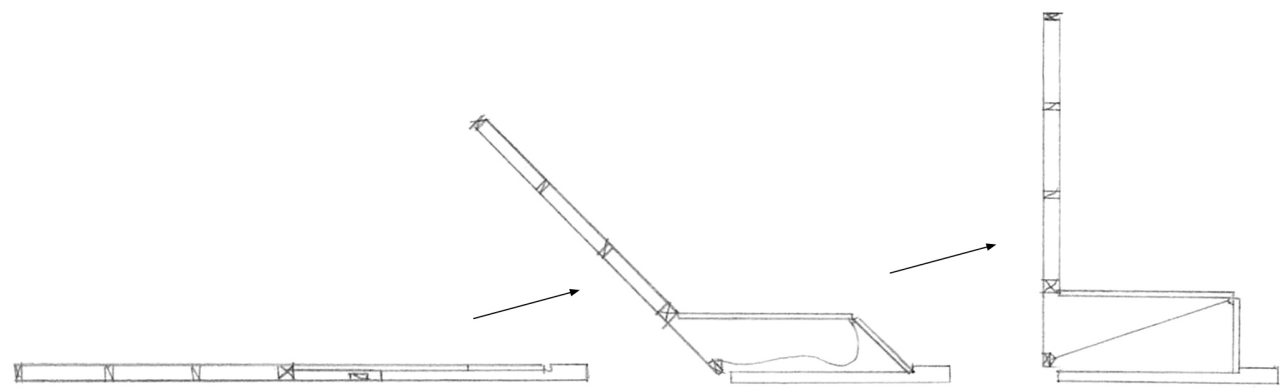

Fig. V-06. The project also incorporated unfolding seating within the floor and roof module instantly creating space and function upon erection

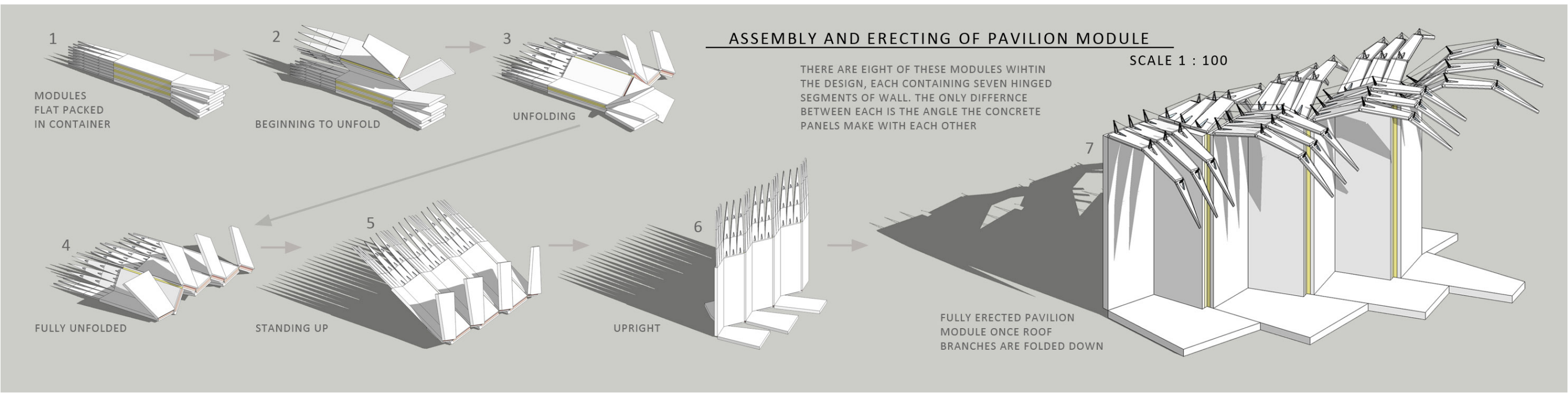

Fig. V-04. The flat-pack assembly of this pavilion is a method for testing in this these as it makes on-site construction minimal through simple assembly - unfolding architecture is friendlier than kit-set to erect due to pre-joined elements 
VI 


\section{Preliminary Design}

The preliminary design section - MODULAR - explores the modular aspects of existing pallets by simplifying the method to only considering pallet dimensions rather than structural make-up.

This process seeks to determine possible form without the constraints of structure and appropriate scale for design based on pallet module.

The section structure starts by looking at joint types and moves towards larger scale and more demanding design forms in an iterative design process
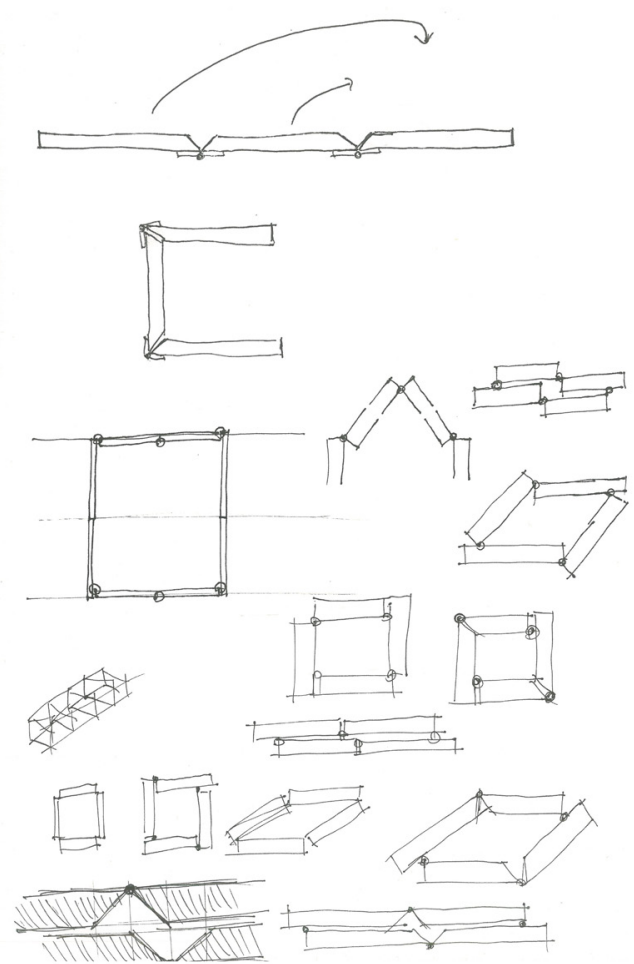

Fig. VI-01. Sketch designs dealing with hinged mitred joints 
Fig. VI-02. The unfolding frame test - built at 1:20 scale - looks at scale and proportion relative to a person, determining that two standard pallets stacked lengthway is an appropriate size for shelter. This would make 2000 or $2400 \mathrm{~mm}$ depending on orientation.

Fig. VI-03. The Folding Whare, by Callum Dowie at Unitec Auckland in 2009, was a design for a hut or emergency shelter that was easily transported and rapidly erected where existing housing had been destroyed (Bell, 2012, p. 114). A main focus where existing housing had been destroyed (Bell, 2012, p. 114). A main focus
of the design was the hinged structural panel construction allowing for a flatof the design was the hinged structural panel construction allowing for a flat-
packed deployable unit, given rigidity by tension ties on the outside of the panel joints.

Looking closely at these junctions you can see that the panels fit snuggly together and have been mitred to suit non-right angles.

This strategy was applied to the following experiments. 

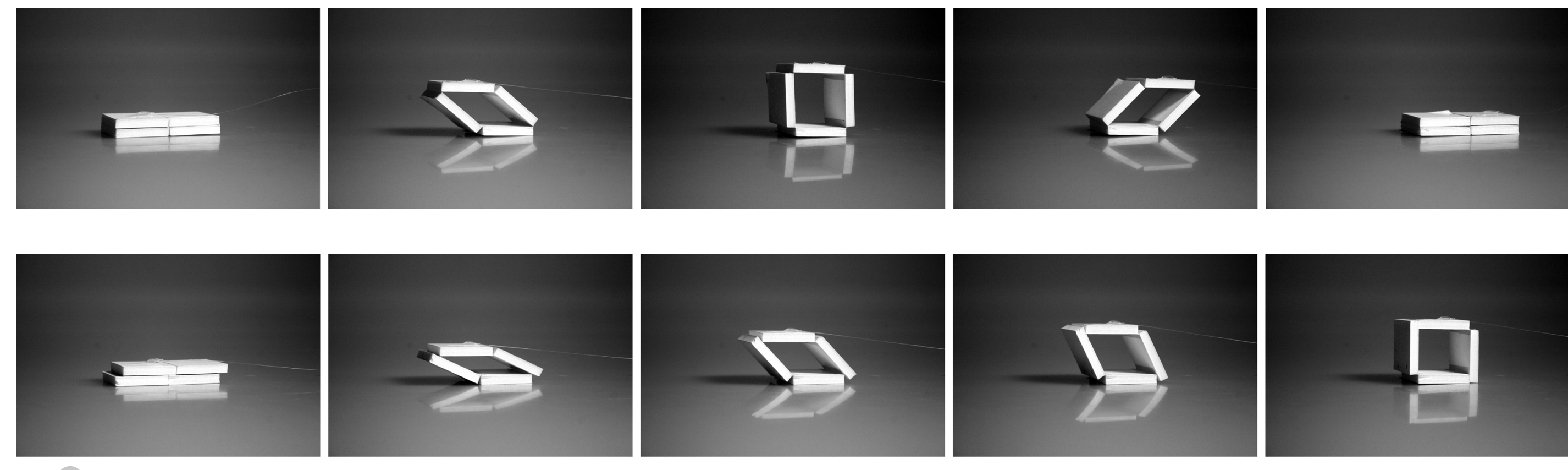

(
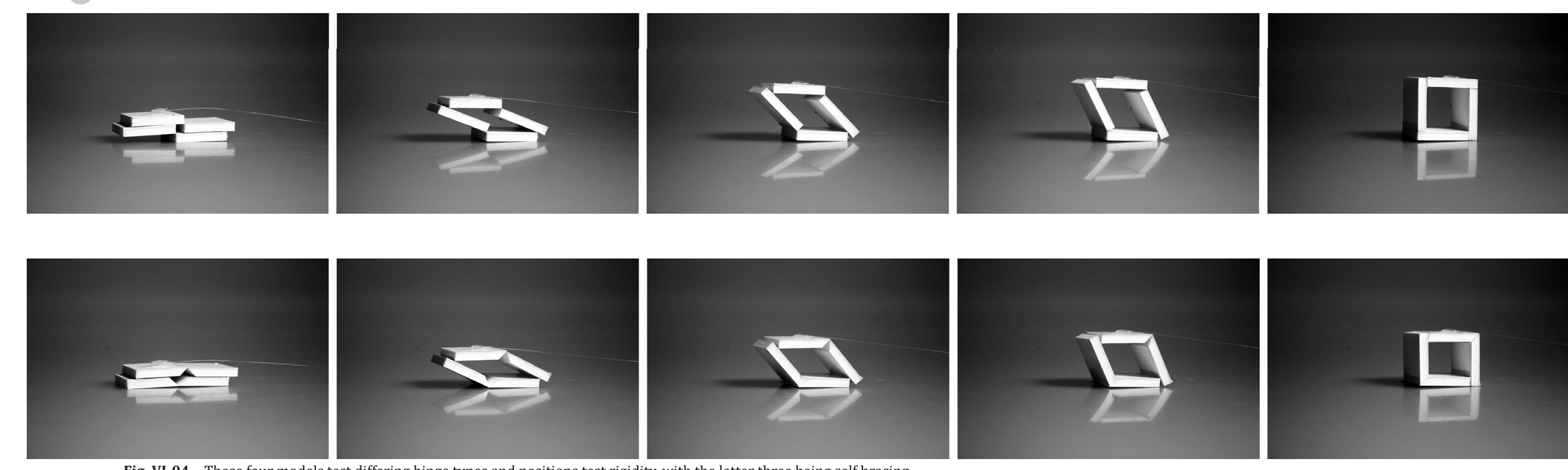

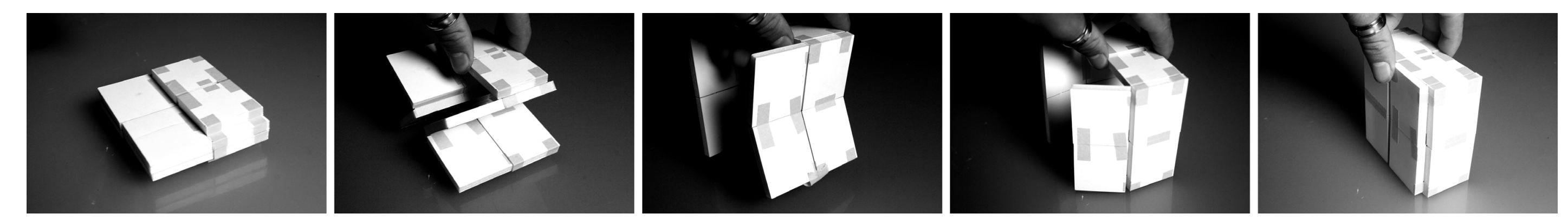

Fig. VI-05. This experiment has a two-way hinge system which self braces when erected. 
Fig. VI-06. The "Garden Ambassadors" Pod design, by Andrew Maynard Architects in Melbourne, Australia, is a solution for a portable volunteer station at the Melbourne Royal Botanic Gardens. The pod is towed by car as a trailer and panels of its cube form fold outward creating various spaces for garden set-up and display purposes.

Shaoqiang, 2014, pp. 136-139)

Of particular interest is the furniture which is stored flat within a wall panel, but then folds down from the opened wall creating table and seating for users. The effectiveness of this design lies in the speed with which the pod can be opened up for use, and the usefulness of design lies in the speed with which the pod can be opened up for use, and the usefulness of
the storage areas of the pod with a planter box of pot-plant holder on its roof, and vast storage within the empty cube itself.
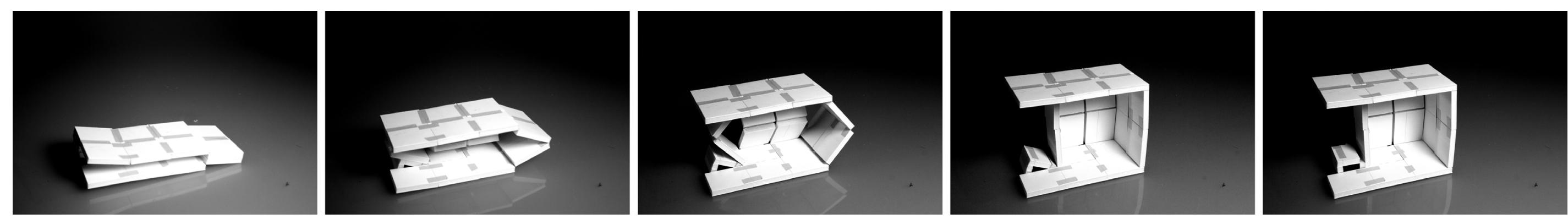

Fig. VI-07. This experiment is based upon the "Garden Ambassadors" Pod design in that it opens up creating space in the process and has incorporated an integrateing unfolding seat.

Works like a 'scissor lift' in that the ground and roof always stay parallel, and the 5:6 ratio rectangular pieces actually have a very good fit. Easy to erect as roof only needs to lift, though could be heavy.
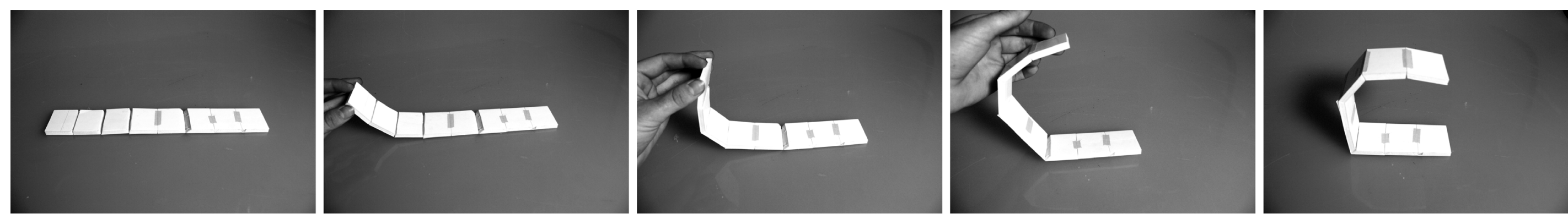

Fig. VI-08. This cantilevering arm reference the previously designed temporary pavilion project (Fig. $\mathrm{V}-05$ ) and builds upon in its nature.

Erects very simply through linear unfolding. System later tested contextually with pallets. 


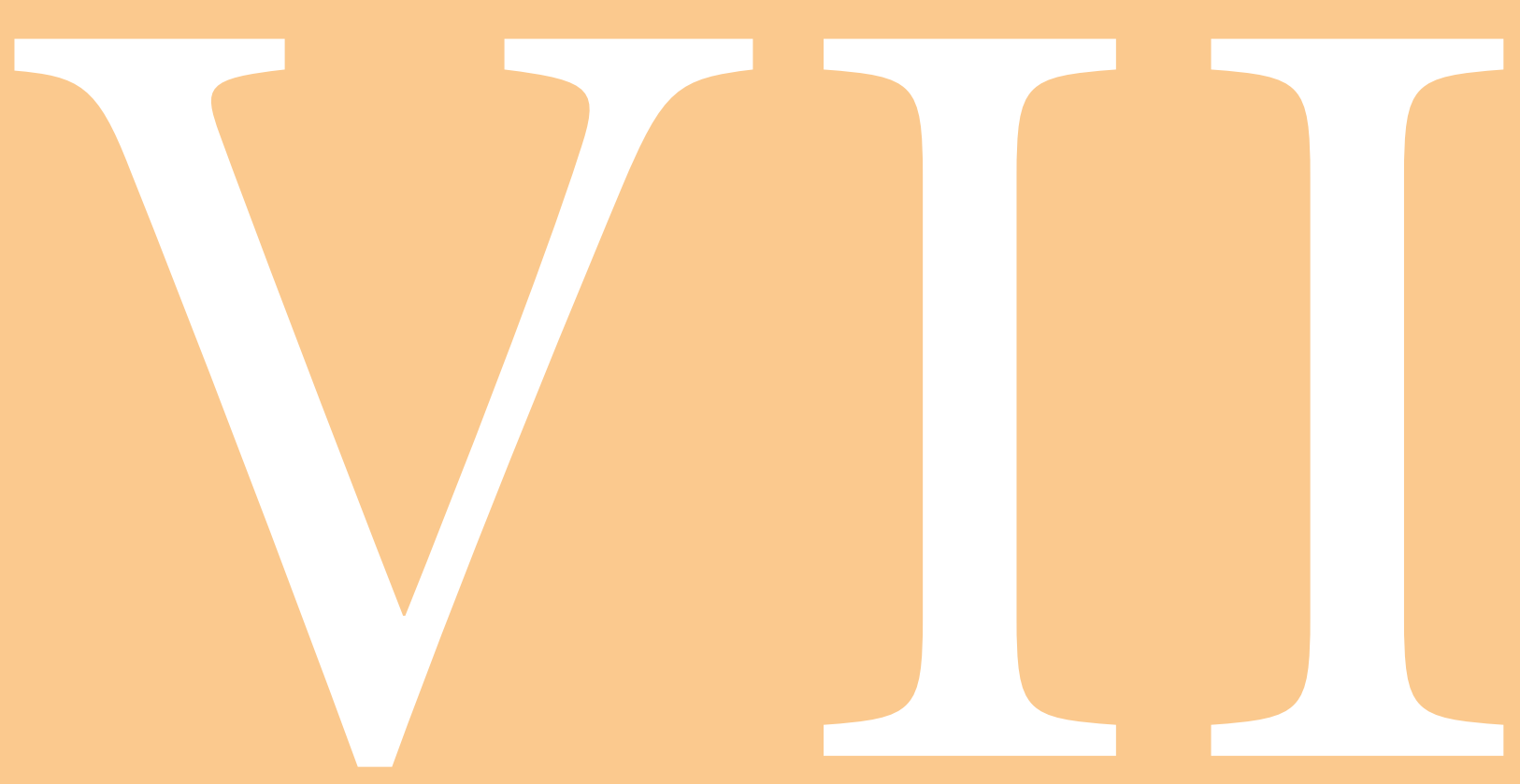




\section{ConTeXtualised Design}

The contextualised design section - STRUCTURE - builds upon the modular tests in the preliminary design section but now thinking in terms of structure and connections.

The section structure builds towards comprehensive understanding of working with existing pallets in order to meet the aims and objectives of the thesis:

- Evaluating existing pallet application for building by type

- Exploring connection details and possible form

- Applying these details and forms to shelter and temporary concepts

- Testing the learned principles and design research in the design and construction of a full scale temporary pavilion 


\section{Existing Pallet Type Applications}

While block pallets allow for greater versatility when shipping in that when packed tightly access from all four sides can be advantageous, stringer pallets are intrinsically more structurally sound when considered in a construction context given the ability of stringers to span (see Fig. VII-01 for pallet type comparison). Stringer pallets are therefore the key pallet type being explored through design.

\begin{tabular}{|c|c|c|c|}
\hline & KEY ELEMENT & KEY USES & BUILT ELEMENTS \\
\hline STRINGER PALLET & STRINGERS & $\begin{array}{l}\text { - Cantilevering } \\
\text { - Spanning } \\
\text { - AsLoad Bearing Element }\end{array}$ & $\begin{array}{l}\text { - Roof Structure } \\
\text { - Load-Bearing Walls } \\
\text { - Floor } \\
\text { - Primary Structure }\end{array}$ \\
\hline $\begin{array}{c}\text { NotCHED } \\
\text { STRINGER PALLET }\end{array}$ & $\begin{array}{l}\text { NOTCHED } \\
\text { STRINGERS }\end{array}$ & $\begin{array}{l}\text { - Stacking } \\
\text { - Cladding } \\
\text { - AsNonLoad Bearing Element }\end{array}$ & $\begin{array}{l}\text { - Floor } \\
\text { - Non Load-Bearing Walls } \\
\text { - Non Structural }\end{array}$ \\
\hline Block Pallet & BLOCKS & $\begin{array}{l}\text { - Stacking } \\
\text { - Cladding } \\
\text { - AsNonLoad Bearing Element }\end{array}$ & $\begin{array}{l}\text { - Floor } \\
\text { - Non Load-Bearing Walls } \\
\text { - Non Structural }\end{array}$ \\
\hline
\end{tabular}

Fig. VII-01. Comparison of strengths of each pallet type when applied to building 


\section{Connection Details \& Formal Qualities}
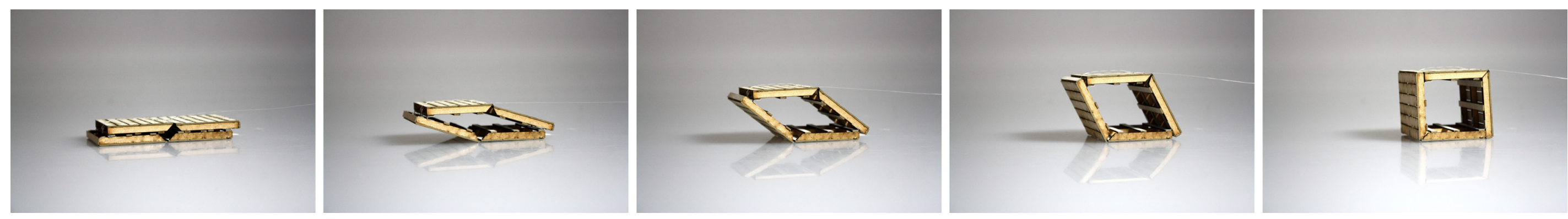

Fig. VII-02. Hinge box type with mitres explored contextually with stringers aligned acting structurally
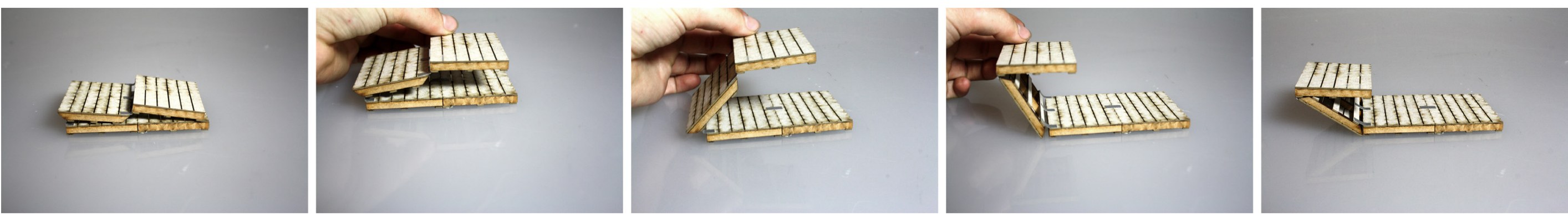

Fig. VII-03. Cantilever test - simple cantilevering seat enabled by aligned stringers and angled due to mitre cuts.

Self bracing due to hinge location 

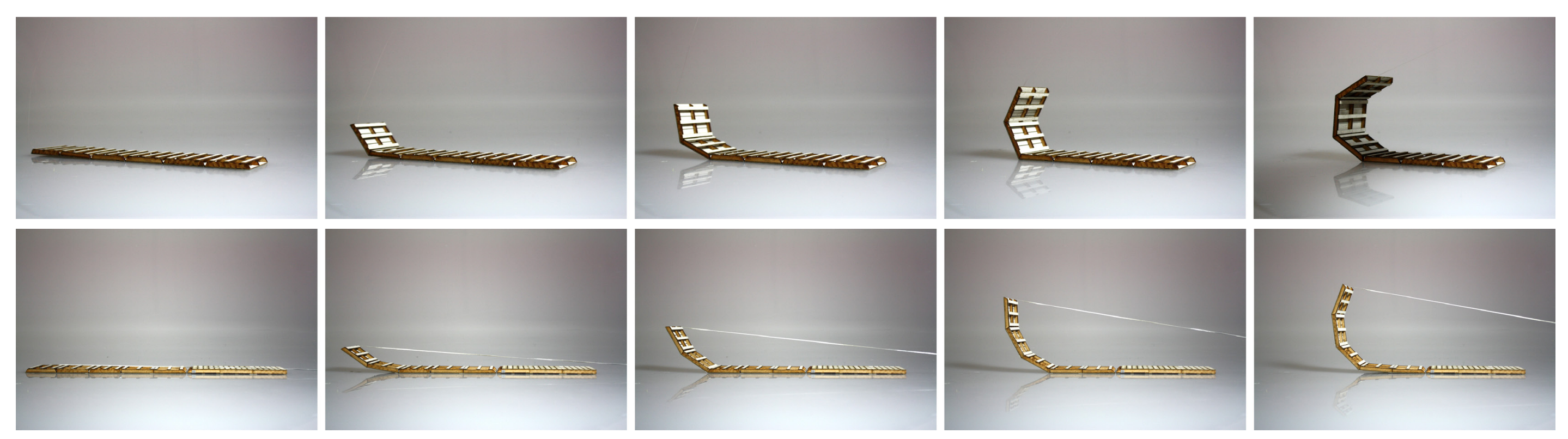


$$
\begin{aligned}
& 0 \\
& 0 \\
& \hline \\
& \hline
\end{aligned}
$$




\section{Shelter Concept Design}

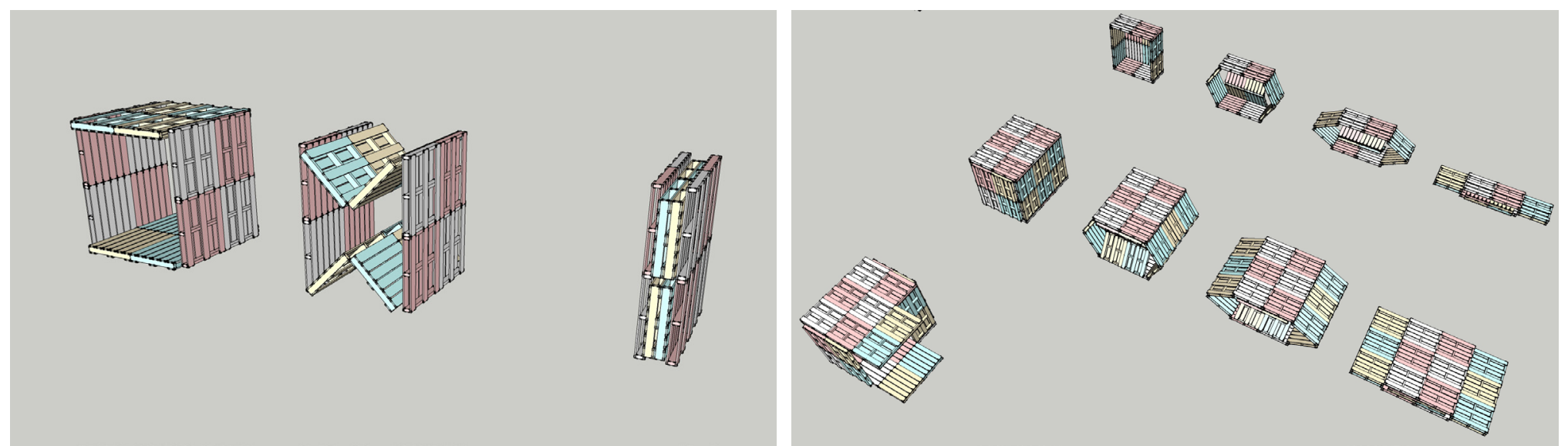

Fig. VII-06. SketchUp models building on previous hinge experiments and foam board models to create shelter
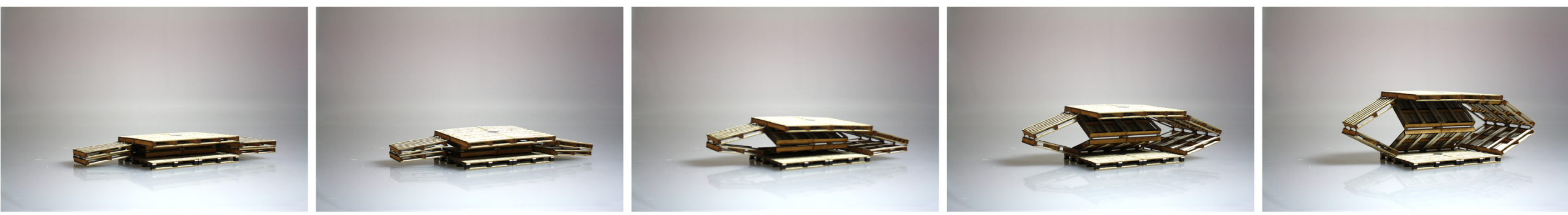

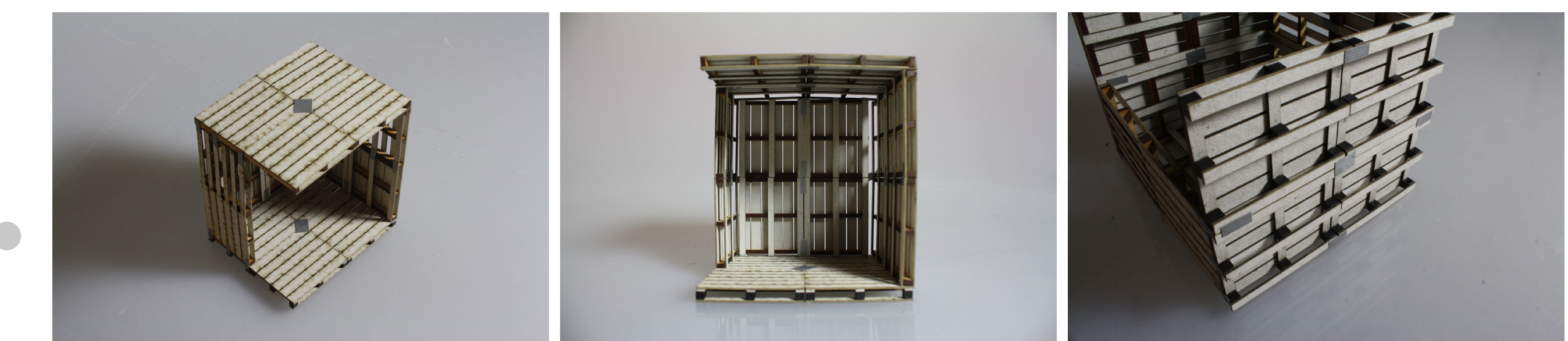

Fig. VII-07. Laser-cut version of pop-up shelter design making use of stringer pallets for walls and block pallets for the floor where spanning isn't required
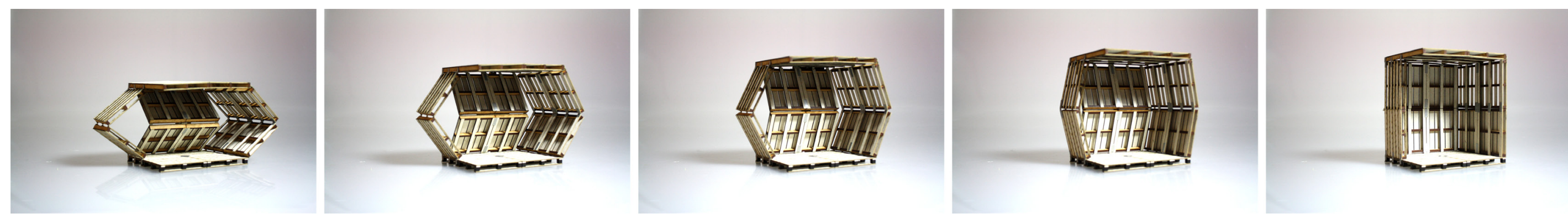

Fig. VII-08. Opening sequence of pop-up shelter design 

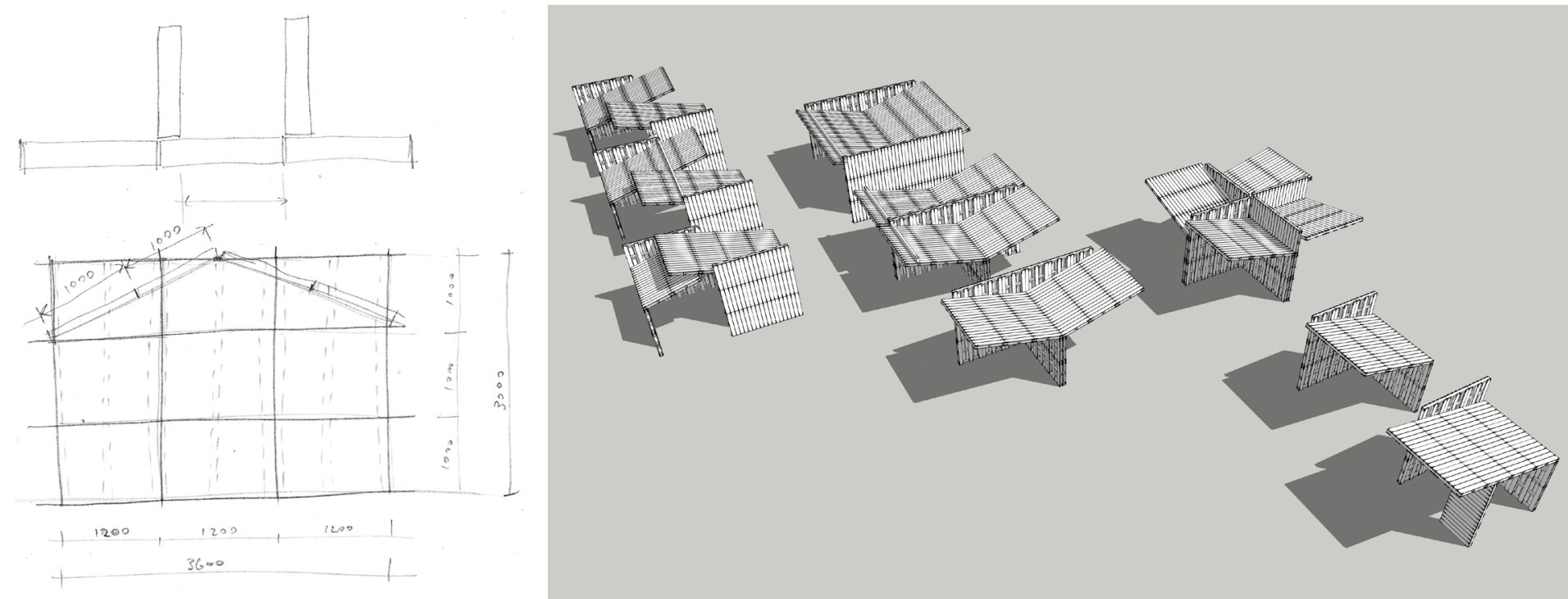

Fig. VII-09. Sketch and SketchUp tests dealing with alignment of pallets to inform shelter 


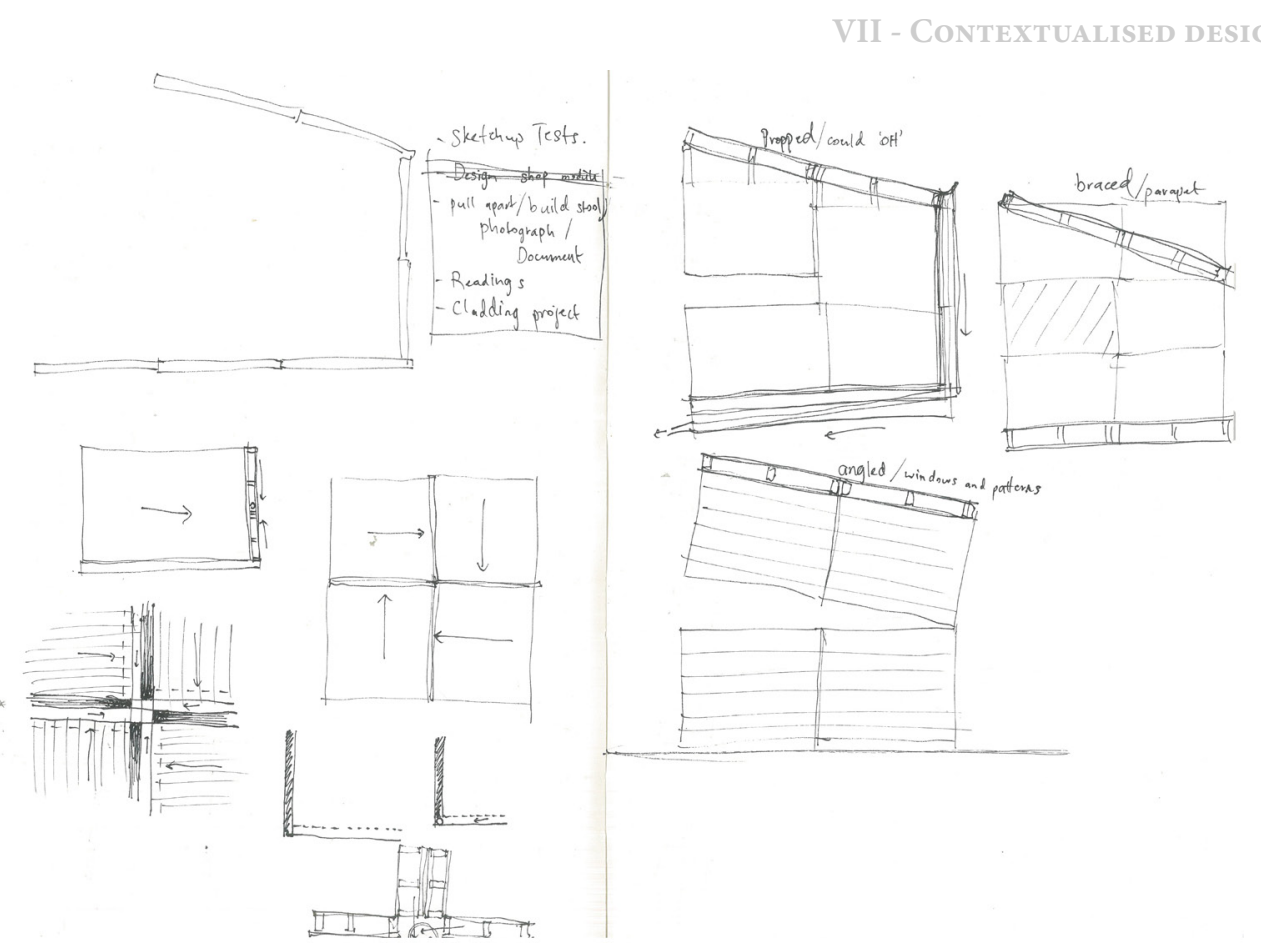

Fig. VII-10. Sketch design continuing the theme of alignment informing shelter
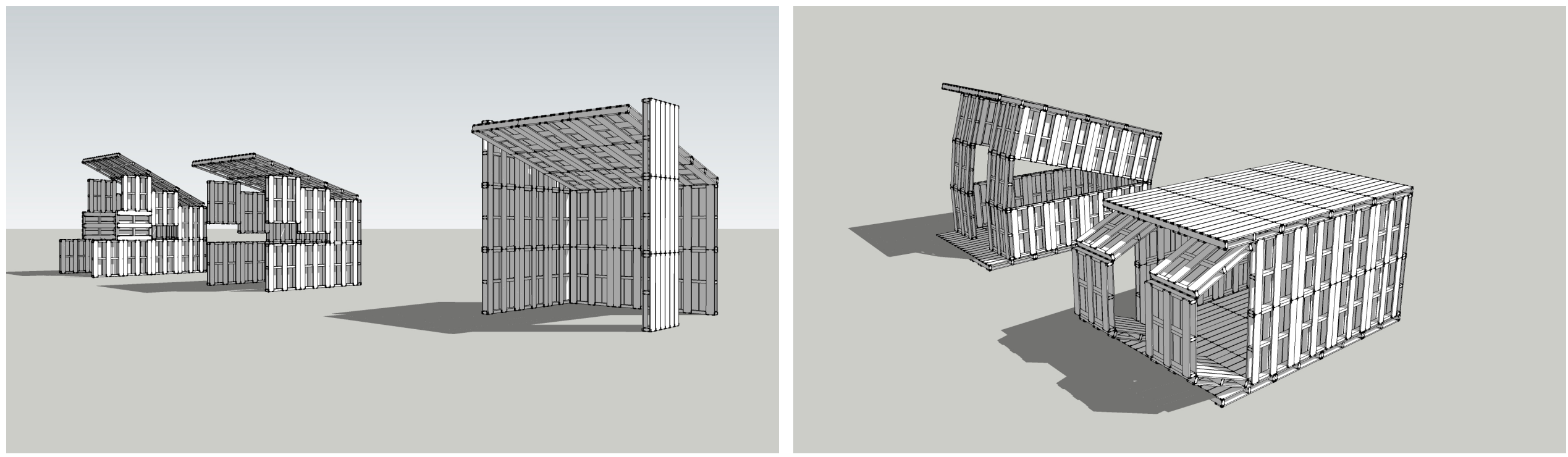

Fig. VII-11. SketchUp designs testing sketch shelter ideas. Alignment of second shelter enables interesting opening mechanism and open/closed state 


\section{Full-Scale Temporary Pavilion}

The aim was to create a low-tech temporary and structurally sound pavilion design for easy transport and assembly.

The form is based upon previous hinged cantilevering shelter concepts but given additional structure 


\subsection{STRUCTURE}

The structure aims to add additional bracing on the outside of the pavilion ensuring safety and stability beyond the support of hinges alone.

The designed structural nature is based upon bracing modules with each other by extending the stringers to align with other extended stringers. The resultant form in elevation can be seen as two squares with the second rotated by 45 degrees, where the external nodes act to brace the adjacent internal pallets to each other (Fig. VII-12).

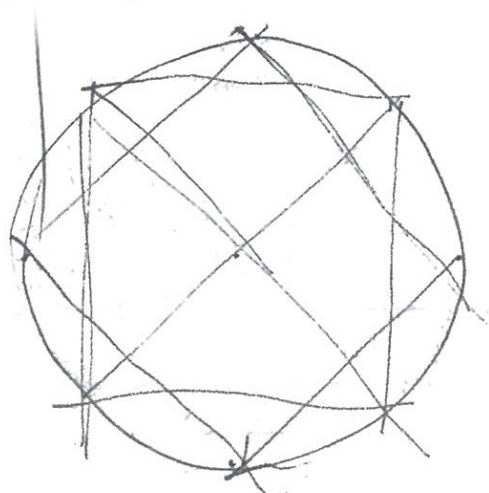

Fig. VII-12. Structural rationale sketch

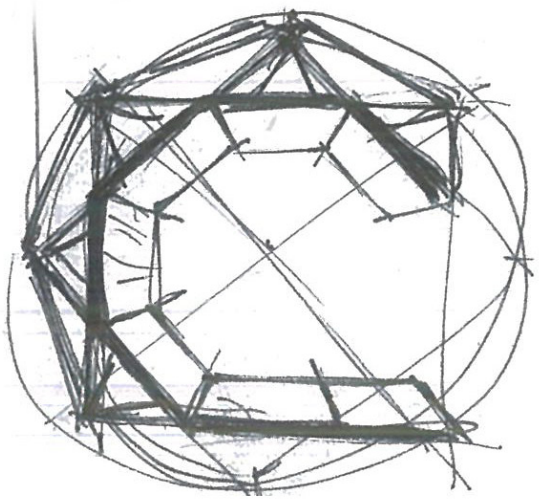

Fig. VII-13. Early model with wire, rather than timber, tension support between nodes and without the module's diagonal brace elements

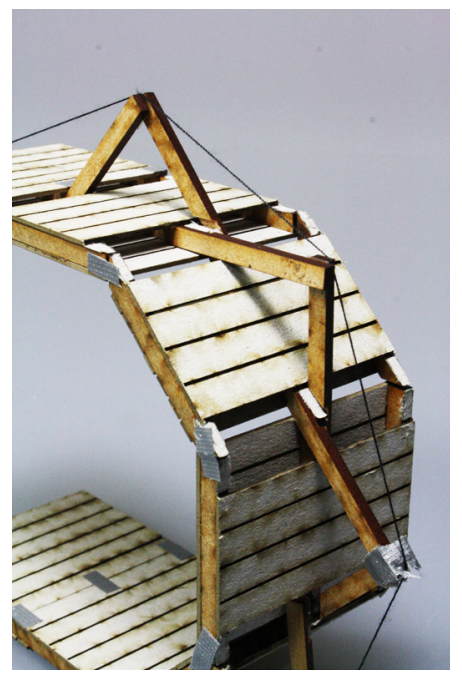

Ways in which to integrate this structural system were explored and the final design acts to three-dimensionalise the bracing with addition of diagonal elements and an extra structural element acting as a nodal brace (Fig. VII-13, Fig. VII-14 \& Fig. VII-15). The resultant structure follows a skeletal form and acts as a truss. See Fig. VII- 15 for structural analysis.

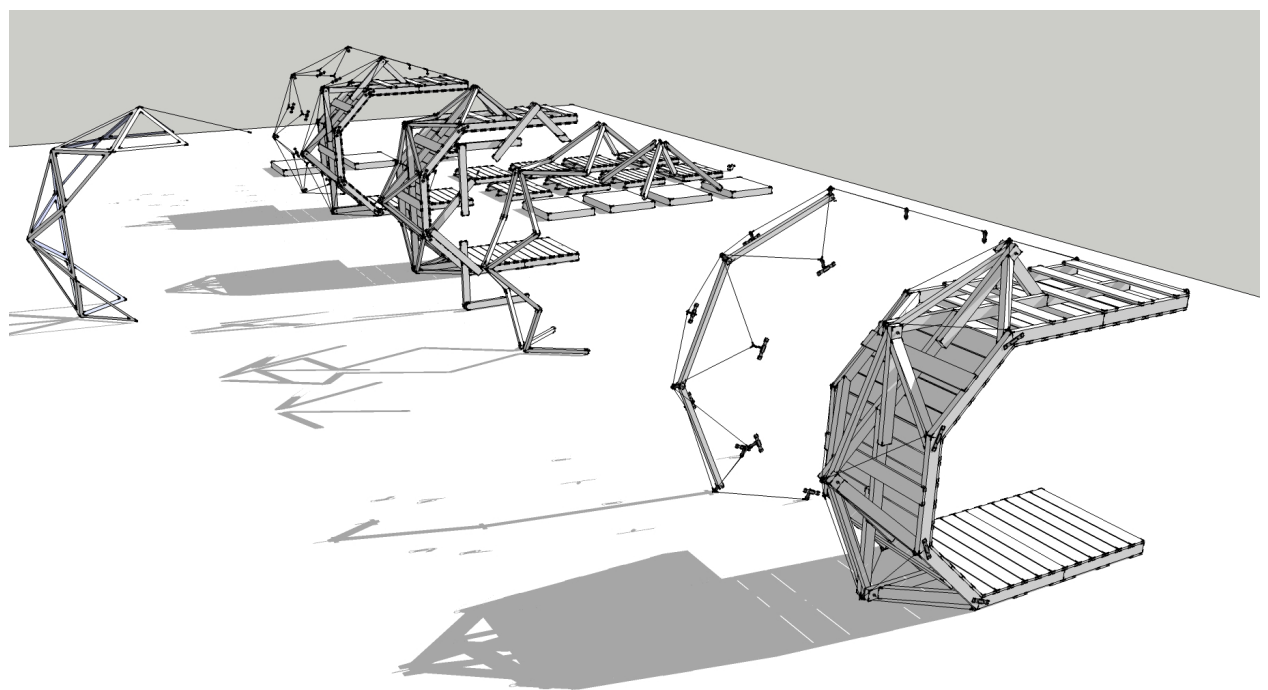

Fig. VII-14. SketchUp structural integration experiments
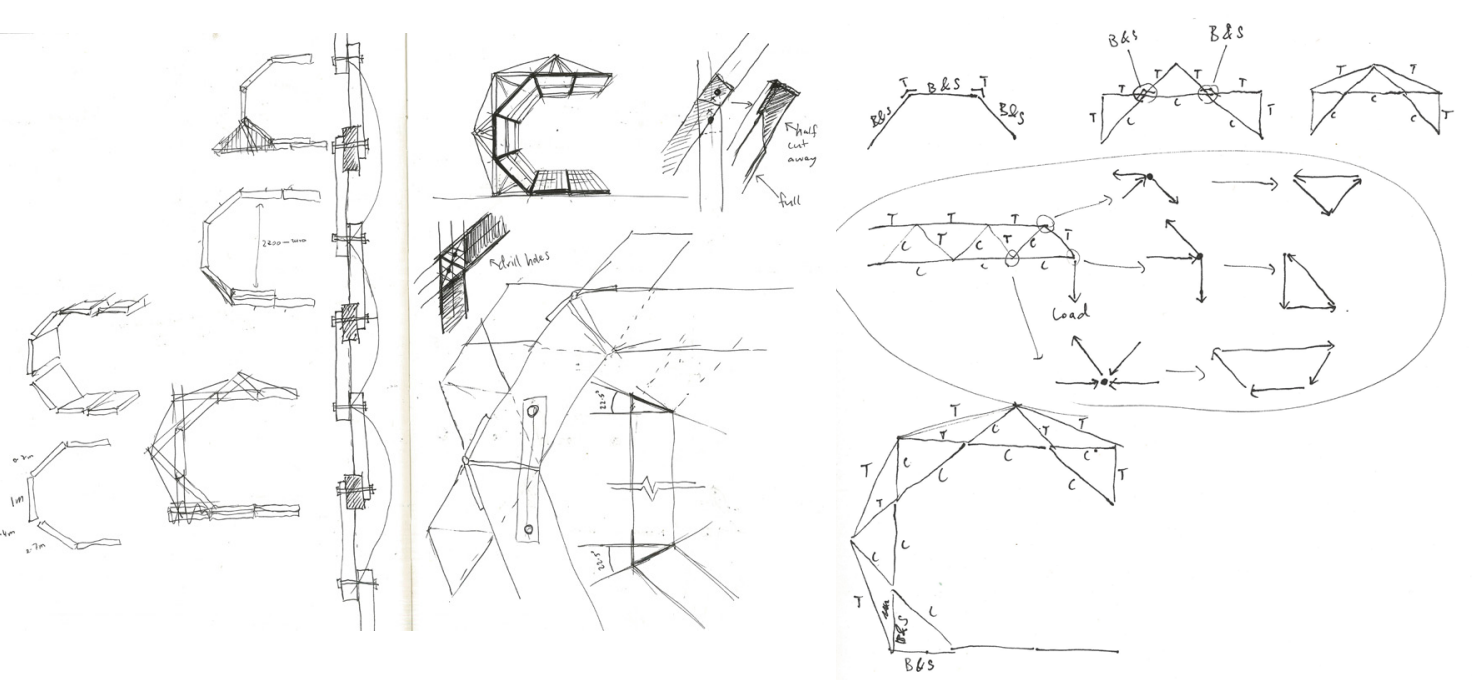

Fig. VII-15. Structural integration sketches and structural analysis 


\subsection{Construction}

The design including additional structure fits a standard module. These modules overlap when prefabricated together with bracing fitting within the pallet depth.

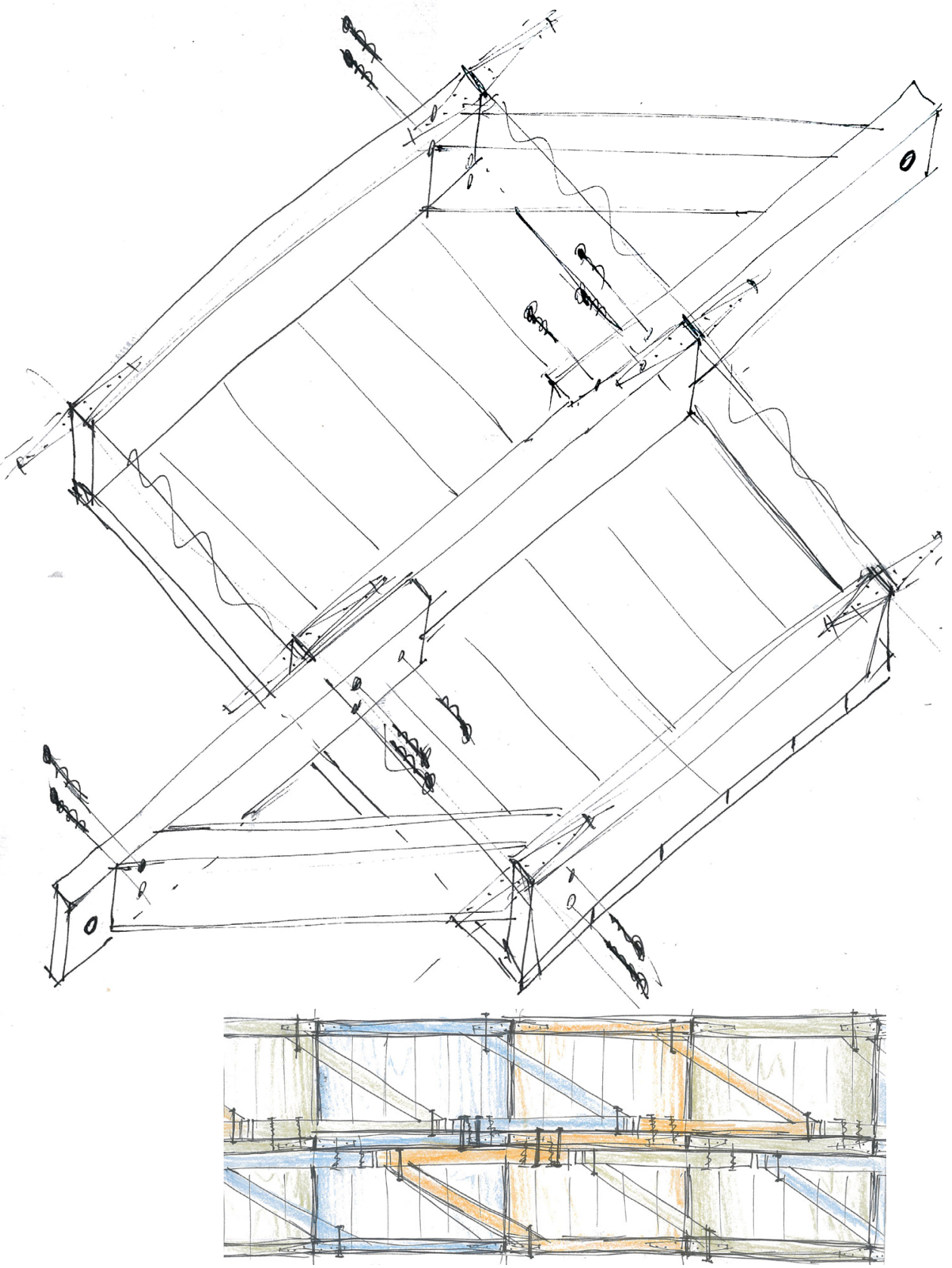

Fig. VII-16. Sketches of designed module and its modular integration 
To build such a system required near identical pallets. A source was found and pallets were laid out to determine the order in which the stringers - structure - were best aligned.

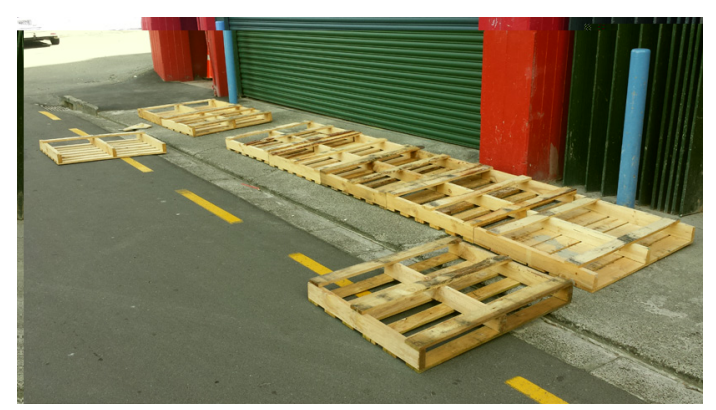

Fig. VII-17. Testing pallet order to best stringer alignment
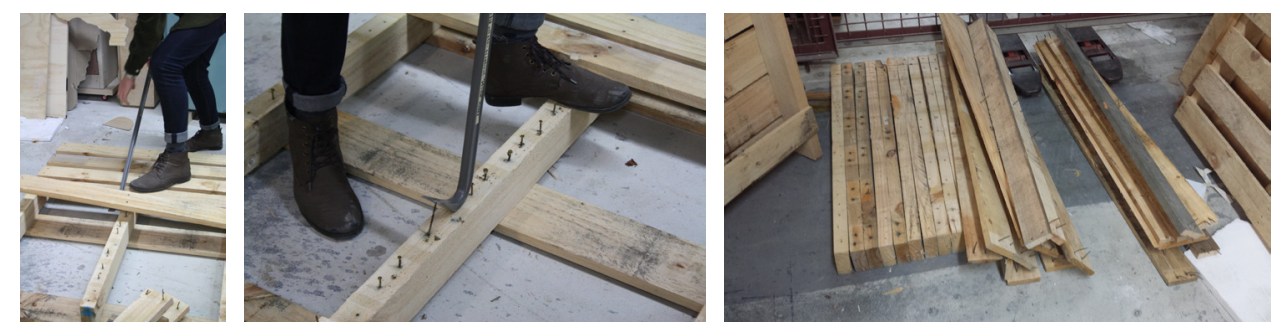

Fig. VII-18. Dismantling pallets for additional stringer components
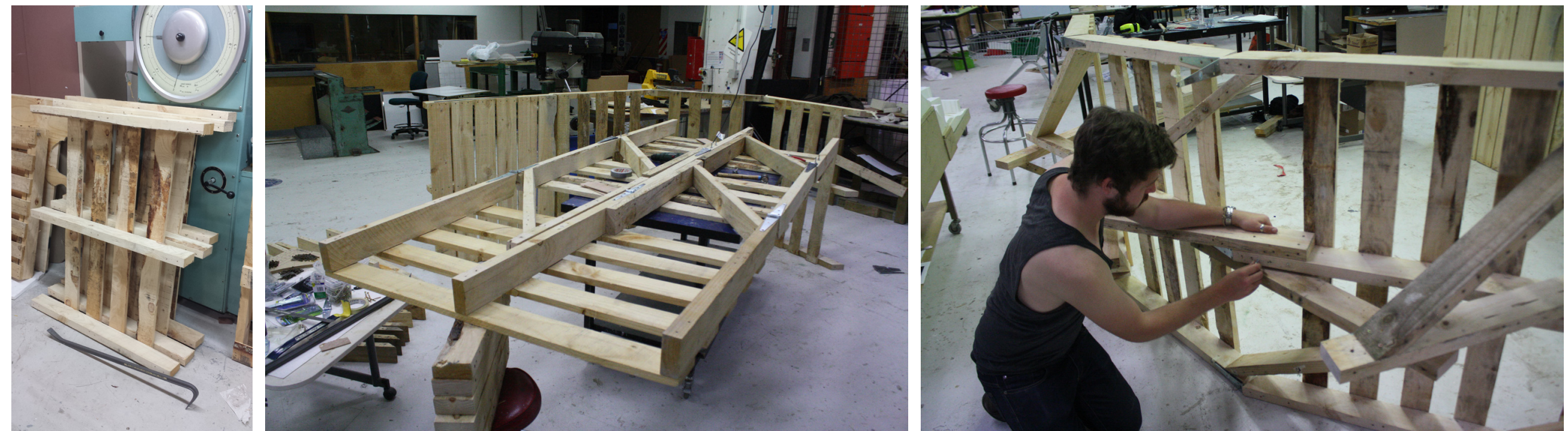


\subsection{Transport \& Assembly}

The level of prefabrication - number of modules combined - in the design depended on transportability medium. The built pavilion was dismantled into four segments to fit in an elevator for exhibition deployment.

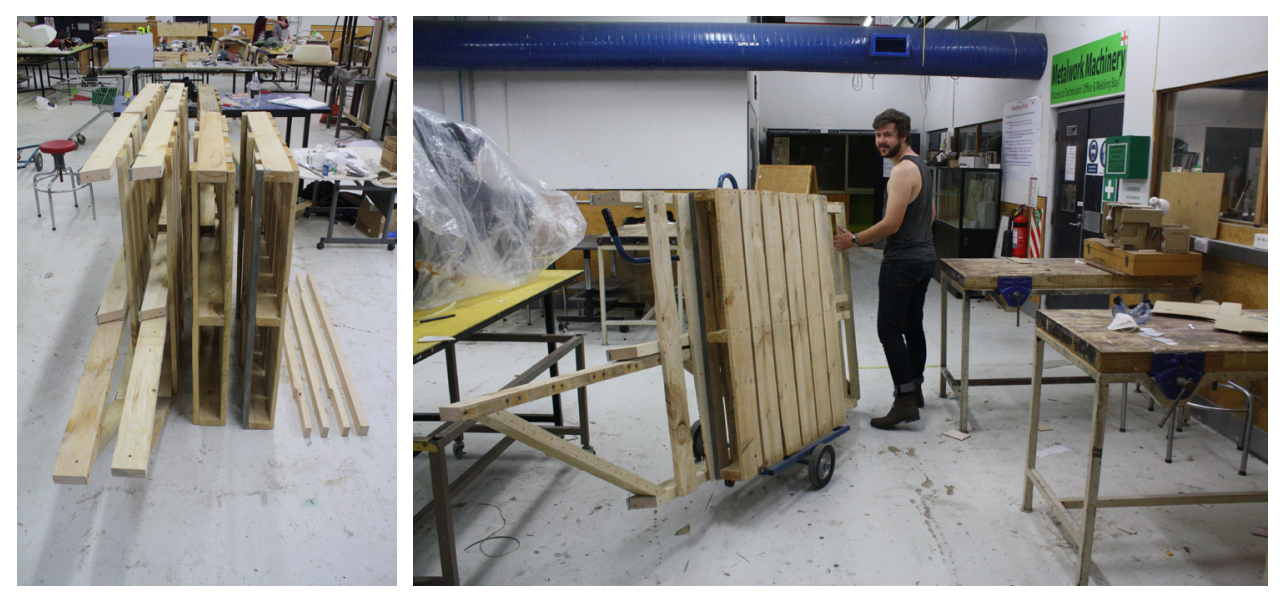

Fig. VII-20. Pavilion divided into manageable madules - able to fit in elevator
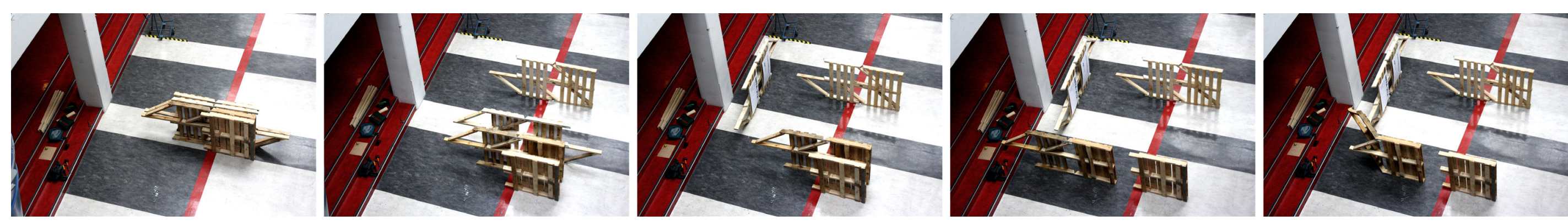


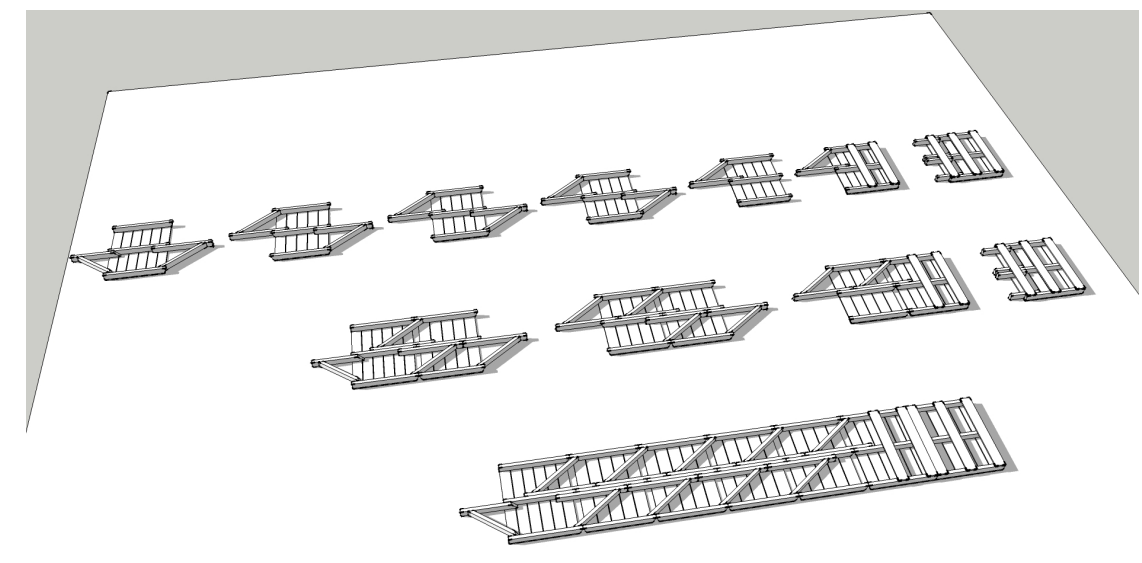

Fig. VII-21. Levels of prefabrication - individual, segments \& whole

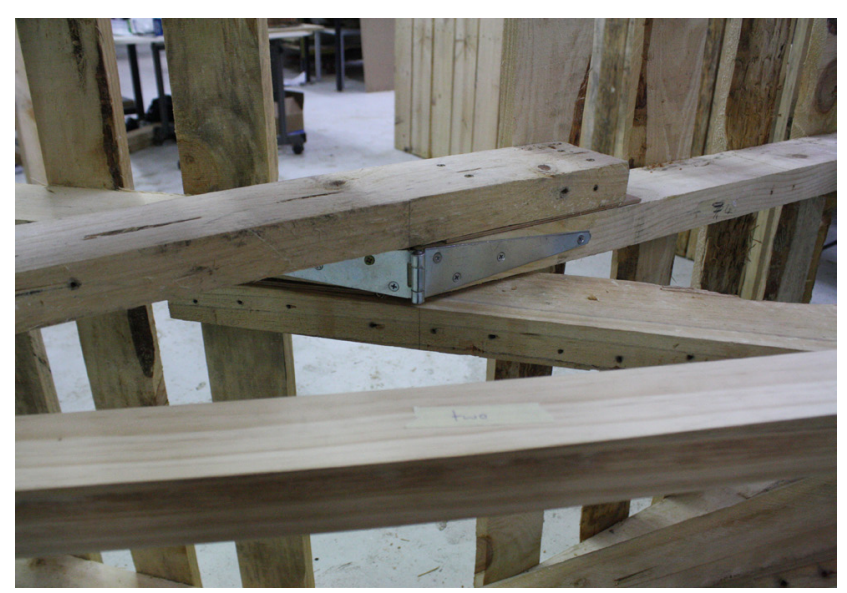

Fig. VII-22. Photo details of central stringer hinge and structural node

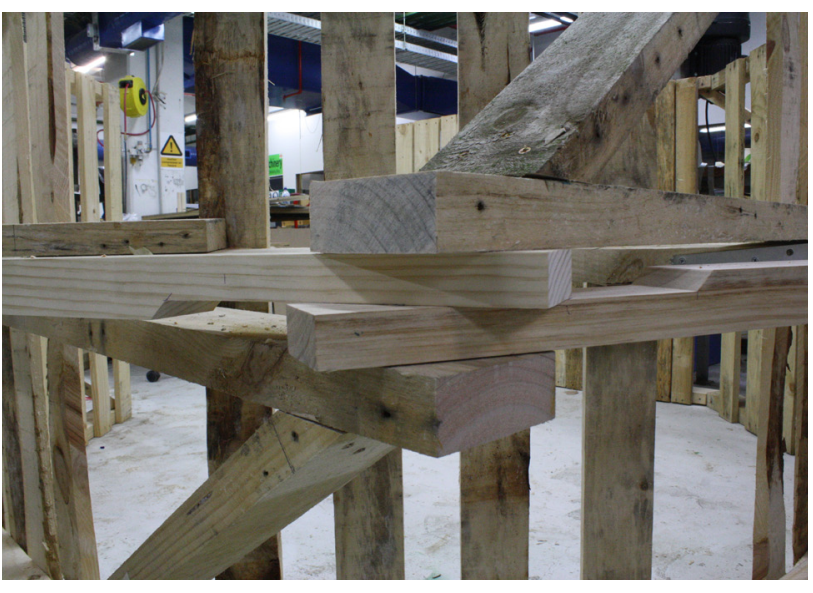

3

Utilising pre-drilled holes and bolts assembly took 45 minutes for one person with

only a spanner and then three people to stand it up.

Ideally pavilion would be fully assembled prior to deployment for quicker erection.
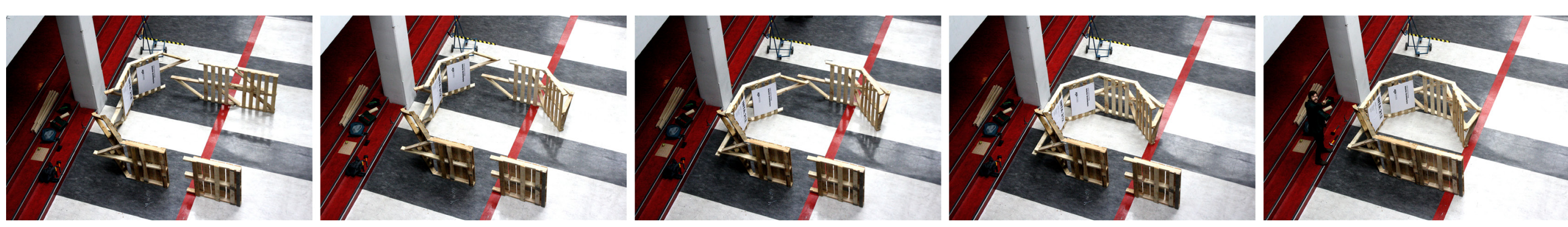

Fig. VII-23. Built pavilion assembly sequence 


\subsection{Pavilion Display}

DAY:

The pavilion was built in time for the thesis final review and was talked to as part of presenting.

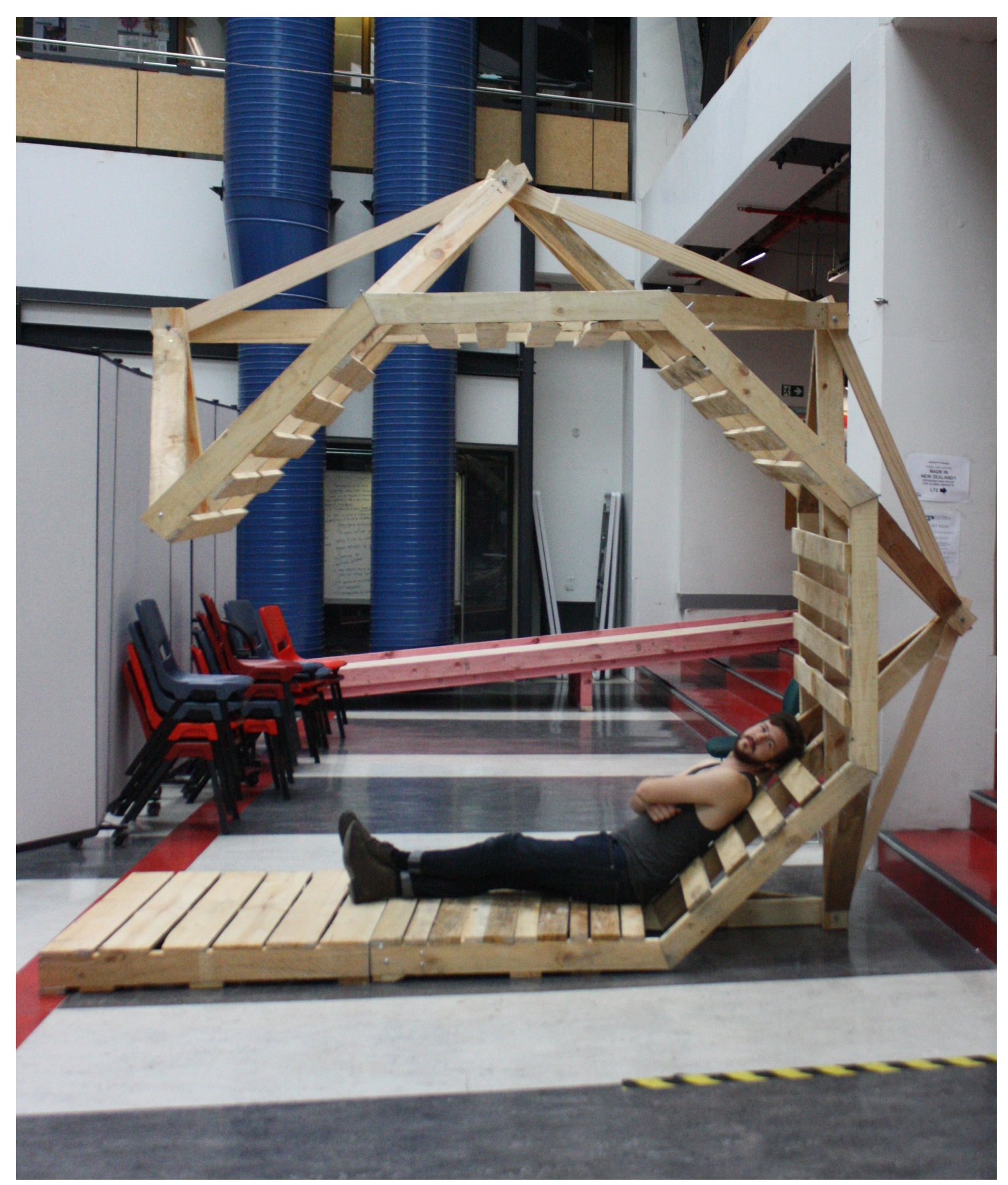



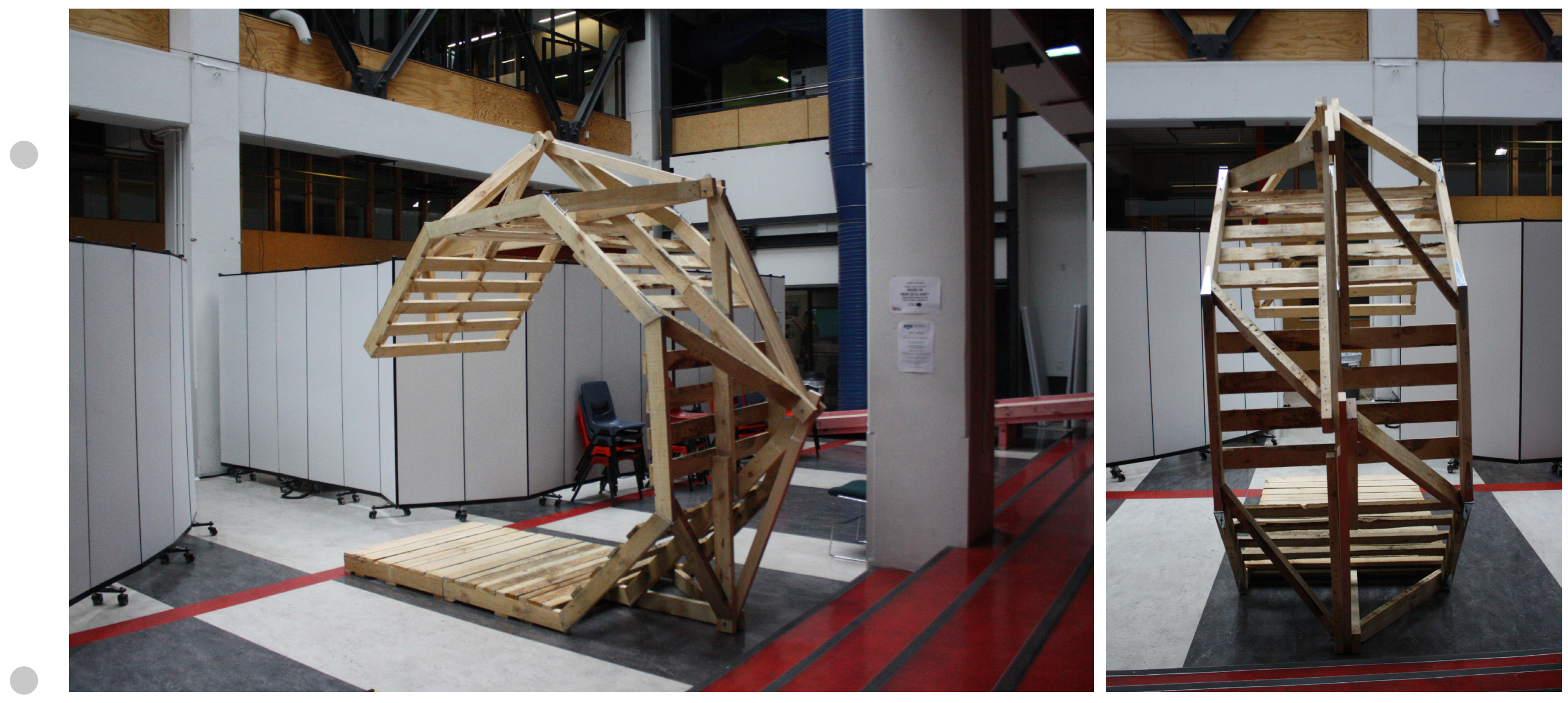
The pavilion was also displayed as part of a university exhibition for modular light pavilions. Illumination was by way L.E.D. strips to emphasis the pallet dimension to express the pavilion's structure. The pavilion acted as the plaque for the exhibition - which was a huge success.

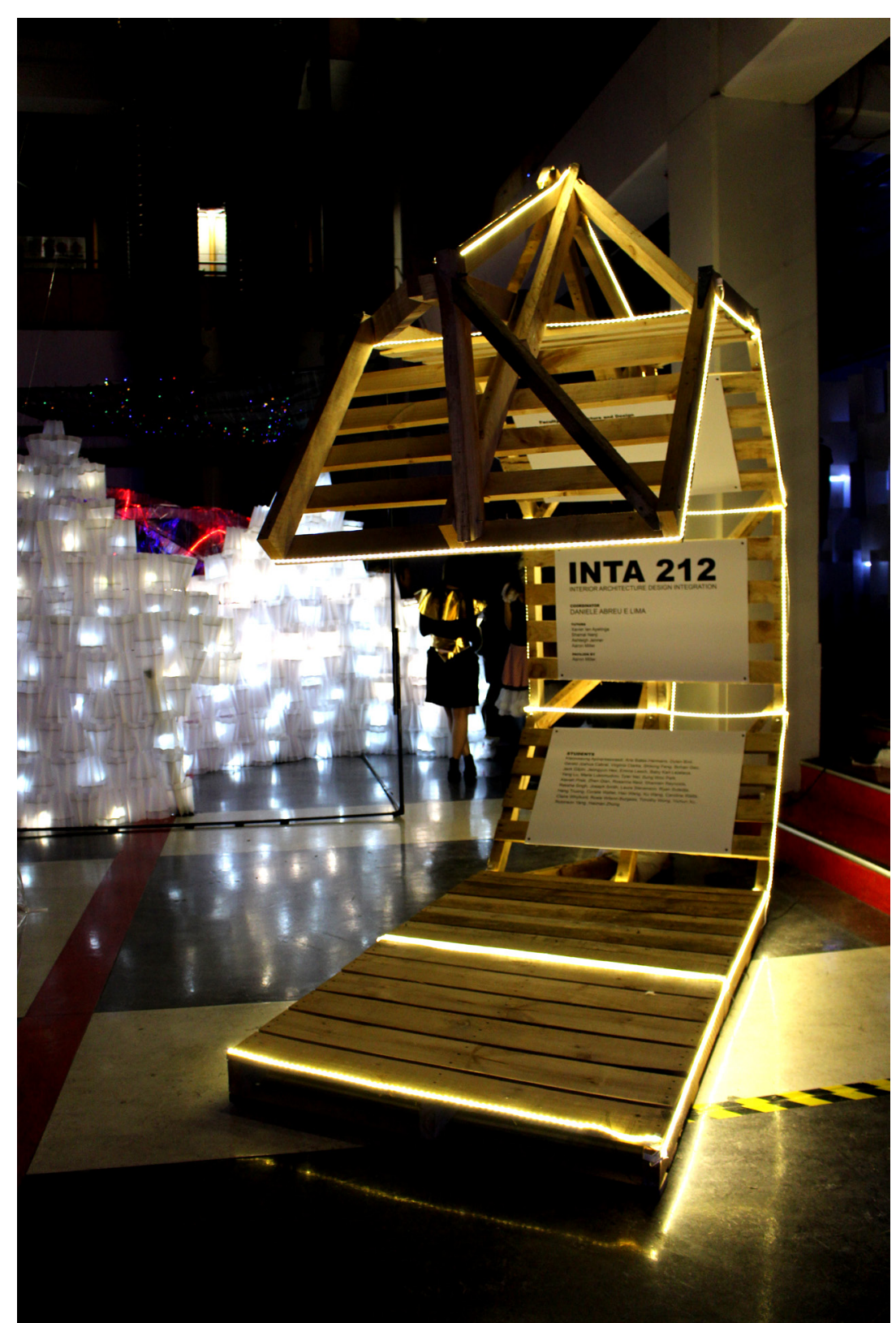

Fig. VII-26. Illuminated pavilion, from front

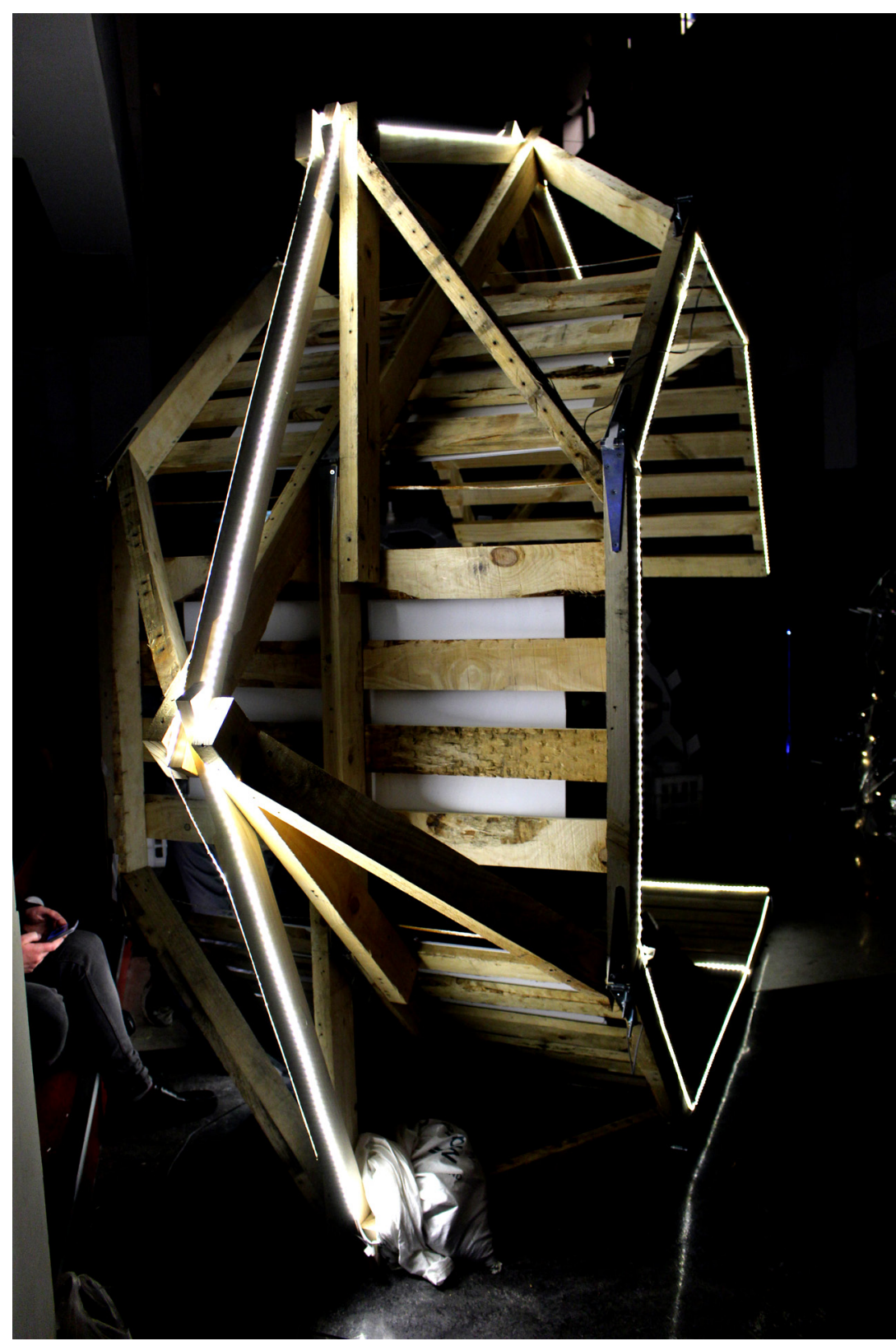

Fig. VII-27. Illuminated pavilion, from rear showing structural expression 

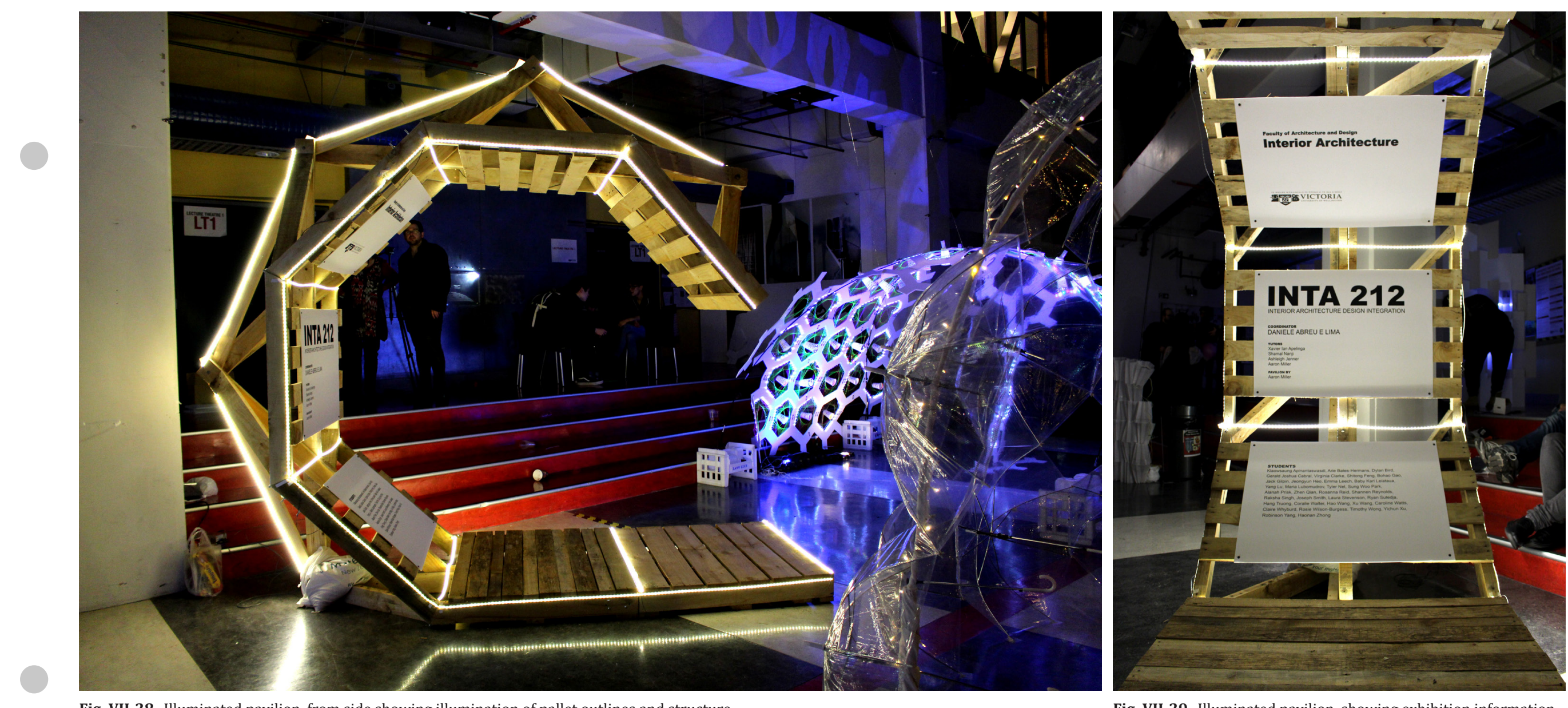

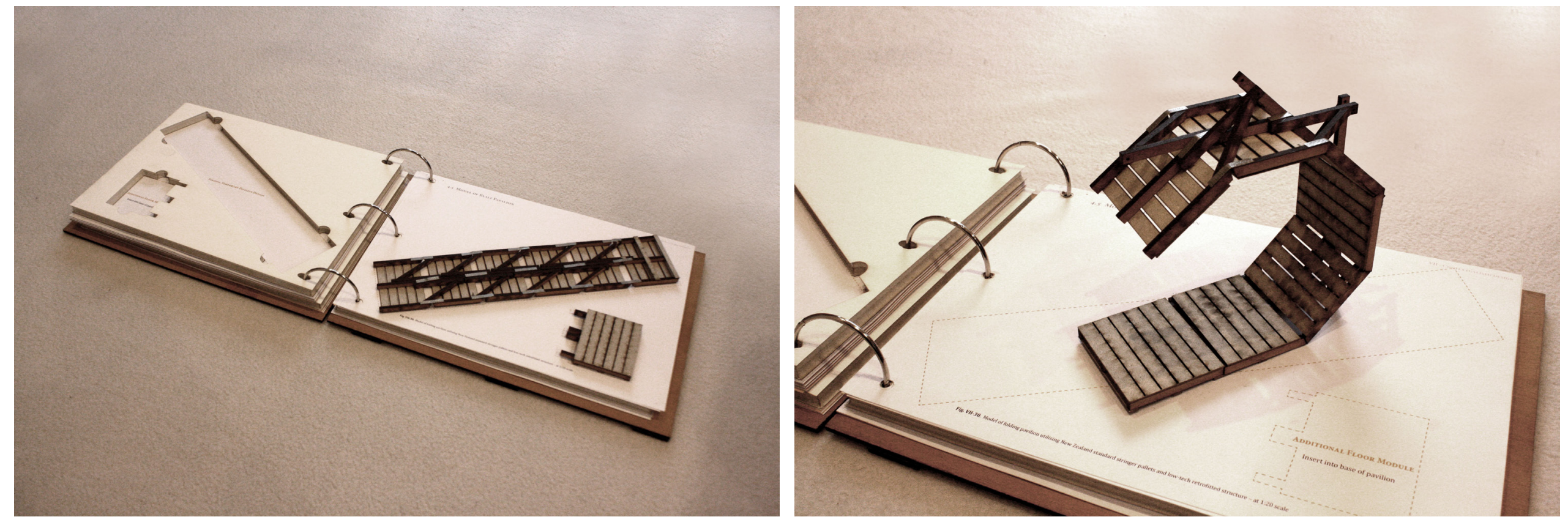


\subsection{Model of Built Pavilion}



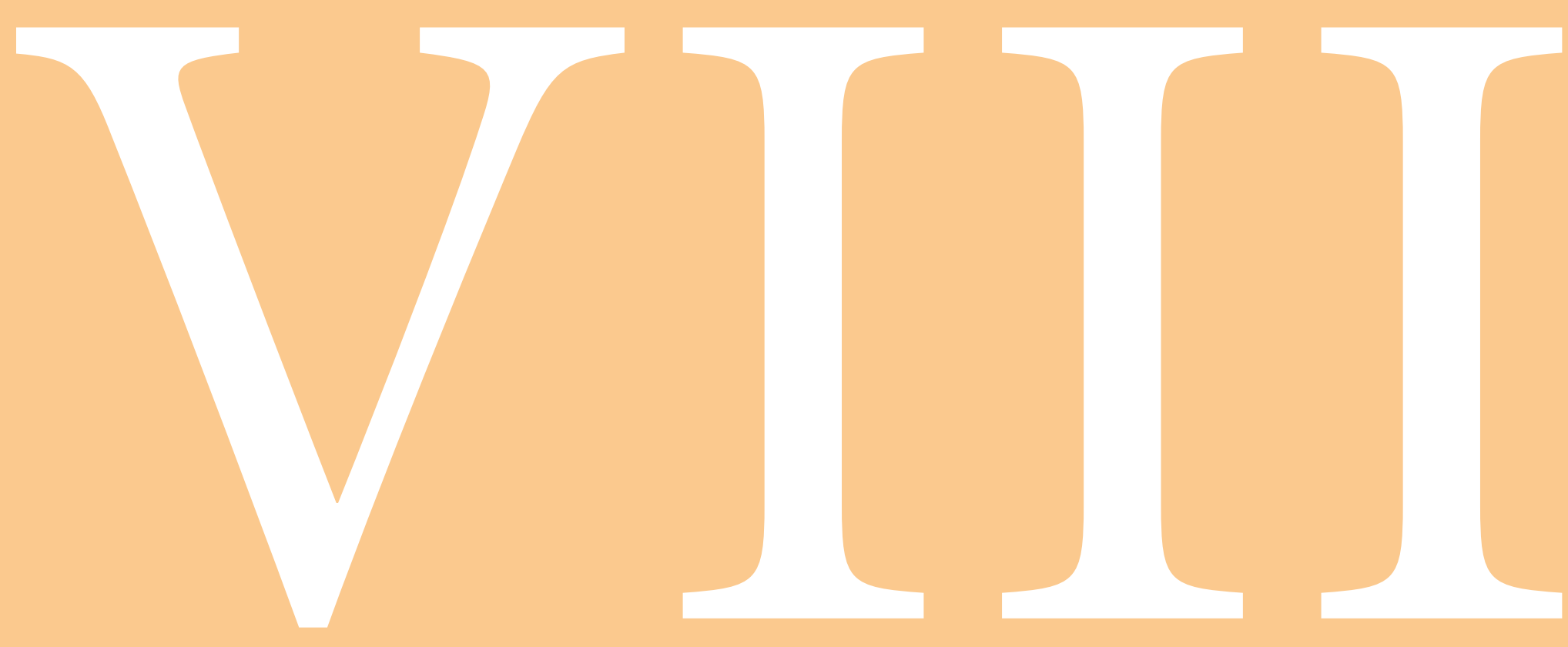
Existing pallets require external construction systems in order to be utilised in construction. This section aims to develop the 'building pallet' - a pallet which aims to act as a universal modular building component post shipping.

The ideas of being modular and structural as previously designed for are built upon in this section; however the new pallet's design aims to foster its modular and structural nature as its primary function rather than being enabled by additional material, structure and systems.

The key design driver is universality and this is approached in terms of modularity, structure, connection details and versatile application - able to act structurally as wall, roof and floor. The base pallet will need to be initially built with high precision for this universality to occur.

Post shipping, prefabrication will occur on the pallet transforming it into a highly finished prefabricated modular system; however it is important that the 'building pallet' must - above all else - act as an efficient and cost effective shipping solution like the highly optimised existing pallet. If this does not occur the pallet design would not have any chance of being integrated into the shipping industry, thus not becoming abundantly available for construction after their shipping lives around the world.

The re-design explores a new 'building pallet' and develops the most successful solution into a prefabrication system framework which is applied to design. 


\section{1. 'Building Pallet' Concepts}
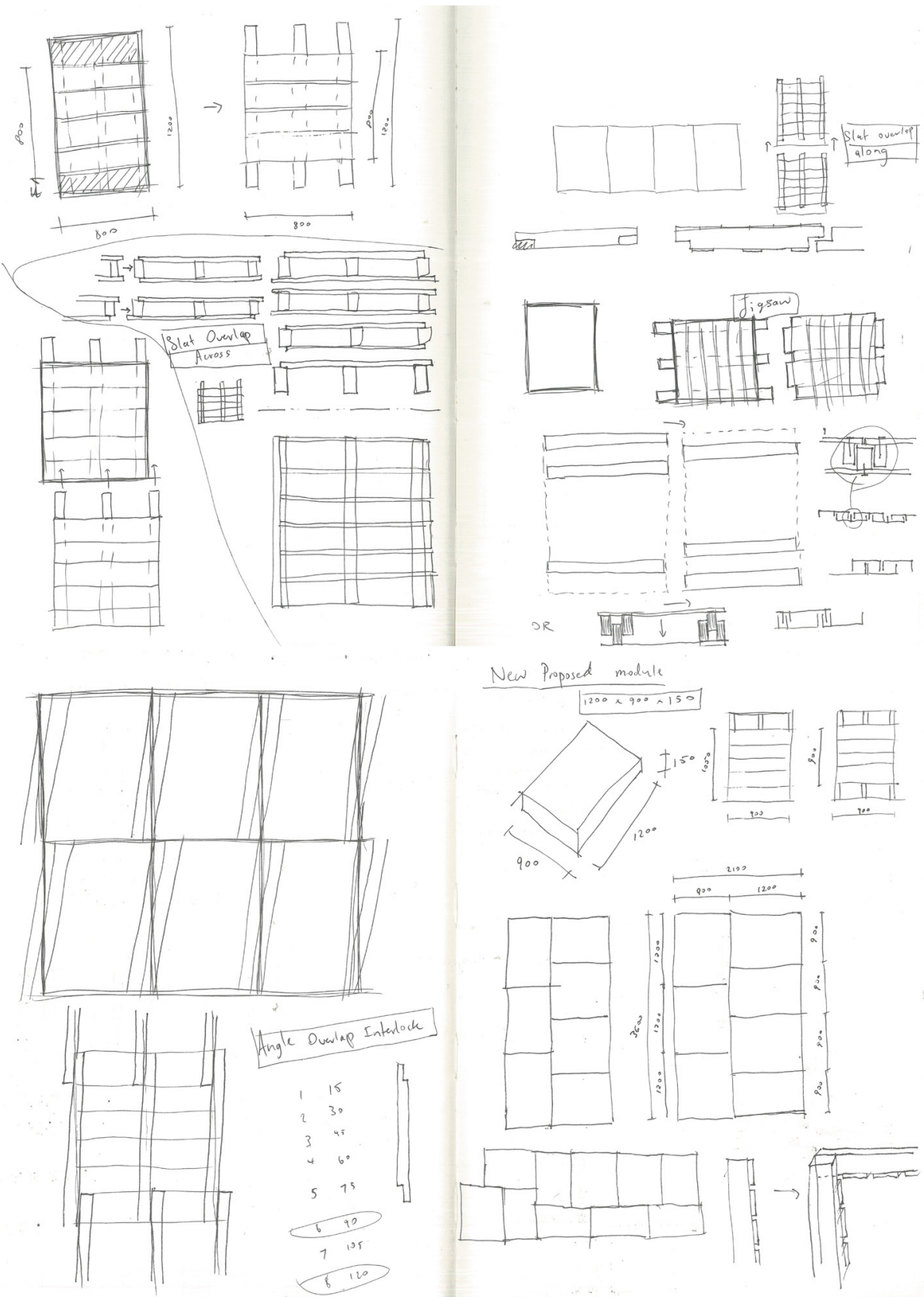

$\frac{\text { New Propsed module }}{\sqrt{2000 \times 900 \times 150}}$
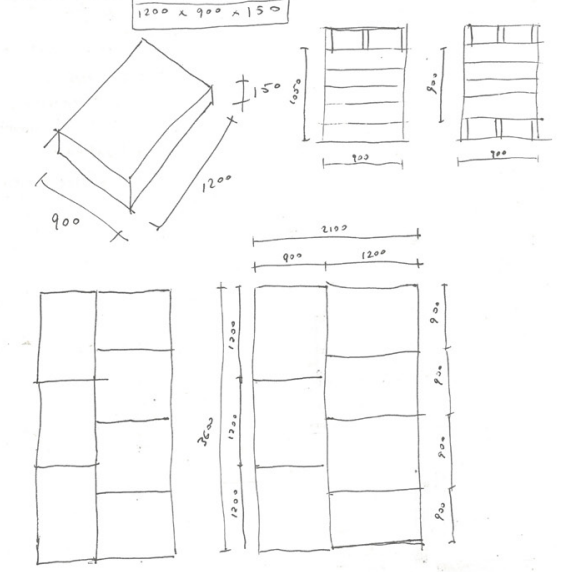

Fig. VIII-01.Sketch designs experimenting with module, structure and overlapping 

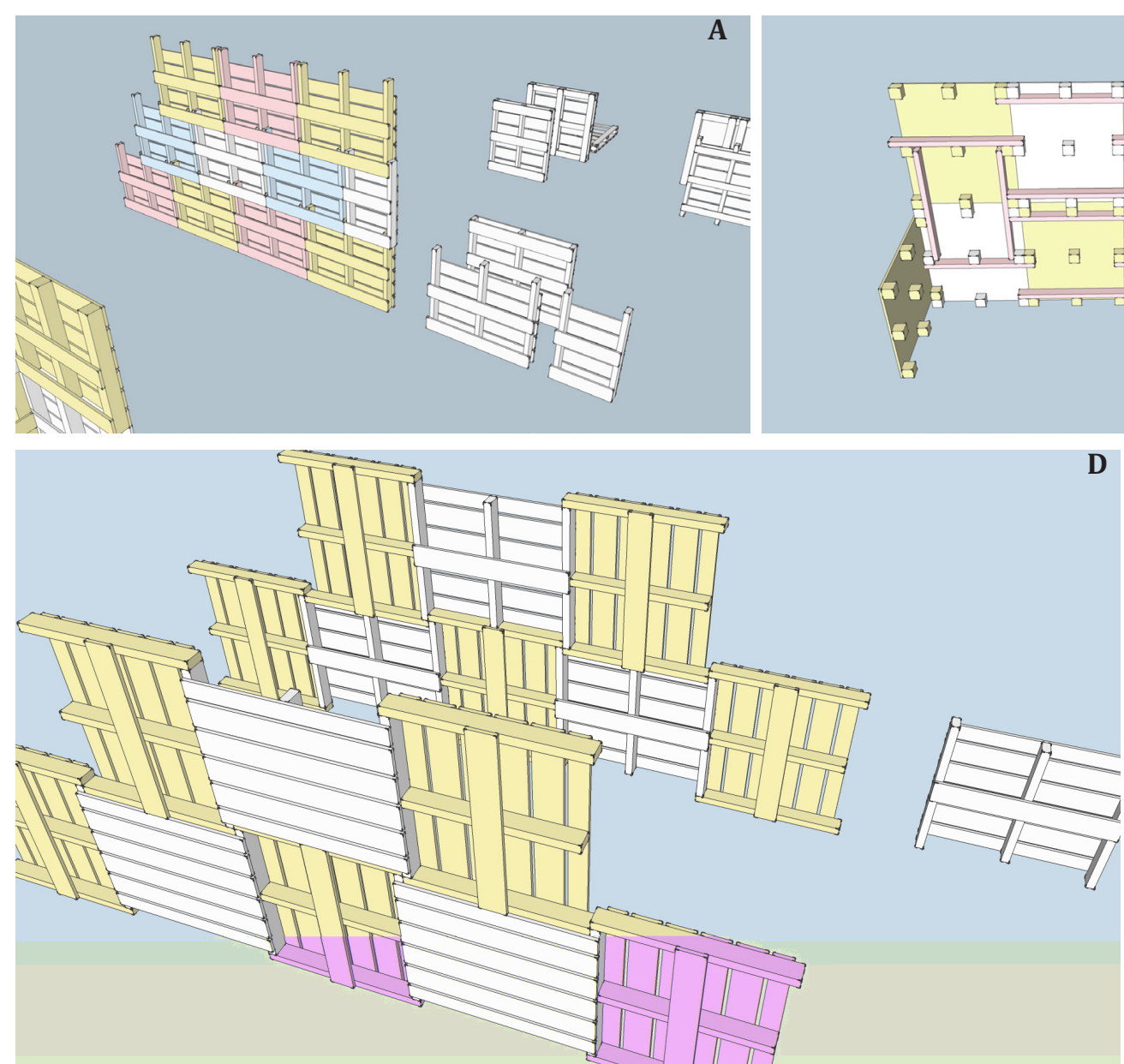

B
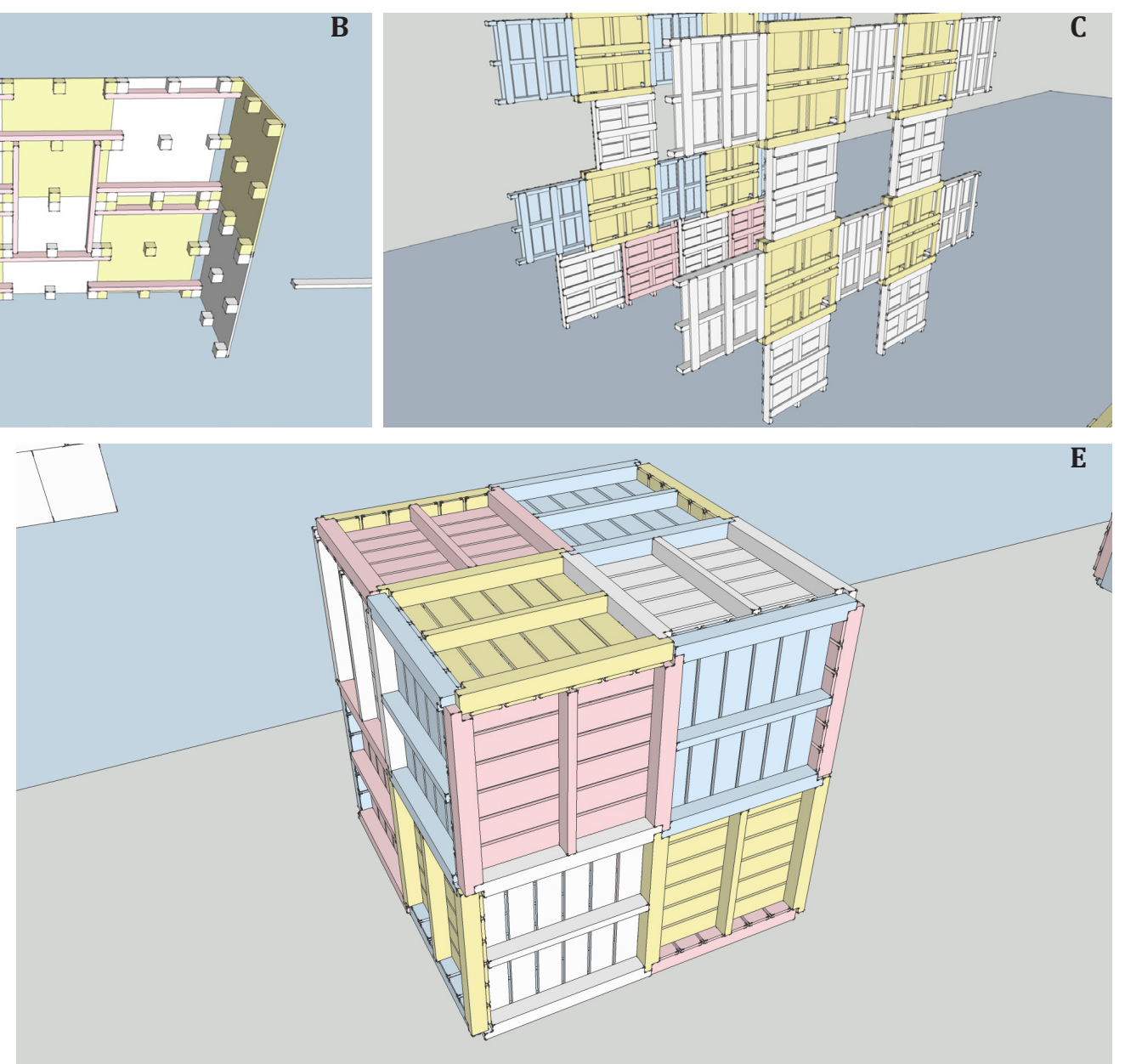

Fig. VIII-02.Testing of various 'building pallet' ideas. The key issue is how to transfer load between adjacent pallet.

- 'A' has the stringers literally overlapping and interlocking in a brick-type fashion.

- 'B' looks at using additional beams between block pallets in different arrangement to gain strength in both directions

- ' $C$ ' utilises a system of both block and stringer pallets which alternate, however holes are created by this system where neither module can fit

- 'D' has a shorter central stringer allowing adjacent pallets for fit within the outside stringers. When arranged in larger area there is no leftover space.

- ' $E$ ' is a develpment of ' $D$ ' where the outside stringers are doubled in thickness with a small cut-out at each end. This system - unlike the the others - has the ability to wrap around corners and the thickened outside pallets create an aligned structural grid 


\section{2. 'Building Pallet' Application}

See original images in Shaoqiang, 2014, pp. 46-49

Fig. VIII-03. The Liina Transitional Shelter, by Aalto University Wood Program in Helsinki, Finland is a prefabricated and portable solution for use as a post-disaster emergency shelter. The temporary building transports flat-packed in a standard shipping container, and is able to be assembled by 2 adults in one day using only basic tools aided by a simple installation diagram. It is designed for use by a family of five for up to five years - while the post-disaster reconstruction phase is underway. (Shaoqiang, 2014, pp. 46-49)

The construction of this shelter is of significant interest as the panels act as cladding, insulation and importantly - primary structure. Also the panel joints are expressed in the interior giving an aesthetic of the shelter's construction to users. The wall panels have several types which are all built to the same module dimension, giving a sense of continuity to the design and making the construction very simple as it means the joints between all panel frames are identical and all irregularities are only within panels themselves. The assembly diagram shows the simplicity of the project assembly, however this design, while being modular, is not adaptable and is a singular solution with a set design, seemingly governed by the set size of the waterproofing plastic wrap.

Fig. VIII-04.SketchUp comparison of various dimension pallets (A). The chosen dimenion module is $1200 \times 1000 \mathrm{~mm}$ with $100 \mathrm{~mm}$ wide and deep outside stringers which have an extra piece sticking out to allow overlap of modules. This leaves a $1000 \mathrm{~mm}$ gap between structural grid stringers. Ideal building height would have an interior dimension of $2100 \mathrm{~mm}$ - two pallets high - to minimise bracing requirements.

' $\mathrm{B}$ ' is a visualisation showing possible arrangement of modules.

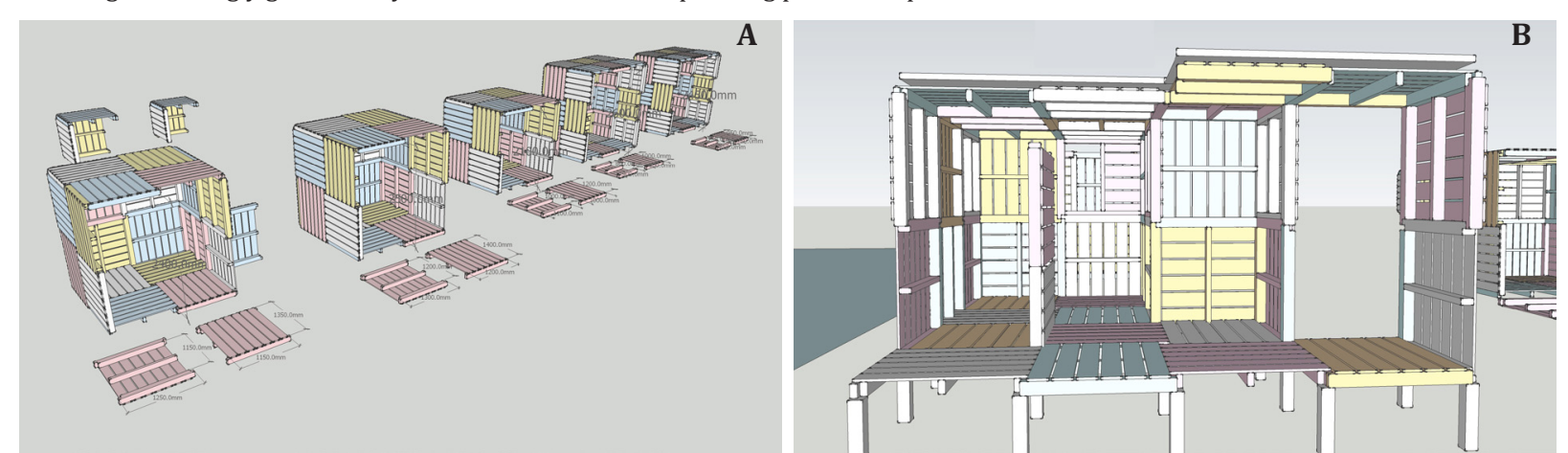

Pallet system module 'E' from Fig. VIII-02 was selelected as the ideal 'building pallet' due to its ability to connect around corners and create a consistent structural grid of stringers in three-dimensions - a true universal building component.

The idea is that discarded pallets would be collected and prefabricated in factories into specific high quality panel types, each applicable as a different building element - floor, roof and walls of various cladding types (see Fig. VIII-07). Existing timber decking would then existing on the interior surface, while prefabricated waterproofing modules would be fastened to the outside - slightly larger than the pallet modular $1100 \mathrm{~mm}$ centre grid to allow overlap. The pallet aesthetic is shown on the interior, while the pallet outline is still expressed on the exterior due to cladding boundaries. Windows, doors and interior partitions are prefabricated separately and built to fit into gaps left by removing pallets. Various flashing caps and sealants are also applied to waterproof the corners and junctions. 


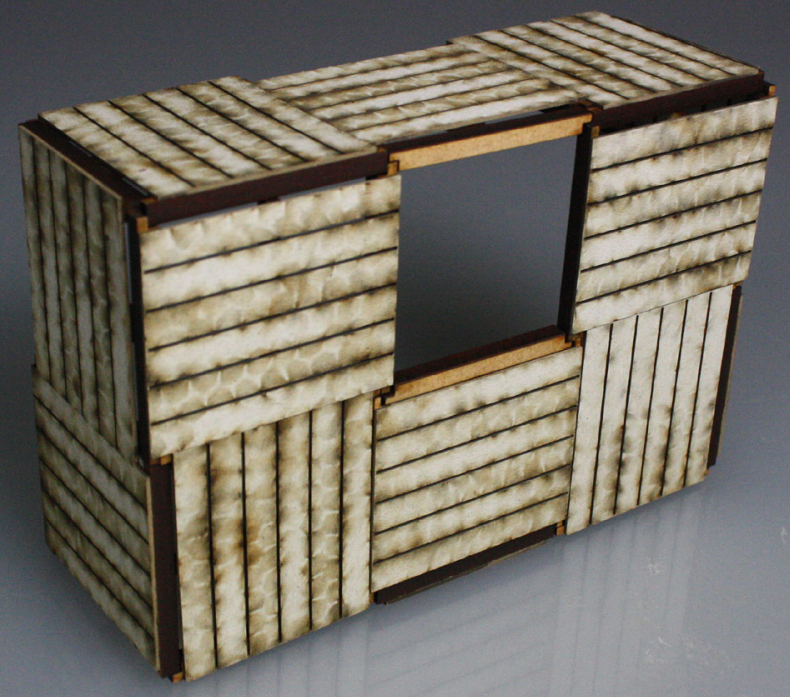

Fig. VIII-05.Laser-cut model testing 'building pallet' in a standard shelter form. Sealant will be required between panels and flashing will be required around corners due to discontinuation of cladding.

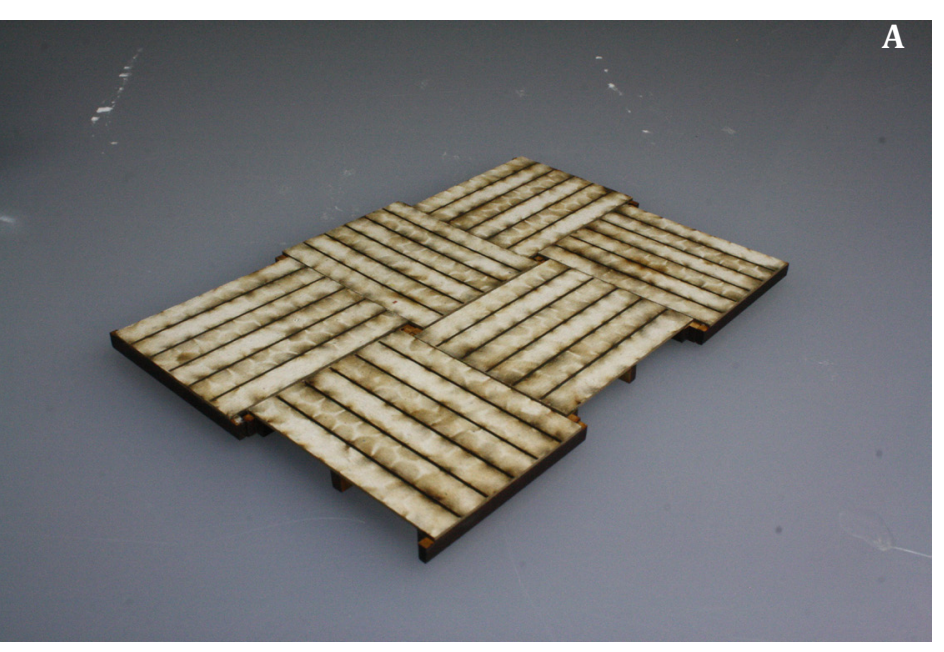

(
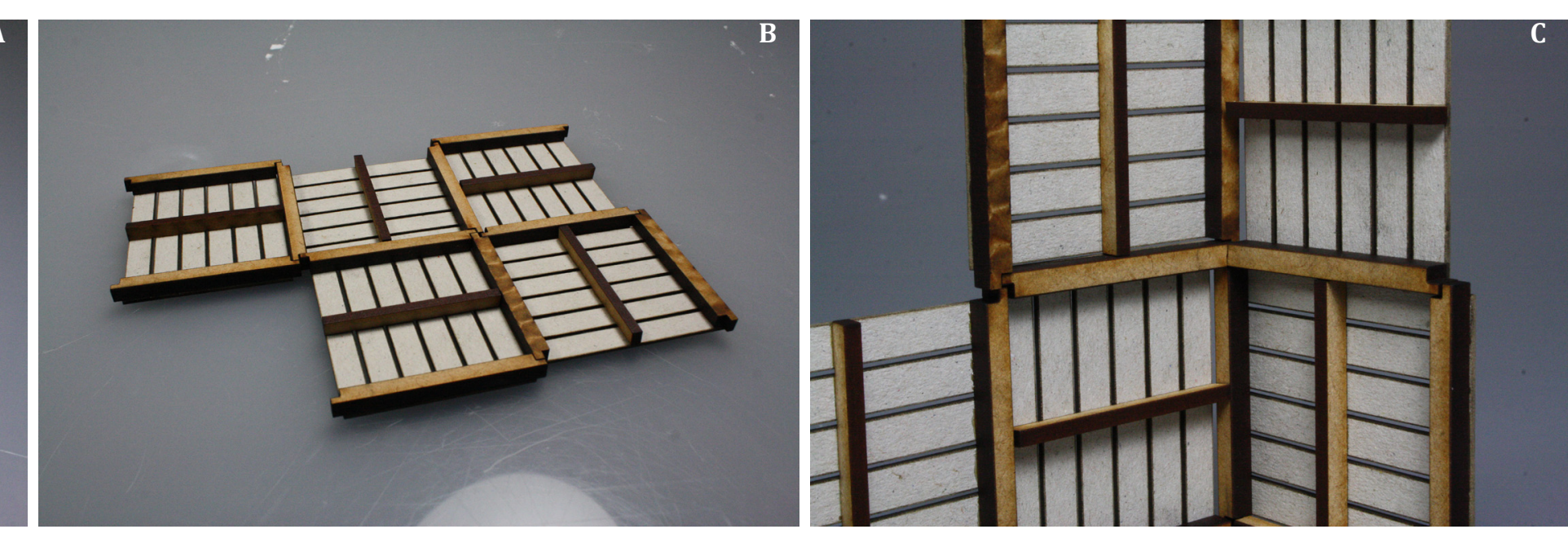

Fig. VIII-06.Various laser-cut 'building pallet' arrangements. 'A' showing pattern creating on flooring by module. ' $\mathrm{B}$ ' and ' $\mathrm{C}$ ' show the structural overlap on flat and around a corner. 

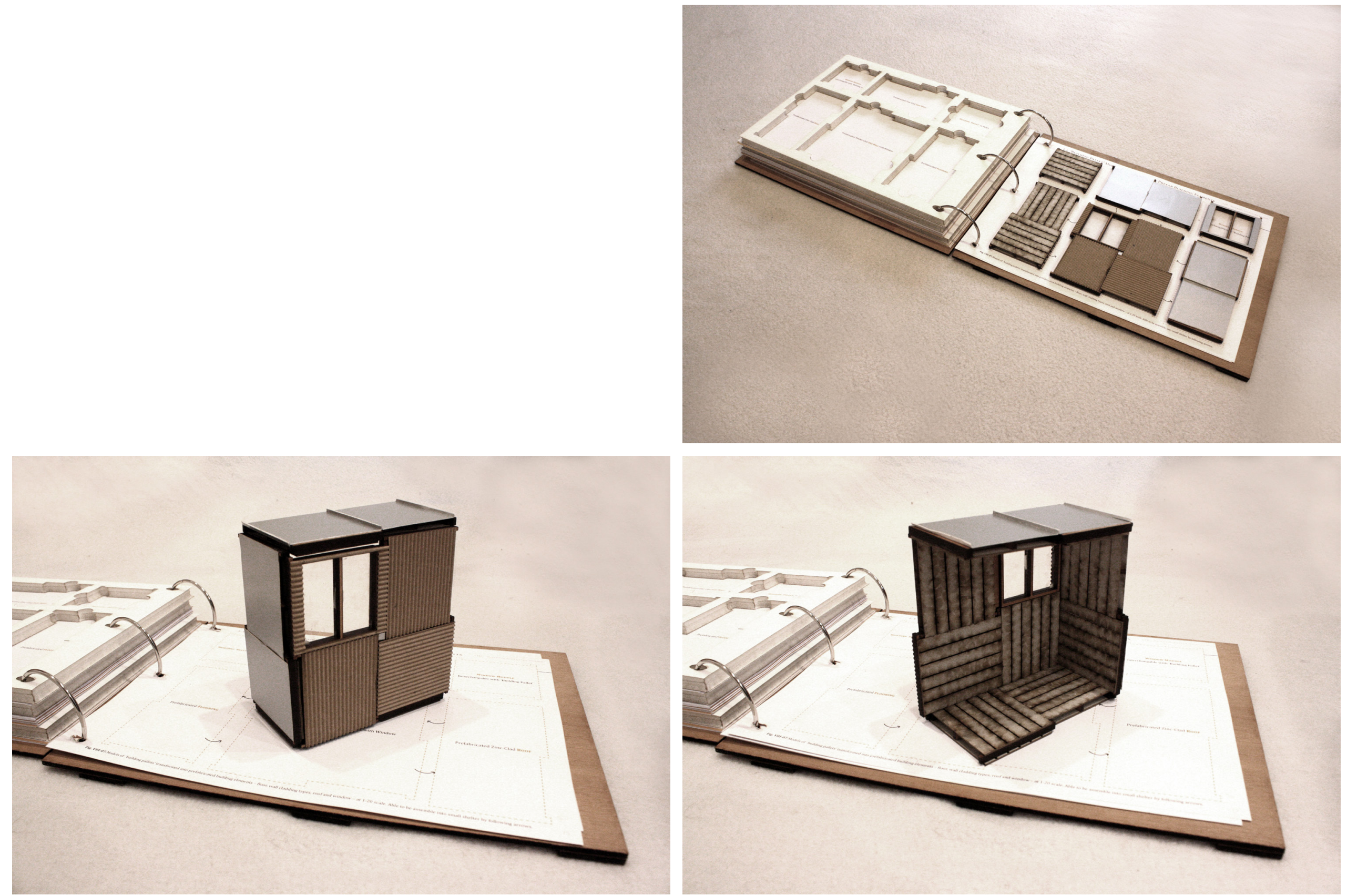
2.1 'Building Pallet' Models with Subsequent Prefab Building Elements

VIII - 'BUILDING PALLET' RE-DESIGN

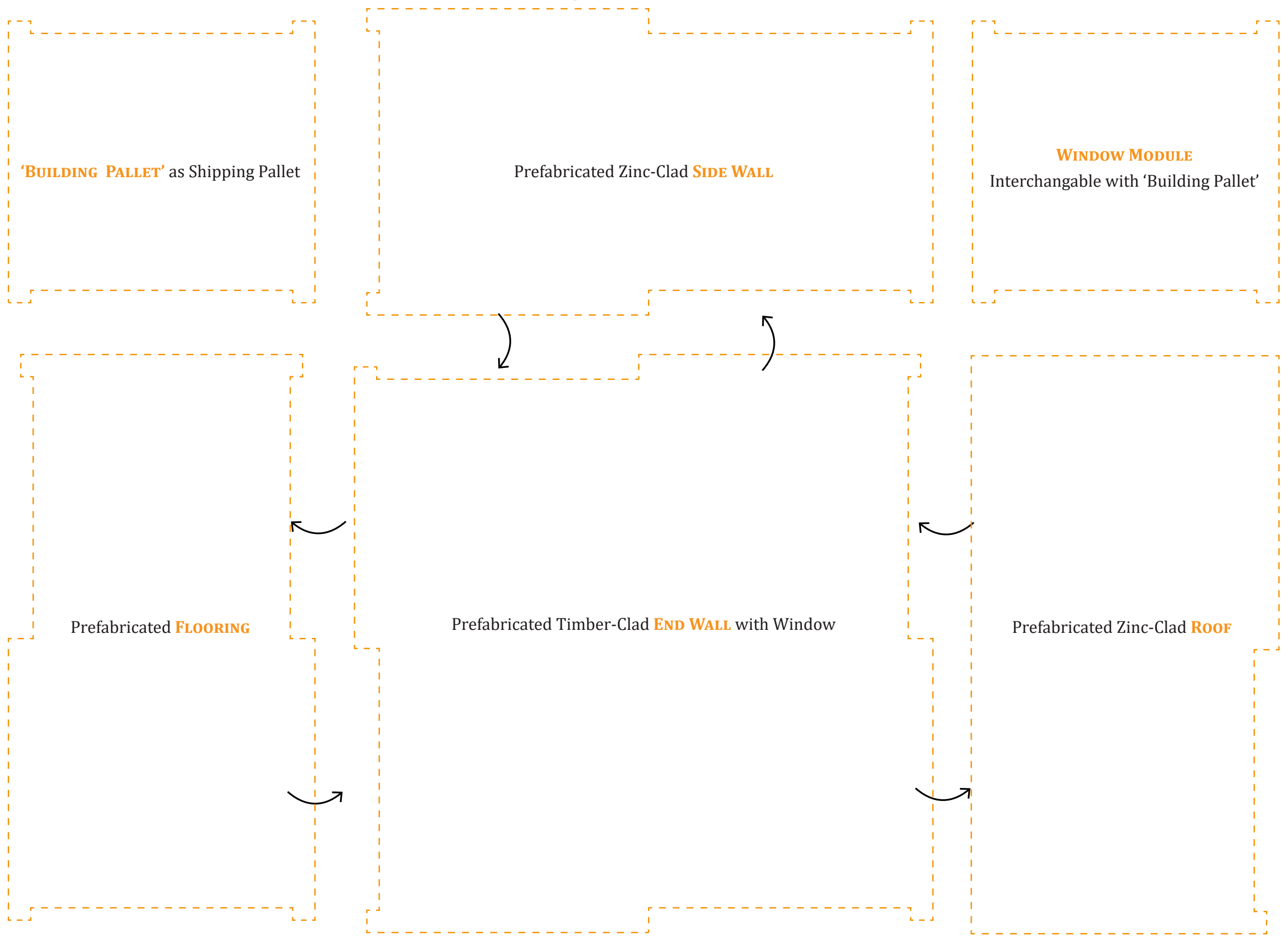




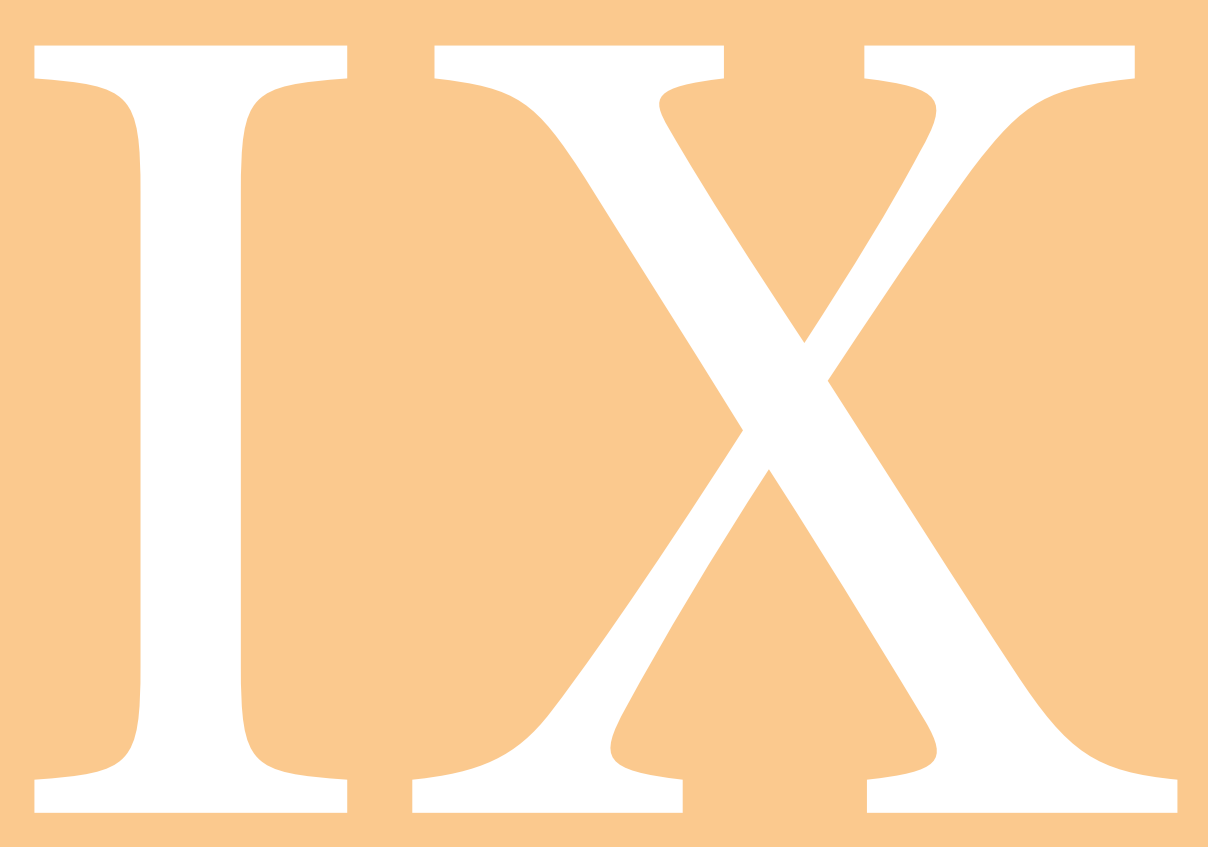


The project only considered existing pallets for design; however it became apparent due to their irregularities and low quality - a new pallet design may lend itself better to the construction industry. Thus the thesis has two distinct design phases: utilising existing pallets and creating and applying a new 'building pallet' to design.

The conclusions and relection to the two distinct design phases have been separated and follow. 


\section{Existing Pallet Conclusions}

The thesis aimed to determine the extent to which timber pallets can be utilised in construction, particularly aiming to determine their value as a primary structural element. The aim was also to develop a system to re-use discarded pallets utilising their module to create temporary architecture which is low-cost, low-tech, portable and easy to assemble.

The full-scale temporary pavilion design acts as the endpoint to the existing pallet design phase and the full design process allowed great understanding of building with pallets.

Pallets are a highly useful building material due to their module. The stringer pallet type allows for innovative architectural form by the use of their structural nature through cantilevers. Despite the low typical strength of pallet timber a system was developed which took advantage of the pallet module and made use of disassembled pallet components to create low-tech, structurally sound architecture. The final developed system is also highly portable and has simple assembly making it easily redeployable. These attributes allow the thesis to add valuable knowledge to the realm of temporary pallet architecture.

Limitations of pallet usefulness in construction that have arisen are in terms of sourcing issues. Whilst 'returnable pallets' are very standard in dimension, discarded pallets are usually inconsistent in type, dimension and quality. Sourcing enough consistent pallet modules for building is therefore difficult, limiting their application in construction at a large scale. For the built pavilion difficulty occurred sourcing the fourteen consistent stringer pallets required for use whole and in components. If time and care is spent sourcing higher quality and more modular pallets their workability is improved

In conclusion, pallet use as primary structure has been shown to be possible in an innovative, low-tech and affordable manner, just not at a scale valuable to humanitarian aid. 


\section{2. 'Building Pallet' Conclusions}

The opportunity became apparent during this research thesis that a new pallet design with inherent application as a building component solution may be possible, informing the addition of this design phase.

The research aimed to design a 'building pallet' that had value in the realm of prefabricated architecture as a universal panel building component. Specifically the solution aimed to apply the principles of prefabrication to a modular design problem, resulting in an attractive, affordable, efficient and adaptable architectural system solution. Other aims were that the designed system would act as primary structure and warrant minimal additional materials.

The 'building pallet' solves these problems from a systems point of view as the assembly of architecture forms a structural grid in three-dimensions and with only small gaps between panels. Transformation of the base pallet module into highly finished, versatile prefabricated components can occur once pallets leave shipping circulation. Pallets would be prefabricated into different building elements - floor, variously clad walls and roof - with additional material only required to create windows, doors and flashings as sealing element.

The design is limited in that the system is only structurally sound when walls and roofs are braced by perpendicular members. This limits the span of roof and walls without additional structure. However a sound structure can be achieved using extra 'building pallets' to create additional corners and extra walls perpendicular at the perimeter either internally as partitions or externally as supports.

The thesis only explores the 'building pallet' as a concept, not going into detailed design of the prefabricated retrofitted system. Future refinement is warranted in terms of the structural jointing detail of how the stringers specifically clasp to each other at their four-way junctions. This resolution would determine the feasibility of this system in the real world.

The future of this research certainly has potential to fulfil the research aims. Upcycling on this scale could prove revolutionary if given the opportunity. 
Arieff, A., \& Burkhart, B. (2002). Prefab. Layton, Utah: Gibbs Smith.

Bachmayr, A. V. (2004). The Pallet Truss: A Low-Cost Alternative Roof Structure. In J. Kennedy (Ed.), Building Without Borders: Sustainable Construction for the Global Village (pp. 27-29). Gabriola, B.C.: New Society Publishers.

Bahamon, A. (2002). Prefab: Adaptable, Modular, Dismountable, Light, Mobile Architecture. New York: LOFT and HBI.

Banham, R. (1980, July 25). Theory and Design in the First Machine Age (2nd ed.) Cambridge: MIT Press.

BC Studies \& Lefeber: Hexa. (2013, September 16). Domus. http://www.domusweb. it/en/architecture/2013/09/13/bc_studies_michael_lefeber_hexa_structures. html

Bell, P. (2009). Kiwi Prefab: Prefabricated Housing in New Zealand: an Historical and Contemporary Overview with Recommendations for the Future (Master's thesis, Victoria University of Wellington, New Zealand). Retrieved from http:// researcharchive.vuw.ac.nz/handle/10063/1111

Bell, P. (2010, November 17-19). Kiwi Prefab: Re-Framing Attitudes towards Prefabrication in New Zealand. Paper presented at the 5th Australasian Housing Researchers' Conference, Auckland New Zealand

Bell, P., \& Southcombe, M. (2012, November 1). Kiwi Prefab: Cottage to Cutting Edge. Auckland: Aalto Books.

Bergdoll, B., \& Christensen, P. (2008, July 20 - October 10). Exhibition text Home Delivery: Fabricating the Modern Dwelling Exhibition Museum of Modern Art, New York.
Brynjolfsson, E., \& McAfee, A. (2014, January 20). The Second Machine Age: Work, Progress, and Prosperity in a Time of Brilliant Technologies. New York: W. W. Norton \& Company.

Bunde, K. (2014, September 18). DIY Wood Pallet Projects: 35 Rustic Modern Upcycling Ideas to Personalize Your Space. Avon, Massachusetts: Adams Media.

Charlesworth, E., \& Marshall, A. (Eds.) (2014). Humanitarian Architecture: 15 Stories of Architects Working After Natural Disasters. London: Routledge.

Deamer, P. (2012, November 1). Offsite/Onsite. In P. Bell \& M. Southcombe, Kiwi Prefab: Cottage to Cutting Edge (pp. 10-13). Auckland: Aalto Books.

Descartes, R. (1998, September 15). Discourse on Method (3rd ed.). Indianapolis: Hackett Publishing Company.

Drouet, A. (2015, July 1). 100\% Pallet: From Freight to Furniture: 21 DIY Designer Projects. London: Scriptum Editions.

Echavarria, P. (2006). Portable Architecture: And Unpredictable Surroundings. Barcelona: Arian Mostaedi.

Gagg, R. (2011, November 28). Texture + Materials. Basics Interior Architecture, Volume 5, 64-65.

Gleason, C. (2013, March 1). Wood Pallet Projects: Cool and Easy-to-Make Projects for the Home and Garden. East Petersburg, Pennsylvania: Fox Chapel Publishing.

International Plant Protection Convention. (n.d.). What we do. Retrieved from https://www.ippc.int/en/what-we-do/

Jacobs, J. (1961). The Death and Life of Great American Cities. New York: Random House. 
Kennedy, J. (Eds.) (2004). Building Without Borders: Sustainable Construction for the Global Village. Gabriola, B.C.: New Society Publishers.

Kieran, S., \& Timberlake, J. (2003, December 2). Refabricating Architecture. New York: McGraw-Hill Education.

Köbberling, F., \& Kaltwasser, K. (2006). City as a Resource: One Man's Trash is Another Man's Treasure. Berlin: Jovis.

Kronenburg, R. (2002). Preface. In J. Siegal (Ed.) Mobile: The Art of Portable Architecture (pp. 12-15). New York: Princeton Architectural Press.

Kronenburg, R. (2003a). Portable Architecture (3rd ed.). Burlington, MA: Architectural Press.

Kronenburg, R. (Eds.) (2003b, September 2). Transportable Environments 2. London: Spon Press.

Kronenburg, R. (2008). Portable Architecture: Design and Technology. Birkhäuser Architecture.

Lin, C. Y. (1999, May). The Representing Capacity of Physical Models and Digital Models. In Proceedings of the CAADRIA (pp. 53-62). Retrieved from

http://cumincad.architexturez.net/system/files/pdf/d14b.content.pdf

Meinhold, B. (2010, February 4). Inhabitat: Efficient \& Affordable Wood House Made From Shipping Pallets.

http://inhabitat.com/pallet-haus-an-efficient-affordable-modular-house/

Meinhold, B. (2013). Urgent Architecture: 40 Sustainable Housing Solutions for a Changing World. New York: W. W. Norton \& Company.

Montaner, J. M. (1999). Architecture and Criticism. Barcelona: Gustavo Gili.
Nappo, D., \& Vairelli, S. (2010, September 1). HOMES ON THE MOVE: Mobile Architecture (Bilingual ed.). Potsdam: h.f.ullmann.

Sanderson, D., \& Burnell, J. (Eds.) (2013). Beyond Shelter After Disaster: Practice, Process and Possibilities. London: Routledge.

Scoates, C. (2003). LOT-EK: Mobile Dwelling Unit. New York: Distributed Art Publishers.

Shaoqiang, W. (Eds.) (2014). New Portable Architecture: Designing Mobile \& Temporary Structures. Barcelona: Promopress.

Siegal, J. (Eds.) (2002). Mobile: The Art of Portable Architecture. New York: Princeton Architectural Press.

Siegal, J. (2008). More Mobile: Portable Architecture for Today. New York: Princeton Architectural Press.

Southcombe, M. (2012, November 1). Re-fabricating Prefab. In P. Bell \& M. Southcombe, Kiwi Prefab: Cottage to Cutting Edge (pp. 10-13). Auckland: Aalto Books.

Staib, G., Dörrhöfer, A., \& Rosenthal, M. (2008). Components and Systems: Modular Construction - Design, Structure, New Technologies. Basel: Birkhäuser Architecture.

Stohr, K., \& Sinclair, C. (2006, January 15). Design Like You Give A Damn: Architectural Responses To Humanitarian Crises. San Francisco: Architecture for Humanity.

The Pallet House. (2010). I-Beam Architecture and Design. http://www.i-beamdesign.com/new-york-humanitarian-projects-design/ 


\section{LIST OF FIGURES}

I INTRODUCTION

Figure I-01 Photo of discarded pallets in Wellington. Author's own image, 2015 . . . . . 1

II Pallet OvervieW

Figure II-01 Diagram comparing pallet structure types. Author's own image, 2015 . . . . 9

Figure II-02 Diagram comparing pallet structural make-up. Author's own image, 2015 . . . 9

Figure II-03 Scaled models of variations of the New Zealand pallet module. Author's

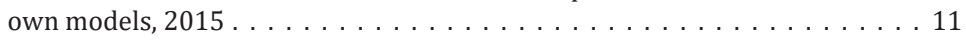

Figure II-04 Photo of typical pallet stamp. Author's own image, $2016 \ldots \ldots \ldots \ldots 13$

Figure II-05 Photo of pavilion test pallets at original pallet source. Author's own image, $2015 \ldots \ldots \ldots \ldots$

III LITERATURE REVIEW

Figure III-01 Philippe Besnard's Modulopal. (Drouet, 2015, p.155) . . . . . . . . . 17

Figure III-02 Image of 'pallet truss' being assembled. (Bachmayr, 2004, p.28). . . . . . . . 17

Figure III-03 Sequential images of the construction of Karaza Theatre. (Kronenburg 2003, pp. 58-59) . . . . . . . . . . . . . . . . . . . . . . 18

Figure III-04 Diagram comparing individual components to prefab components. (Kieran \& Timberlake, 2003, p.40) . . . . . . . . . . . . 19

Figure III-05 Images of Bell's five prefabrication scales. (Bell, 2010, p.4) . . . . . . . . . 19

Figure III-06 Bell's research findings on prefabrication advantages. (Bell, 2010, p.4) . . . . 21

Figure III-07 LOT/EK's Mobile Unit Dwelling. (http://www.lot-ek.com/MDU-Mobile-

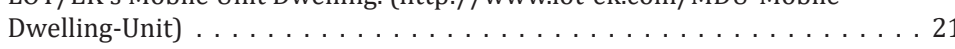

Figure III-08 Single Family House no 17, Exhibition Stuttgart 1927, image of steel framing, ground \& first floor plans. (Staib et al., 2008, p.25) . . . . . . . 23

Figure III-09 Prefabricated house by Konrad Wachsmann of 'General Panel Corporation', 1945. (Staib et al., 2008, p.27). . . . . . . . . . . . . . . . . 23

IV CAse Studies

Figure IV-01 Paletten Haus on display in Venice. (Meinhold, 2010) . . . . . . . . 26

Figure IV-02 Paletten Haus dimension comparison. Author's own image, 2015 . . . . . . . 27

Figure IV-03 Paletten Haus's glow effect. (http://www.palettenhaus.com/) . . . . . . . 27

Figure IV-04 Assembly images for I-Beam Design's Pallet House. . . . . . . . . .

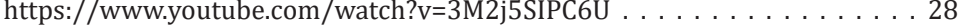

Figure IV-05 Photo of Pallet House prototype in London, 2010. (The Pallet House, 2010) . . 29

Figure IV-06 Cover image from Domus's online magazine. . . . . . . . . . . . (BC Studies \& Lefeber: Hexa, 2013) . . . . . . . . . . . . 30

Figure IV-07 External and internal views of Hexa Structures. (BC Studies \& Lefeber:

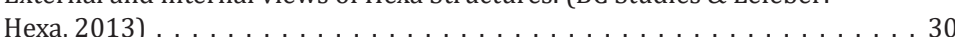


Figure IV-08 View through BINA Kabina pavilion. (http://mdh.no/project/bina-kabina/) .32

Figure IV-09 BINA Kabina during a night presentation. . . . . . . . . . . . . .

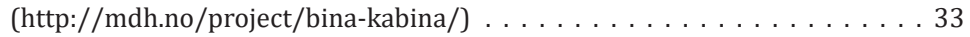

Figure IV-10 Facade and entrance to Polish Pavilion. Author's own image, 2015 . . . . . . 34

Figure IV-11 Inside view of Polish Pavilion. Author's own image, $2015 \ldots \ldots \ldots$. . . . 35

Figure IV-12 Structural joint of Polish Pavilion's facade. Author's own image, 2015 . . . . 35

\section{INITIAL EVALUATION}

Figure V-01 Early sketches creating building elements. Author's own image, 2014 . . . 37

Figure V-02 Creating portal frames from pallet components. Author's own image, 2014 . 37

Figure V-03 Furniture design sketch experiment. Author's own image, $2014 \ldots \ldots \ldots 38$

Figure V-04 Assembly of pavilion from previous work. Author's own image, 2012 . . . . . 39

Figure V-05 Unfolding seating from previous work. Author's own image, 2014 . . . . . . 39

Figure V-06 Cantilevering structure model from previous work. Author's own image, 201239

\section{Preliminary Design}

Figure VI-01 Sketches playing with hinges $\ldots \ldots \ldots \ldots \ldots \ldots \ldots \ldots \ldots \ldots$

Figure VI-02 Unfolding frame model. Author's own image . . . . . . . . . 42

Figure VI-03 Folding Whare being assembled in the Unitec School of Architecture

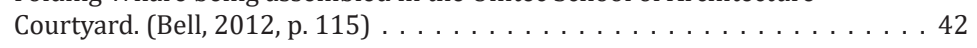

Figure VI-04 Foam board hinge models. Author's own images $\ldots \ldots \ldots \ldots \ldots \ldots 4$

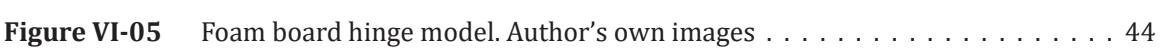

Figure VI-06 “Garden Ambassadors" Pod opening diagram. (Shaoqiang, 2014, p.136) . . . 45

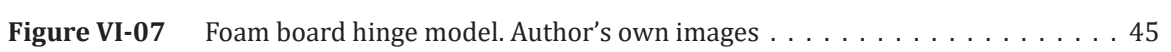

Figure VI-08 Foam board hinge model. Author's own images . . . . . . . . . . . . . . 45

\section{Contextualised Design}

Figure VII-01 Pallet type application comparison. Author's own image . . . . . . . . 48

Figure VII-02 Laser-cut hinge model. Author's own images. . . . . . . . . . . . . . . . . 49

Figure VII-03 Laser-cut cantilevering seat model. Author's own images . . . . . . . . . . . 49

Figure VII-04 Models exploring cantilevers and enclosure. Author's own models, 2015 . . . 51

Figure VII-05 Sketches \& SketchUp mitre tests. Author's own images, $2015 \ldots \ldots \ldots \ldots 51$

Figure VII-06 SketchUp shelter tests. Author's own images, 2015 . . . . . . . . . . . 52

Figure VII-07 Laser-cut pop-up shelter test. Author's own images, $2015 \ldots \ldots \ldots$

Figure VII-08 Laser-cut pop-up shelter opening sequence. Author's own images, 2015 . . . 53

Figure VII-09 Sketch \& SketchUp shelter concept. Author's own images, 2015. . . . . . . . 54

Figure VII-10 SketchUp shelter concept. Author's own images, 2015 . . . . . . . . . . . . 55

Figure VII-11 Sketch shelter concept. Author's own images, 2015 . . . . . . . . . . . . . 55
Figure VII-12 Early structure test. Author's own image, $2015 \ldots \ldots \ldots$. . . . . . . . . . 57

Figure VII-13 Structural rationale sketch. Author's own image, 2015 . . . . . . . . . . 57

Figure VII-14 SketchUp structural integration experiments. Author's own image, 2015 . . . 57

Figure VII-15 SketchUp structural integration experiments. Author's own image, 2015 . . . 57

Figure VII-16 Module and modular integration sketch. Author's own images, 2015 . . . . 58

Figure VII-17 Arranging for stringer alignment. Author's own image, 2015 . . . . . . . . . 59

Figure VII-18 Dismantling pallets. Author's own images, 2015 . . . . . . . . . . . 59

Figure VII-19 Workshop construction and assembly. Author's own images, 2015 . . . . . . . 59

Figure VII-20 Transport of pavilion module. Author's own images, $2015 \ldots \ldots \ldots$. . . . 60

Figure VII-21 Levels of prefabrication. Author's own image, $2015 \ldots \ldots \ldots \ldots \ldots$

Figure VII-22 Built pavilion assembly sequence. Author's own image, $2015 \ldots \ldots \ldots$. . . . 61

Figure VII-23 Photo details. Author's own images, $2015 \ldots \ldots \ldots \ldots \ldots \ldots \ldots \ldots$

Figure VII-24 Final pavilion - day. Author's own image, $2015 \ldots \ldots \ldots \ldots \ldots \ldots \ldots 6$

Figure VII-25 Final pavilion - day. Author's own images, $2015 \ldots \ldots \ldots \ldots \ldots \ldots$

Figure VII-26 Final pavilion - night. Author's own image, $2015 \ldots \ldots \ldots \ldots$. . . . . . 64

Figure VII-27 Final pavilion - night. Author's own image, $2015 \ldots \ldots \ldots \ldots$. . . . . . . 64

Figure VII-28 Final pavilion - night. Author's own image, $2015 \ldots \ldots \ldots \ldots$

Figure VII-29 Final pavilion - night. Author's own image, $2015 \ldots \ldots \ldots \ldots$

Figure VII-30 Scaled model of modular folding pavilion. Author's own models, $2016 \ldots 67$

\section{VIII 'Building Pallet' Re-Design}

Figure VIII-01 Sketch 'building pallet' concept. Author's own images, $2016 \ldots \ldots \ldots \ldots 70$

Figure VIII-02 SketchUp final solution development. Author's own images, 2016 . . . . . . 72

Figure VIII-03 Liina Transitional Shelter precedent images. (Shaoqiang, 2014, pp. 46-49). . 72

Figure VIII-04 Laser-cut basic shelter. Author's own images, $2016 \ldots \ldots \ldots \ldots \ldots 73$

Figure VIII-05 Laser-cut element models. Author's own images, 2016 . . . . . . . . . 73

Figure VIII-06 Scaled models of 'building pallet' prefab elements. Author's own models, 201675

IX Conclusions And CRItical Reflection 